Check for updates

Cite this: Phys. Chem. Chem. Phys., $2017,19,15613$

Received 25th April 2017, Accepted 30th May 2017 DOI: 10.1039/c7cp02711g

rsc.li/pccp

\section{Carbon nitrides: synthesis and characterization of a new class of functional materials}

\begin{abstract}
T. S. Miller, ${ }^{a}$ A. Belen Jorge, ${ }^{b}$ T. M. Suter, ${ }^{a}$ A. Sella, ${ }^{a}$ F. Corà ${ }^{a}$ and P. F. McMillan (D) *a
Carbon nitride compounds with high N:C ratios and graphitic to polymeric structures are being investigated as potential next-generation materials for incorporation in devices for energy conversion and storage as well as for optoelectronic and catalysis applications. The materials are built from $\mathrm{C}$ - and $\mathrm{N}$-containing heterocycles with heptazine or triazine rings linked via $\mathrm{sp}^{2}$-bonded $\mathrm{N}$ atoms $\left(\mathrm{N}(\mathrm{C})_{3}\right.$ units) or $-\mathrm{NH}$ - groups. The electronic, chemical and optical functionalities are determined by the nature of the local to extended structures as well as the chemical composition of the materials. Because of their typically amorphous to nanocrystalline nature and variable composition, significant challenges remain to fully assess and calibrate the structure-functionality relationships among carbon nitride materials. It is also important to devise a useful and consistent approach to naming the different classes of carbon nitride compounds that accurately describes their chemical and structural characteristics related to their functional performance. Here we evaluate the current state of understanding to highlight key issues in these areas and point out new directions in their development as advanced technological materials.
\end{abstract}

\section{Introduction}

Carbon nitride solid state compounds are emerging as important materials for energy and sustainability applications ranging

${ }^{a}$ Department of Chemistry, Christopher Ingold Building, University College London, 20 Gordon Street, WC1H 0AJ, London, UK. E-mail: p.f.mcmillan@ucl.ac.uk

${ }^{b}$ Materials Research Institute, School of Engineering and Materials Science, Queen Mary University of London, Mile End Rd, E1 4NS, London, UK from visible-UV light harvesting and photocatalysis, ${ }^{1-5}$ to fuel cell and electrolyzer catalyst supports, ${ }^{6-8}$ as redox catalysts, ${ }^{9-12}$ as well as for other emerging areas. ${ }^{5,13-18}$ These applications all rely on the unique set of optical, electronic, and chemical properties possessed by the carbon nitrides, combined with their synthesis from readily available precursors, and their resistance to adverse chemical and physical environments. However, further development of these materials requires addressing and resolving fundamental questions concerning their chemical and structural

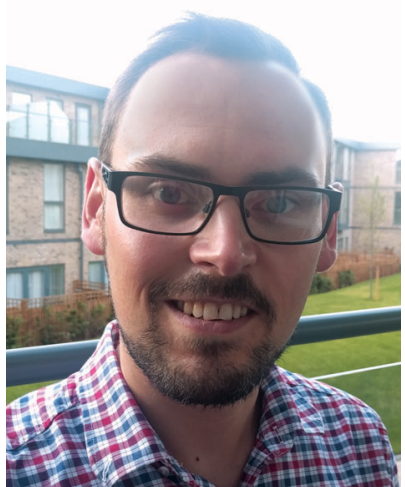

T. S. Miller
Thomas S. Miller currently works as a research associate in the Dept. of Chemistry at UCL. His research interests span from fundamental electrochemistry to materials discovery/characterisation and the development of devices for electrochemical energy storage and generation. He received his $\mathrm{PhD}$ from the University of Warwick in 2014, where he studied the electrochemical applications of carbon nanotubes and graphene. In his recent work he has produced new methods for the scalable production of $2 D$ materials and created carbon nitride composites for application in fuel cells, batteries, electrolyzers and supercapacitors.

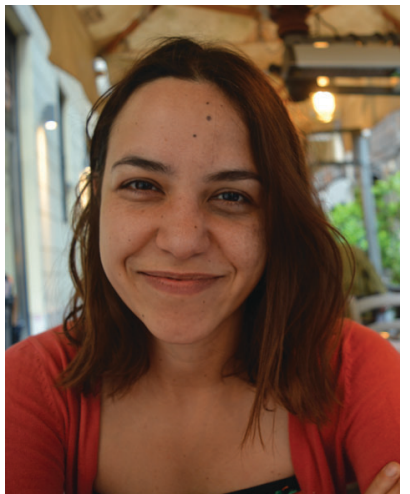

A. Belen Jorge
Ana Belen Jorge graduated in Chemistry in Canary Islands in 2004. She obtained her $P h D$ in Materials Science from the Instituto de Ciencia de Materiales and the Universidad Autonoma de Barcelona in 2009. After some time in industry, she decided to come back to academia in 2011, and moved to London to conduct a postdoc at UCL investigating new graphitic carbon nitrides for energy applications. Currently, she is an academic fellow at the Materials Research Institute, QMUL. Her research focuses in creating new hybrid materials for energy, including oxygen electrocatalysts and photoanodes for photofuel cells and water splitting. 
nature in relation to their properties so that they can be designed and optimized for current and future applications. The rate of publication concerning these compounds is accelerating: at the time of writing, Web of Science records approximately 18000 papers with "carbon nitride" or " $\mathrm{C}_{3} \mathrm{~N}_{4}$ " in the title or abstract (Fig. 1). Now is a critical time to assess our current understanding of the physical, chemical and structural properties of these materials in relation to their functionality.

A first issue to be addressed concerns the most appropriate nomenclature used to describe the different classes of carbon nitride materials generated by various chemical and physical routes. It has become increasingly common to refer to them as " $\mathrm{g}-\mathrm{C}_{3} \mathrm{~N}_{4}$ ", and we find that the Wikipedia entry for "graphitic carbon nitride" states: "Graphitic carbon nitride $\left(\mathrm{g}-\mathrm{C}_{3} \mathrm{~N}_{4}\right)$ is a family of compounds with a general formula near to $\mathrm{C}_{3} \mathrm{~N}_{4}$ and structures based on heptazine units which, depending on reaction conditions, exhibit different degrees of condensation, properties and reactivities". ${ }^{19}$ That definition is misleading for a number of reasons. First, most of the materials prepared to date contain not only $\mathrm{C}$ and $\mathrm{N}$, but also substantial quantities of $\mathrm{H}$ as an essential component of their structures, and these carbon nitride forms are in fact best described as $\mathrm{C}_{x} \mathrm{~N}_{y} \mathrm{H}_{z}$ compounds. Next, those materials produced by linked heptazine (tri-s-triazine, $\mathrm{C}_{6} \mathrm{~N}_{7}$ ) units the layers are unlikely to be completely condensed "graphitic" structures, but instead form zigzag polymer chains similar to those found in Liebig's melon, with a limiting composition near $\mathrm{C}_{2} \mathrm{~N}_{3} \mathrm{H}^{20-22}$ Only a very few reports have described structures that form fully condensed layers with $\mathrm{C}_{3} \mathrm{~N}_{4}$ stoichiometry, but these have been shown to be based on linked triazine $\left(\mathrm{C}_{3} \mathrm{~N}_{3}\right)$ rings rather than heptazine units. ${ }^{23,24}$

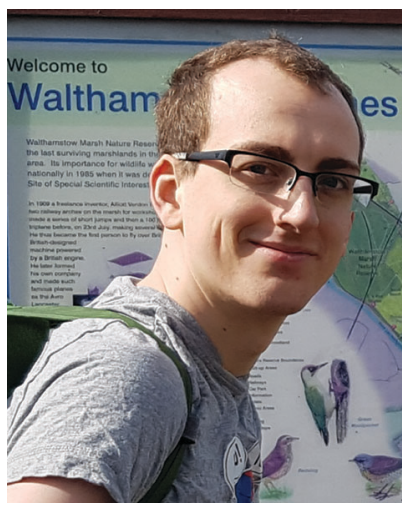

T. M. Suter
Theo M. Suter graduated with an MSci in Chemistry with Molecular physics from Imperial College London in 2014. He is now in the final year of his PhD at University College London, where he works on the synthesis, characterisation and functionalisation of layered carbon nitrides. His particular focus is the exfoliation and ion exchange of highly crystalline frameworks.

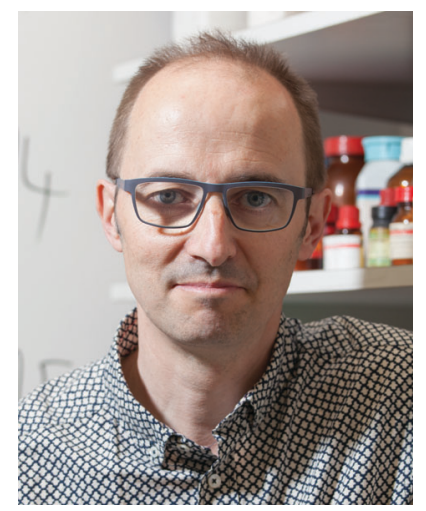

A. Sella

Italian by birth, Andrea Sella studied organometallic chemistry with Robert H. Morris (Toronto) and Malcom L. H. Green (Oxford). His research interests focus on inorganic synthesis in areas ranging from the lanthanides to the allotropes of phosphorus and tin. He is heavily involved in the development of undergraduate practicals that incorporate citizen science and outreach into traditional exercises, to strengthen community and environmental awareness among undergraduates. He is also known as a broadcaster, being a regular contributor to radio and television, such as the recent 74 part series on The Elements on BBC World Service He is known online as @SellaTheChemist.

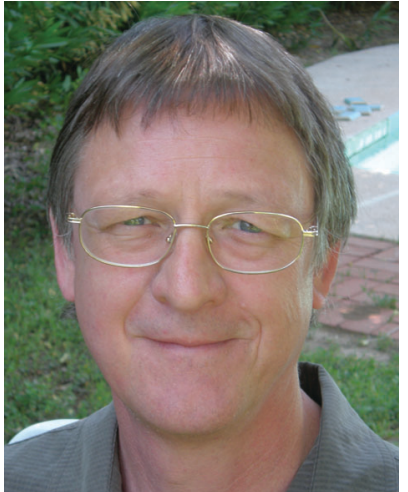

P. F. McMillan

Paul F. McMillan is Ramsay Professor of Chemistry at UCL. He obtained his PhD at Arizona State University (1981) and remained there until 2000 when he moved to London to establish research programmes in solid state chemistry and high pressure science. His work on carbon nitrides began in Arizona and extends to developing them for energy applications and as nanomaterials. Other research interests include amorphous materials and ticular emphasis is given to the integration of computational studies with experimental synthesis and characterisation methods, both as an analytical tool to assist the interpretation of experiment, and predictive to identify significant targets in advance of experiment.

Furio Corà graduated at the a $\mathrm{PhD}$ in Chemistry from the University of Portsmouth. He has Fellow at the Royal Institution of Great Britain (2001-2006), before sor of Computational Chemistry. He employs electronic structure calculations to investigate functional, electronic and catalytic properties of crystalline solids. Par-

\section{F. Corà}

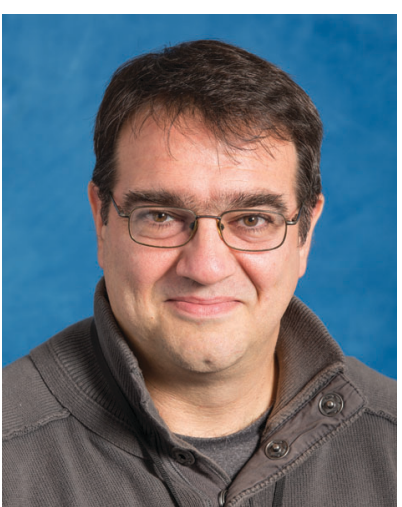

high pressure biology/biophysics. He received a Wolfson-Royal Society Research Merit Award (2001-2006), the Solid State Chemistry award in 2003, an EPSRC Senior Research Fellowship (2006-2011) and the Peter Day award in 2011. 


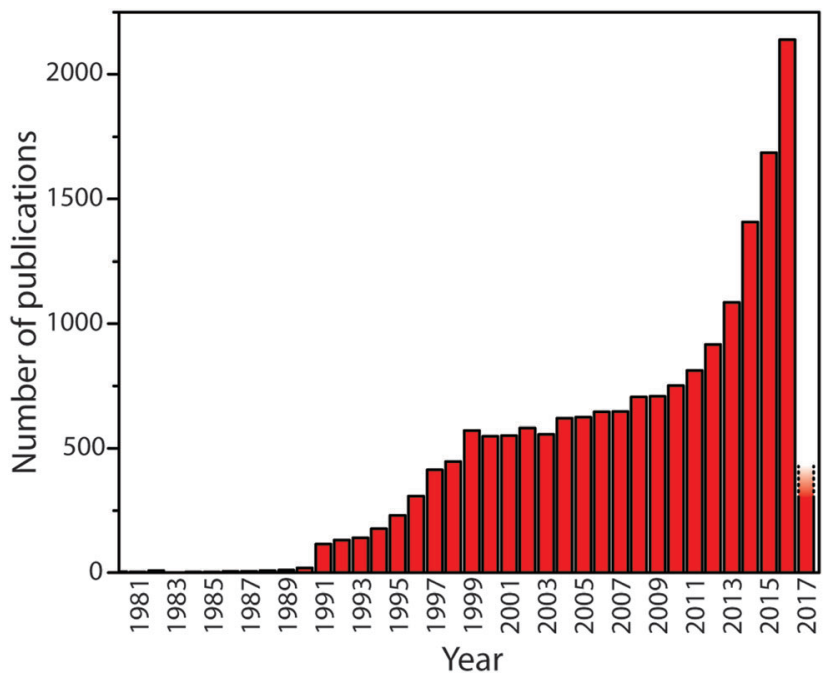

Fig. 1 The number of publications containing "carbon nitride" or " $\mathrm{g}-\mathrm{C}_{3} \mathrm{~N}_{4}$ " in title or abstract by year until early 2017. The rapid upsurge in activity beginning in 1991 followed the theoretical prediction in 1989 by Cohen and $\mathrm{Liu}^{28}$ that a high density phase containing $\mathrm{sp}^{3}$-bonded $\mathrm{C}$ atoms might exist. The recent activity has been promoted by discoveries that indicate the "graphitic" materials might have useful properties for catalysis and energy conversion or storage, as well as other potential applications.

Another series of compounds containing planar carbon nitride layers are also formed by polytriazine imide-linked (PTI) units that provide hosts for intercalated ions including $\mathrm{Li}^{+}, \mathrm{Cl}^{-}$and $\mathrm{Br}^{-}$, as well as additional $\mathrm{H}^{+}{ }^{25-27}$ It is interesting to note that the PTI layers have composition $\mathrm{C}_{2} \mathrm{~N}_{3} \mathrm{H}$, equivalent to that of Liebig's melon (Fig. 2).

In the interests of devising a useful nomenclature that captures the structural and chemical properties of these different types of material, we propose a hierarchical approach (Fig. 2a). We suggest that all of the compounds that are likely to contain layered elements within their structures can be generally referred to as "gCN" or "GCN", to reflect the fact that carbon and nitrogen are the main components and that at least some elements of the structure can be compared with the extended planes of graphite. When describing specifically those compounds formed by thermolysis and other reactions resulting in polymeric materials related to Liebig's melon it could be appropriate to use terms such as $\mathrm{gCN}(\mathrm{H})$ or $\mathrm{pCN}(\mathrm{H})$, to further specify the presence of large amounts of $\mathrm{H}$ as an essential component and the more or less condensed nature of the amorphous to nanocrystalline structures. The crystalline phases based on imide-linked polytriazine sheets with intercalated ions should be termed PTI-MX, where $\mathrm{M}^{n+}$ and $\mathrm{X}^{n-}$ refer to the intercalated species. Finally, the specific term " $\mathrm{g}-\mathrm{C}_{3} \mathrm{~N}_{4}$ " should be reserved for those materials that are determined to have a composition that closely matches that ideal stoichiometry, with minimal incorporation of hetero-atoms such as $\mathrm{H}$ or $\mathrm{O}$, and that are determined to be based on $\mathrm{sp}^{2}$-bonded $\mathrm{C}$ atoms. Within that category we could further specify the fully condensed crystalline graphitic layers of "TGCN" (triazinebased graphitic carbon nitride), ${ }^{23,24}$ and "HGCN" (heptazinebased graphitic carbon nitride) referring to a theoretically

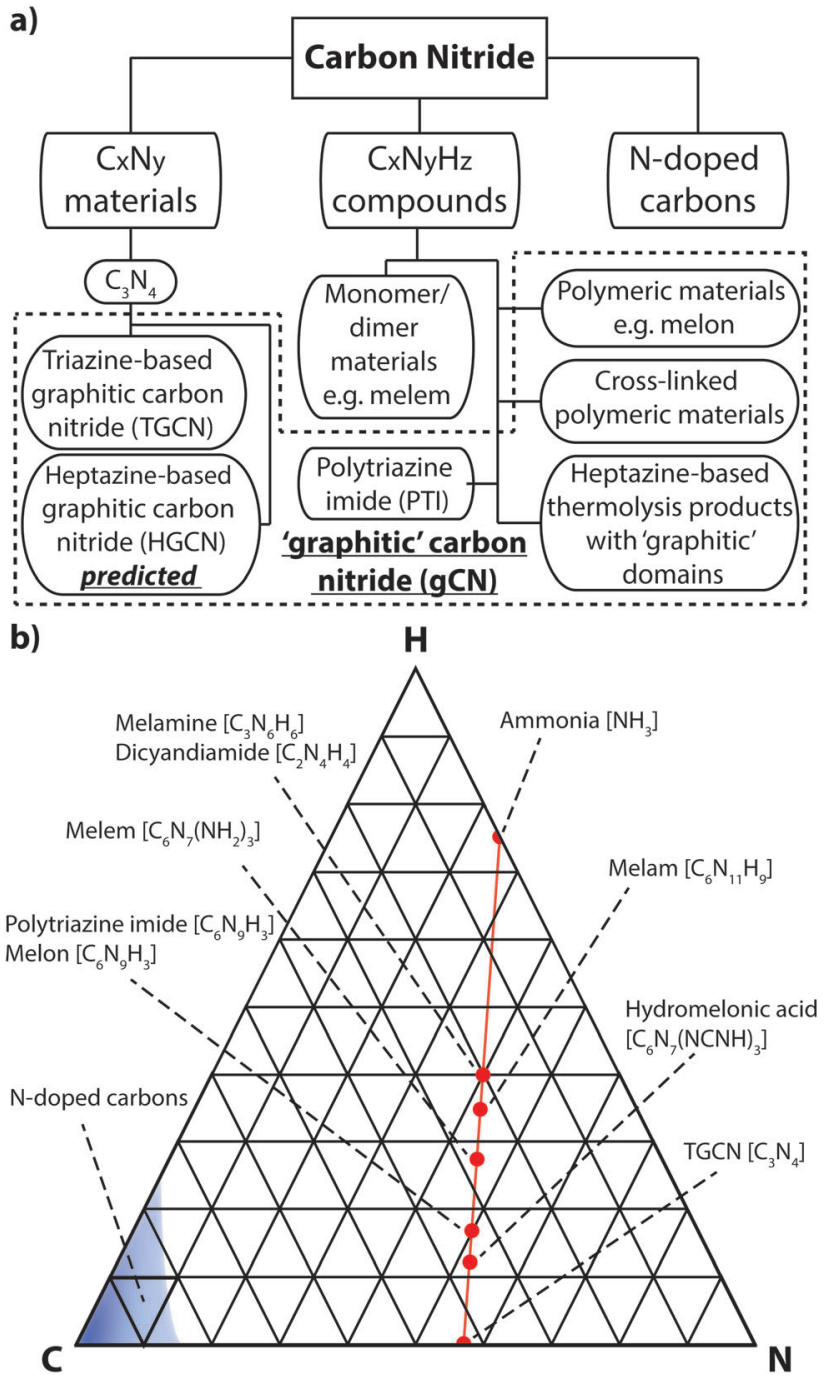

Fig. 2 (a) Diagram showing the various classes of carbon nitrides. The dashed box indicates materials often designated graphitic carbon nitride (gCN). (b) Ternary plot of important types of carbon nitride materials projected on to a $\mathrm{C}-\mathrm{N}-\mathrm{H}$ compositional diagram. Semimetallic N-doped graphite and graphene materials cluster near the pure $\mathrm{C}$ pole (elemental analysis results based on ref. 29 and 30), whereas stoichiometric gCN compounds are concentrated around a tie-line extending between melamine or DCDA to approximately $\mathrm{C}_{2} \mathrm{~N}_{3} \mathrm{H}$ via loss of $\mathrm{NH}_{3}$ component. Complete loss of $\mathrm{NH}_{3}$ would result in $\mathrm{C}_{3} \mathrm{~N}_{4}$.

predicted range of heptazine-based layered compounds that have not yet been demonstrated experimentally.

We also note that several other classes of materials have also been described as "graphitic carbon nitrides". These include $\mathrm{N}$-doped graphites or graphenes, that usually contain up to only a few percent nitrogen distributed randomly over the $\mathrm{sp}^{2}$-bonded sites (Fig. 2b). ${ }^{29,30}$ These materials are typically metallic to semimetallic that distinguishes them from the semiconducting gCN compounds, that contain alternating $\mathrm{N}$ and $\mathrm{C}$ atoms in welldefined structural positions determined by local valency rules. However, such N-doped carbons have applications as sensors, ${ }^{35}$ and for energy storage ${ }^{31}$ and conversion ${ }^{7}$ as well as catalysis, ${ }^{32}$ especially when spatial correlations exist between regions of high 
nitrogen content and the metal nanoparticles that constitute the catalytic centres. $^{33,34}$ Related to these are the electrochemically and catalytically active "carbon nitride" materials that have been produced by selectively embedding N-rich domains surrounding metal atom clusters within a predominantly carbonaceous matrix. ${ }^{8}$

\section{Discovery and emergence of carbon nitride materials}

\subsection{Early history}

Following Carl Scheele's seminal work on prussic acid (HCN) ${ }^{36}$ chemists began to investigate related chemical series, and this led to discovery of compounds containing the thiocyanate $\left(\mathrm{SCN}^{-}\right)$anion. Porret ${ }^{37}$ produced a mercurous variety of the salt and Berzelius first prepared mercury(II) isothiocyanate $\mathrm{Hg}(\mathrm{SCN})_{2}$. Building on the demonstration by Gay Lussac that cyanogen $\left((\mathrm{CN})_{2}\right)$ gas could be produced by heating $\mathrm{Hg}(\mathrm{SCN})_{2}$, Berzelius attempted to form the analogous thiocyanogen $\left((\mathrm{SCN})_{2}\right)$ by heating his new compound. ${ }^{38,39}$ That experiment was not successful, as large amounts of $\mathrm{CS}_{2}$ and $\mathrm{N}_{2}$ were evolved and $\mathrm{HgS}$ sublimed. When $\mathrm{Hg}(\mathrm{SCN})_{2}$ was mixed with elemental sulphur and heated a small quantity of $(\mathrm{SCN})_{2}$ was produced, along with $\mathrm{CS}_{2}$ and $\mathrm{N}_{2}$. The reaction was violent and the formation of copious amounts of a porous pumice-like solid mass was noted, breaking open the apparatus. In his own attempts to obtain thiocyanic acid (HSCN) by treating $\mathrm{Hg}(\mathrm{SCN})_{2}$ with $\mathrm{H}_{2} \mathrm{~S}$,
Wöhler reported a characteristic "snake-like" appearance of the voluminous porous solid residue that emerged as the salt was burned in air. ${ }^{38,39}$ That remarkable and seemingly magical property later led to the development of pyrotechnic materials that were packaged and sold as "Pharaoh's serpents" eggs, following a loose reference to the mystical behavior of Moses' staff. $^{40}$ The commercial enterprise ended as the health and safety implications of releasing mercury and cyanide into the atmosphere became better appreciated, in addition to unfortunate reports of people confusing the wrapped pellets with ingestible sweets. Informative reviews of this early history were published by Irving $^{38}$ and Davis. ${ }^{39}$ A recent YouTube video shows the process of producing and then igniting $\mathrm{Hg}(\mathrm{SCN})_{2}$ to form "Pharaoh's serpents", including the safety considerations that must be respected to carry out the reactions. ${ }^{41}$ The overall decomposition reaction is written as:

$$
2 \mathrm{Hg}(\mathrm{SCN})_{2} \rightarrow 2 \mathrm{HgS}+\mathrm{CS}_{2}+\mathrm{C}_{3} \mathrm{~N}_{4}
$$

The carbon nitride forms a yellow-brown porous solid. ${ }^{42}$

\subsection{Liebig's melon and related structures}

In a classic series of investigations, Justus, baron von Liebig described the formation and properties of various $\mathrm{C}_{x} \mathrm{~N}_{y} \mathrm{H}_{z}$ compounds that were given names such as "melem" $\left(\mathrm{C}_{6} \mathrm{~N}_{10} \mathrm{H}_{6}\right)$, "melam" $\left(\mathrm{C}_{6} \mathrm{~N}_{11} \mathrm{H}_{9}\right)$ and "melamine" $\left(\mathrm{C}_{3} \mathrm{~N}_{6} \mathrm{H}_{6}\right)$ (Fig. 2 and 3). ${ }^{43-45}$ The work was continued and complemented by others, ${ }^{46}$ and the extensive series of investigations have helped establish the a)

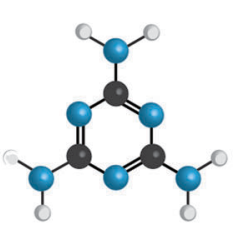

b)

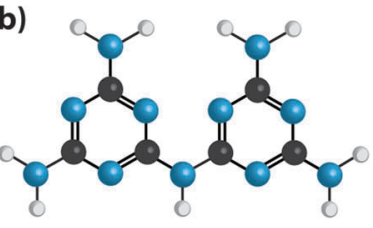

c)

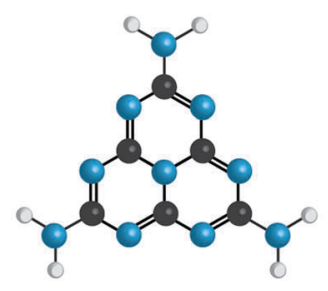

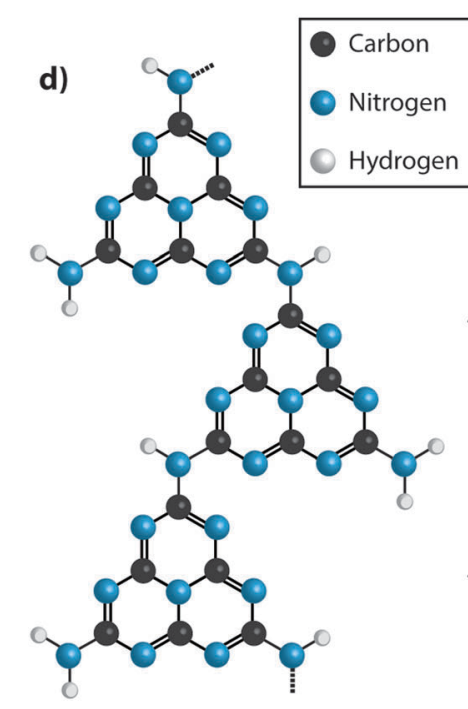
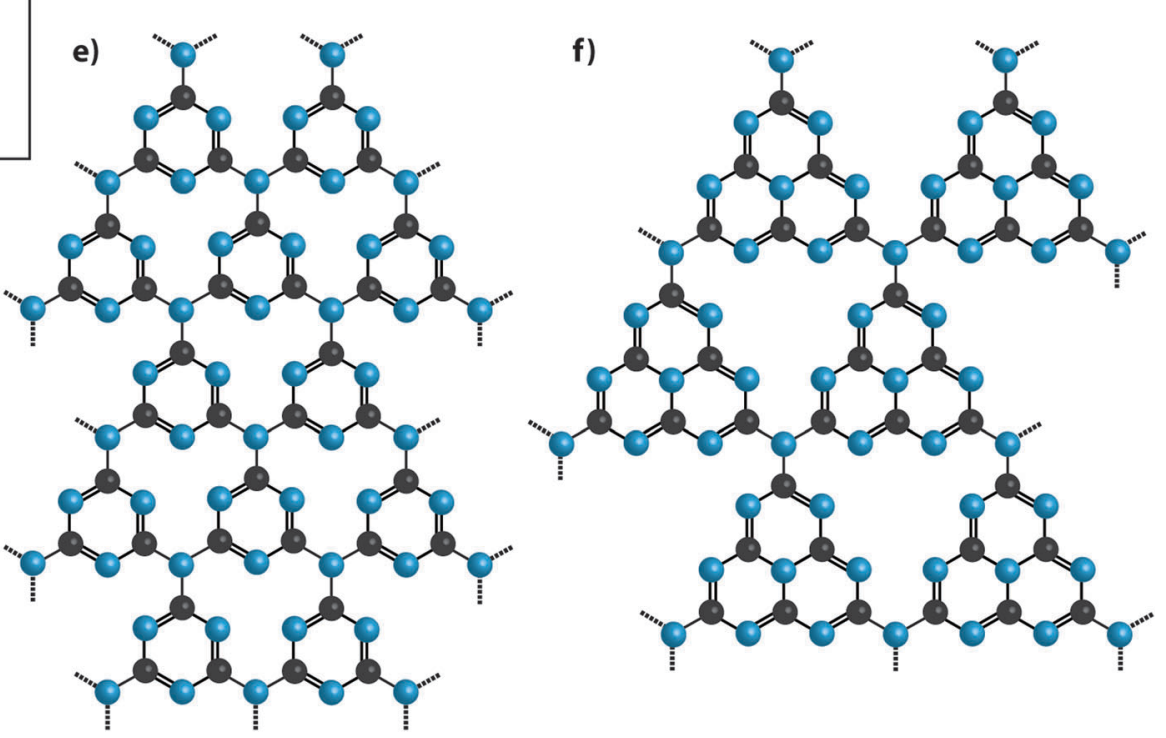

Fig. 3 Structural motifs for carbon nitride molecules and solid state structures. (a) Melamine (b) melam (c) melem (d) melon (e) fully condensed triazine based $\mathrm{C}_{3} \mathrm{~N}_{4}$ structure (TGCN) (f) fully condensed polyheptazine (tri-s-triazine) $\mathrm{C}_{3} \mathrm{~N}_{4}$ structure. 
chemical compositions. ${ }^{42,47}$ Liebig first applied the term "melon"43 to a yellow, amorphous residue formed by heating to redness the yellow precipitate formed by the action of $\mathrm{Cl}_{2}$ on an aqueous KSCN solution, with no apparent justification for the choice of name ("Wenn man diesen Körper, den ich Melon nennen will. ..”) (p. 5 in ref. 33). A similar solid product was also obtained by ignition of ammonium thiocyanate $\left(\mathrm{NH}_{4} \mathrm{SCN}\right)$, or from intimate mixtures of $\mathrm{KSCN}$ and $\mathrm{NH}_{4} \mathrm{Cl}$. The name was also extended to the yellow product formed by heating $\mathrm{Hg}(\mathrm{SCN})_{2}$ in air, that gave rise to the "Pharaoh's serpents" phenomenon described above. ${ }^{42,48}$ Liebig showed that the composition of his "melon" showed significant variability between different synthesis experiments, ${ }^{43}$ although the limiting stoichiometry is found to lie near $\mathrm{C}_{2} \mathrm{~N}_{3} \mathrm{H}$ (or $\mathrm{C}_{6} \mathrm{~N}_{9} \mathrm{H}_{3}$ ), with an ideal structural formula determined for the nanocrystalline material as $\mathrm{C}_{6} \mathrm{~N}_{7}(\mathrm{NH})\left(\mathrm{NH}_{2}\right) \cdot{ }^{21}$

Typical modern approaches to forming gCN materials related to Liebig's melon involve thermolytic condensation of molecular precursors including melamine $\left(\mathrm{C}_{3} \mathrm{~N}_{3}\left(\mathrm{NH}_{2}\right)_{3}\right)$, cyanamide and its dimer (dicyandiamide, $\mathrm{C}_{2} \mathrm{~N}_{4} \mathrm{H}_{4}, \mathrm{DCDA}$ ), as well as $\mathrm{N}$-rich molecules such as urea $\left(\mathrm{CN}_{2} \mathrm{OH}_{4}\right) \cdot{ }^{22,49,50}$ An early account of the thermolysis pathway from melamine giving rise to products with different $\mathrm{C}_{x} \mathrm{~N}_{y} \mathrm{H}_{z}$ compositions was given by May. ${ }^{47}$ More recent results confirm the suggested general scheme. ${ }^{22,49-51}$ This synthesis procedure results in polymeric materials that have a limiting composition near that of Liebig's melon, with structures derived from ribbon-like elements formed by linked chains of heptazine $\left(\mathrm{C}_{6} \mathrm{~N}_{7}\right)$ units. $^{20-22,49,50,52}$ Among the amorphous materials produced at higher temperatures, some elements containing more highly condensed graphite-like domains may be present, but this has not been proved experimentally. It might be expected that the end result from continued elimination of $\mathrm{NH}_{3}$ would cause formation of fully graphitic g- $\mathrm{C}_{3} \mathrm{~N}_{4}$ layers based on linked polyheptazine units (Fig. 3f). Although such structures have been predicted theoretically to constitute the most stable $\mathrm{C}_{3} \mathrm{~N}_{4}$ polymorph, ${ }^{49,53}$ they have not been observed in experiments carried out to date. This is due to the high thermal stability of the heptazine-based $\mathrm{C}_{x} \mathrm{~N}_{y} \mathrm{H}_{z}$ polymers, combined with the fact that carbonaceous species including $\mathrm{C}_{2} \mathrm{~N}_{2}$ begin to be released along with $\mathrm{NH}_{3}$ during heating, thus preventing complete condensation into polyheptazine g- $_{3} \mathrm{~N}_{4}$ layers. ${ }^{42,50,51}$ To date, only two examples of stoichiometric g- $\mathrm{C}_{3} \mathrm{~N}_{4}$ have been described in the literature. ${ }^{23,24}$ Both of these materials were formed by alternative synthesis approaches, and they have structures based on layers of simpler $\mathrm{C}_{3} \mathrm{~N}_{3}$ ( $s$-triazine) structural units linked via $\mathrm{sp}^{2}$-bonded $\mathrm{N}$ atoms ${ }^{23,24}$ (Fig. 3e). Their structures and properties are described below in Section 2.3.

As part of his work to understand the chemistry and structures of the compounds that had begun to be described as "ammono carbonic acids" and carbonic nitrides, ${ }^{42}$ Franklin sent samples of crystalline $\mathrm{Na}_{3} \mathrm{C}_{6} \mathrm{~N}_{9} \cdot 3 \mathrm{H}_{2} \mathrm{O}$ to Linus Pauling for $\mathrm{X}$-ray examination. The resulting analyses indicated the presence of an anion, found to have the structural formula $\mathrm{C}_{3} \mathrm{~N}_{3}(\mathrm{NCN})_{3}{ }^{3-}$. That then led to the proposal by Pauling and Sturdivant, supported by electronic structure arguments, that the family of compounds should be based on the cyameluric $\left(\mathrm{C}_{6} \mathrm{~N}_{7}\right)$ unit as their fundamental building block. ${ }^{54}$ That interpretation was supported by chemical investigations and it led to the suggestion that Liebig's polymeric melon was likewise formed from $\mathrm{C}_{6} \mathrm{~N}_{7}$ units. Finkel'shtein began to refer to the cyameluric nucleus as "sym- $(s-)$ heptazine" to highlight the presence of $7 \mathrm{~N}$ atoms within the central ring unit. ${ }^{48}$ The structure of the parent compound "cyamelurine" or tri-s-triazine $\left(\mathrm{C}_{6} \mathrm{~N}_{7} \mathrm{H}_{3}\right)$ containing this heptazine core unit was first reported in $1982 .{ }^{55}$ Komatsu re-investigated Liebig's syntheses of melon and hydromelonate salts that he proposed would constitute precursors to a fully graphitic $\mathrm{g}-\mathrm{C}_{3} \mathrm{~N}_{4}$ solid, that he presumed would be based on sheets of heptazine units linked by trigonal $\mathrm{N}$ atoms (Fig. 3f). ${ }^{56,57}$ Using a combination of advanced characterization techniques and $a b$ initio theoretical calculations, it is now demonstrated that nanocrystalline Liebig's melon is formed by zig-zag chains of heptazine rings linked via - NH- units and terminated laterally by $-\mathrm{NH}_{2}$ groups, that are linked by $\mathrm{H}$-bonding to form layers (Fig. 3). ${ }^{21}$ The structure of crystalline melem $\left(\mathrm{C}_{6} \mathrm{~N}_{11} \mathrm{H}_{9}\right)$ was also established using a similar range of techniques. ${ }^{58}$ Kroke and Schwartz have described the emergence of similar structural motifs based on condensation reactions starting with cyanamide or DCDA, that produce melamine in a first instance. ${ }^{22}$

All of the fully polymerized $\mathrm{g}-\mathrm{C}_{3} \mathrm{~N}_{4}$ sheet structures based on linked heptazine units predicted by density functional theory (DFT) calculations are indicated to be non-planar, and to have greater stability than layers based on polytriazine networks. ${ }^{49}$ Gracia and $\mathrm{Kroll}^{53}$ calculated the relative energetics of a wide range of layer stacking sequences and different buckling patterns based on such "corrugated" polyheptazine sheet structures, although none of these have been observed in practice. The only fully-polymerized graphitic $\mathrm{C}_{3} \mathrm{~N}_{4}$ materials that have been reported to date contain layers based on triazine $\left(\mathrm{C}_{3} \mathrm{~N}_{3}\right)$ units linked by $\mathrm{sp}^{2}$-bonded $\mathrm{N}$ atoms. Those results are described in the next section.

\subsection{Triazine-based $\mathrm{g}-\mathrm{C}_{3} \mathrm{~N}_{4}$ structures}

In their first synthesis of an extended triazine-based carbon nitride phase, Kouvetakis et al. used designed unimolecular precursors $\left(\mathrm{Me}_{3} \mathrm{E}\right)_{2} \mathrm{~N}\left(\mathrm{C}_{3} \mathrm{~N}_{3}\right) \mathrm{X}_{2}(\mathrm{E}=\mathrm{Sn}, \mathrm{Si} ; \mathrm{X}=\mathrm{F}, \mathrm{Cl})$ to deposit nanocrystalline thin films via chemical vapor deposition (CVD). ${ }^{24,59}$ The $\mathrm{C}_{3} \mathrm{~N}_{4}$ stoichiometry was determined by Rutherford back scattering (RBS), while electron energy loss (EELS) measurements carried out using transmission electron microscopy (TEM) confirmed the presence of $\mathrm{sp}^{2}$-bonded $\mathrm{C}$ and $\mathrm{N}$ atoms. IR data showed the absence of $\mathrm{N}-\mathrm{H}$ groups. High resolution TEM imaging and diffraction data indicated a layered structure based on triazine rings linked by three-coordinated $\mathrm{N}$ atoms to form graphitic sheets (Fig. 3e). Later theoretical studies then predicted the likely existence of various triazine-based g- $\mathrm{C}_{3} \mathrm{~N}_{4}$ polymorphs based on different stacking arrangements of the graphitic sheets, so that stacking disorder might be present within the experimental samples. ${ }^{60,61}$ Algara-Siller et al. were first to report forming bulk crystalline TGCN as a product of condensation reactions involving DCDA in molten salt ( $\mathrm{LiCl} / \mathrm{KCl}$ eutectic mixture) media. ${ }^{23,62}$ The TGCN compound became deposited as a film on the walls of the glass vessel or at the surface of the molten salt 
reaction medium. X-ray photoelectron spectroscopy (XPS) and EELS analysis demonstrated that the $\mathrm{N}: \mathrm{C}$ ratio corresponded to the $\mathrm{C}_{3} \mathrm{~N}_{4}$ composition, with only a small quantity of included $\mathrm{O}$ component. $^{23}$ Analysis of the TEM images and X-ray diffraction (XRD) data combined with DFT predictions indicated a graphitic ${ }_{\mathrm{g}}-\mathrm{C}_{3} \mathrm{~N}_{4}$ structure, with either $\mathrm{AB}$ (space group $P \overline{6} m 2$ ) or $\mathrm{ABC}$ $\left(P 6_{3} \mathrm{~cm}\right)$ stacking of the layers, although the likely presence of layer stacking disorder was also noted. More recently, TGCN samples were exposed to high pressure and high temperature conditions in a diamond anvil cell, and new crystalline peaks appeared indicating formation of a new type of $\mathrm{C}_{3} \mathrm{~N}_{4}$ framework consisting of triazine rings linked by $\mathrm{sp}^{3}$-bonded $\mathrm{C}$ atoms, corresponding to structures predicted by $a b$ initio searching techniques. ${ }^{60,61}$ Such open framework structures have been suggested to be energetically competitive with the graphitic layered compounds, and they could in fact be present within the amorphous materials produced by thermolysis and other reactions at ambient pressure.

\subsection{Polytriazine-imide (PTI) structures}

The production of relatively well-crystallized bulk carbon nitride compounds was reported by Demazeau and colleagues, who used solvothermal reactions involving melamine and cyanuric chloride $\left(\mathrm{C}_{3} \mathrm{~N}_{3} \mathrm{Cl}_{3}\right)$ in the presence of organic bases (triethylamine or di-isopropylethylamine), under high pressure conditions (140 MPa). ${ }^{63}$ Chemical analyses showed that substantial quantities of $\mathrm{Cl}$ as well as $\mathrm{H}$ atoms were incorporated within the structure. Zhang et al. investigated the selfcondensation of aminodichlorotriazine as well as reactions between melamine and cyanuric chloride at higher $P, T$ conditions (1-1.5 GPa; $\left.500-600{ }^{\circ} \mathrm{C}\right)$ to form a family of yellow crystalline products that approached a limiting composition $\mathrm{C}_{6} \mathrm{~N}_{9} \mathrm{H}_{3} \cdot x \mathrm{HCl}$ with $x=1$, also formulated as $\left[\mathrm{C}_{6} \mathrm{~N}_{9} \mathrm{H}_{4}\right]^{+} \mathrm{Cl}^{-} .{ }^{25,64}$ Powder XRD studies revealed series of sharp peaks that were initially interpreted within space group $P 6_{3} / m$ with a dominant peak interpreted as the basal reflection of a layered graphitic compound at $d_{002}=3.22 \AA^{25}$ The corresponding $d_{002}$ reflection of crystalline graphite occurs at $3.36 \AA .{ }^{65}$ EELS measurements established $\mathrm{sp}^{2}$ bonding around the $\mathrm{C}$ and $\mathrm{N}$ atoms and ${ }^{13} \mathrm{C}$ nuclear magnetic resonance (NMR) spectra showed two non-equivalent $\mathrm{C}$ sites with peaks at 166 and $159 \mathrm{ppm}$ in a $2: 1$ ratio, consistent with protonation of the some of the $\mathrm{C}$ atoms within the layers. The combined data indicated a structure with triazine rings linked via - NH- units to form a PTI motif with $\mathrm{C}_{12} \mathrm{~N}_{12}$ ring voids appearing within the 'graphitic' layers (Fig. 4a). The additional $\mathrm{HCl}$ components found to be included in the structure from the synthesis reaction results in one additional $\mathrm{H}^{+}$to become attached to one of the six available $\mathrm{N}$ sites on the triazine units surrounding the large ring, while $\mathrm{Cl}^{-}$ions are accommodated within the layer voids. Interestingly, the composition of the basal layer is $\mathrm{C}_{6} \mathrm{~N}_{9} \mathrm{H}_{3}$ (i.e., $\mathrm{C}_{2} \mathrm{~N}_{3} \mathrm{H}$ ), identical to the limiting stoichiometry of Liebig's melon, as well as that of the defective wurtzite structure containing $\mathrm{sp}^{3}$-bonded $\mathrm{C}$ and $\mathrm{N}$ atoms prepared from DCDA using high- $P, T$ techniques. ${ }^{66,67}$

Bojdys et al. later produced related crystalline materials by reaction of DCDA in a molten salt (eutectic LiCl-KCl) solvent system. A combination of analysis techniques revealed compositions near $\mathrm{C}_{6} \mathrm{~N}_{8.5} \mathrm{H}_{1.5} \mathrm{Li}_{0.8} \mathrm{Cl}_{0.2}$. XRD patterns showed extended series of sharp peaks that were indexed within space group $P 6_{3} \mathrm{~cm}$ with the strongest feature indicating an interlayer $\left(d_{002}\right)$ spacing of $3.36 \AA$ A. The initial structural model proposed for this material contained layers based on linked polyheptazine units, however a detailed structural analysis carried out by Wirnhier et $a .^{26}$ for a crystalline compound with composition $\mathrm{C}_{12} \mathrm{~N}_{17.5} \mathrm{H}_{6.3} \mathrm{Cl}_{1.5} \mathrm{Li}_{3.3}$ led to a different interpretation. It was concluded that the new phase had a structure based on polytriazine imide-linked units, ${ }^{26}$ related to that proposed by Zhang et al. ${ }^{25}$ for $\mathrm{C}_{6} \mathrm{~N}_{9} \mathrm{H}_{3} \cdot \mathrm{HCl}$, but with differences concerning the location of $\mathrm{Cl}^{-}, \mathrm{H}^{+}$and $\mathrm{Li}^{+}$ions within and between the layers. In this crystalline material, the $\mathrm{H}^{+}$ions within - $\mathrm{NH}-$ bridging species are partially replaced by $\mathrm{Li}^{+}$, causing the $\mathrm{Cl}^{-}$ions to be forced out of the intralayer void positions to occupy new sites intercalated between the sheets (PTI.LiCl). Additional charge-balancing $\mathrm{Li}^{+}$ions were modeled to exist within interlayer sites (Fig. 4b and c). In further experiments using $\mathrm{LiBr} / \mathrm{KBr}$ as the eutectic molten salt combination, Chong et al. produced additional PTI based materials containing ions such as $\mathrm{Br}^{-}$(PTI-LiBr) between the layers, ${ }^{68}$ demonstrating that controlling the size of the intercalated ions alters the interlayer spacing, as well as the stacking pattern. Recent studies using multi-dimensional NMR techniques combined with
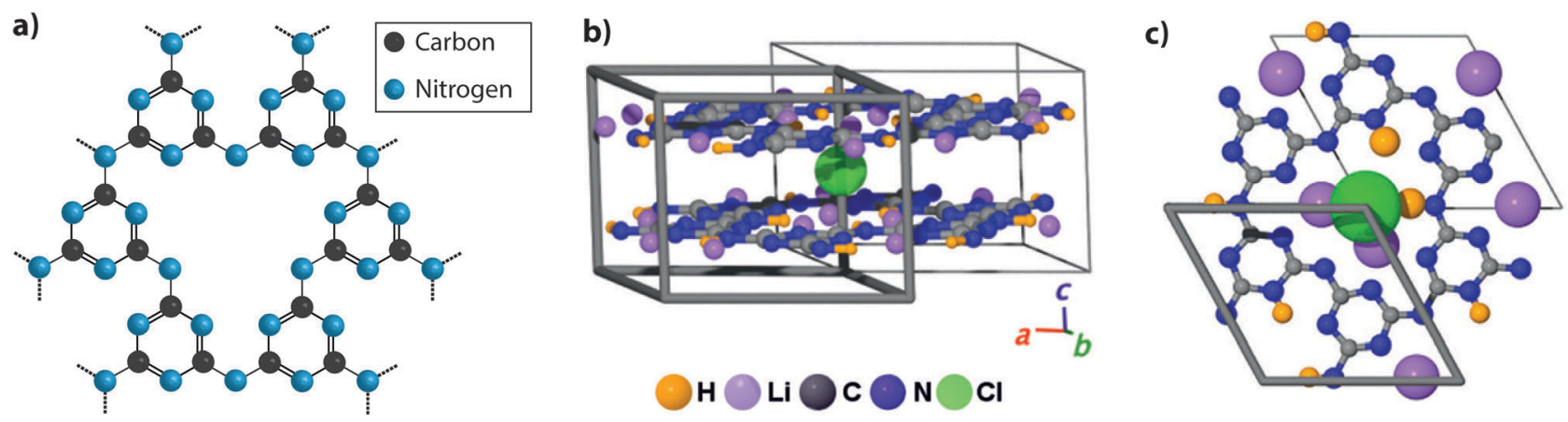

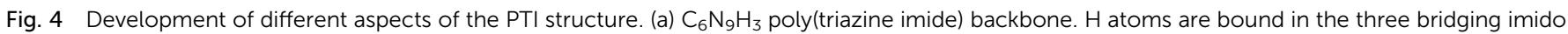

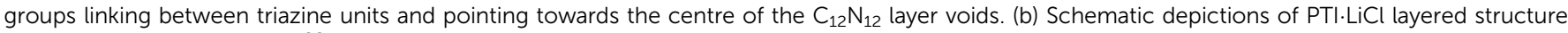

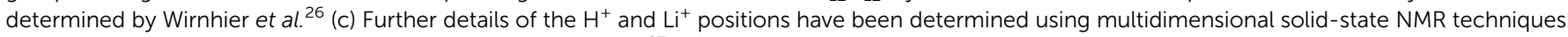
along with PDF analysis of X-ray and neutron diffraction data. ${ }^{27}$ Reprinted with permission from ref. 27 . Copyright John Wiley and Sons. 
pair distribution (PDF) analysis of the diffraction data are now providing an even more detailed view of the local structural arrangements in these crystalline PTI compounds, specifically concerning the locations of $\mathrm{H}$ and $\mathrm{Li}$ atoms or ions within the voids (Fig. 4c). ${ }^{27}$ It should be noted that all PTI materials examined to date maintain a significant $\mathrm{H}$ concentration as an essential component of their structure, as the substitution by $\mathrm{Li}$ is always only partial. ${ }^{25,26,68,69}$

\section{Characterization of carbon nitride materials: techniques and challenges}

Here we summarize techniques used to characterize the chemical composition and structural nature of different classes of carbon nitride materials. We note that due to certain challenges associated with both the particular techniques and the nature of the materials themselves, understanding the chemistry and structure of these solid state compounds remains a project that is still under development. In this section we highlight results that have been obtained to date, while pointing out areas that still need attention.

\subsection{Compositional analysis}

Determining reliable chemical compositions for amorphous to nanocrystalline solid-state materials built from combinations of the "light" elements $\mathrm{C}, \mathrm{N}$ and $\mathrm{H}$ is always challenging, especially when these can contain significant concentrations of other elements such as $\mathrm{O}$, as well as $\mathrm{Li}, \mathrm{Cl}$ and $\mathrm{Br}$. In early investigations into various $\mathrm{C}_{x} \mathrm{~N}_{y} \mathrm{H}_{z}$ compounds, the bulk elemental compositions were determined using classical chemical analysis methods along with gravimetric techniques. Modern studies typically apply commercial $\mathrm{CHN}(\mathrm{O})$ analyzers that employ flash heating to $900-1000{ }^{\circ} \mathrm{C}$, followed by catalytic oxidation and reduction reactions in an inert gas stream. ${ }^{70}$ Thermogravimetric analysis (TGA) is also applied during controlled step heating combined with mass spectrometric analysis to determine the gaseous species evolved, with complementary data on phase changes and thermal decomposition reactions obtained from differential thermal analysis (DTA) or scanning calorimetry (DSC) techniques. $\mathrm{NH}_{3}$ is typically evolved from precursors such as melamine and DCDA above approximately $450{ }^{\circ} \mathrm{C}$, with $\mathrm{C}_{2} \mathrm{~N}_{2}$ and volatile $\mathrm{C}_{x} \mathrm{~N}_{y} \mathrm{H}_{z}$ species, not all of which have been identified, appearing in the gas phase at higher temperatures $\left(480-540{ }^{\circ} \mathrm{C}\right)$. Final decomposition to yield refractory $\mathrm{N}$-doped carbon materials $\left(\mathrm{CN}_{x}\right.$, with residual $\mathrm{N}$ contents ranging up to a few per cent) occurs above $680{ }^{\circ} \mathrm{C}$ (Fig. 5)..$^{2,49-51}$ The evolution of gaseous $\mathrm{C}_{2} \mathrm{~N}_{2}$ and other $\mathrm{C}$-containing species in the intermediate temperature range highlights the fact that such thermolysis reactions cannot be used to attain the ideal $\mathrm{C}_{3} \mathrm{~N}_{4}$ stoichiometry, that would be predicted to constitute the end result of simply removing $\mathrm{NH}_{3}$ component from the N-rich molecular precursors (Fig. 2b). Instead, the limiting compositions for $\mathrm{gCN}(\mathrm{H})$ materials produced in this way appear to lie close to $\mathrm{C}_{2} \mathrm{~N}_{3} \mathrm{H}$, corresponding to those of Liebig's melon $\left(\mathrm{C}_{6} \mathrm{~N}_{7}(\mathrm{NH})\left(\mathrm{NH}_{2}\right)\right)$ or hydromelonic

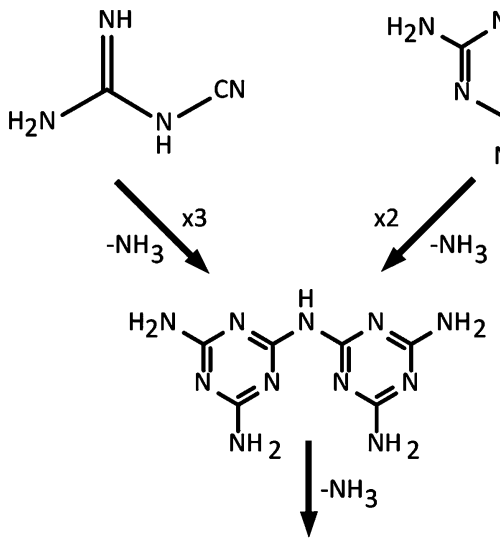<smiles>Nc1nc(N)nc(N)n1</smiles><smiles>CC(C)CN</smiles><smiles>N=c1nc(N)nc(N)[nH]1</smiles><smiles>NC(=[V])/N=C(\N)N=C(N)N</smiles><smiles></smiles>

Fig. 5 Sequence of polymerization reactions proposed for dicyandiamide or melamine leading to Liebig's melon via condensation and elimination of $\mathrm{NH}_{3}$ components. Further condensation reactions could ultimately lead to sideways cross-linking of polyheptazine ribbons to form sheet-like structures, but no fully polyheptazine based $\mathrm{g}-\mathrm{C}_{3} \mathrm{~N}_{4}$ has been observed to date.

acid $\left(\mathrm{C}_{6} \mathrm{~N}_{7}(\mathrm{NCNH})_{3}\right),{ }^{22,49-51}$ as well as that of the graphitic layers found in crystalline PTI compounds, ${ }^{25,26}$ and also the $\mathrm{sp}^{3}$-bonded phase with a defective wurtzite structure produced under high- $P, T$ conditions. ${ }^{66,67}$

Many studies have reported compositional data for $\mathrm{C}_{x} \mathrm{~N}_{y} \mathrm{H}_{z}$ materials prepared for different applications using such thermolysis reactions. Although it is usual for substantial quantities of $\mathrm{H}$ to be recorded as a major component of the gCN compound, we note that many of the publications go on to describe the material as " $\mathrm{g}-\mathrm{C}_{3} \mathrm{~N}_{4}$ ", in the title and abstract as well as throughout the main text. This practice is misleading. In recent work from our group, we prepared series of gCN compounds from a 1:1 mixture of DCDA and melamine heated to $550-650{ }^{\circ} \mathrm{C}$ in an $\mathrm{N}_{2}$ atmosphere. As expected, the $\mathrm{C}: \mathrm{N}$ ratio increased and the $\mathrm{H}: \mathrm{C}$ ratio decreased with increasing synthesis temperature due to loss of $\mathrm{NH}_{3}$ as the condensation reaction proceeded (Fig. 6). However, even after synthesis at $650{ }^{\circ} \mathrm{C}$ the $\mathrm{H}: \mathrm{C}$ ratio remained close to 0.5. Exposure to air or moisture can result in additional $\mathrm{O}$ and $\mathrm{H}_{2} \mathrm{O}$ being incorporated within the samples, and this can affect the determination of $\mathrm{C}: \mathrm{N}: \mathrm{H}$ abundances and elemental ratios. 


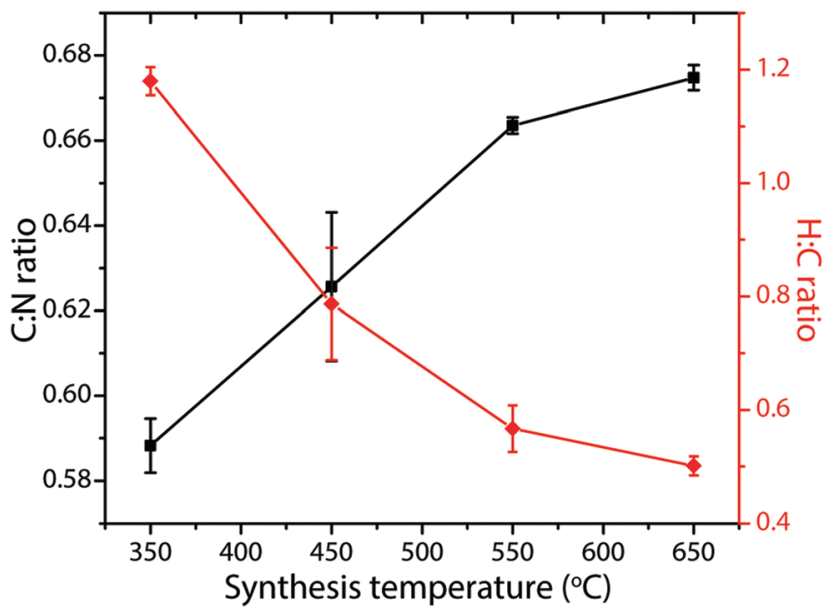

Fig. $6 \mathrm{C}: \mathrm{N}$ and $\mathrm{H}: \mathrm{C}$ atomic\% ratios in $\mathrm{gCN}$ s produced from $1: 1$ melamine: DCDA mixtures as a function of synthesis temperatures between $350-650^{\circ} \mathrm{C}$.

Crystalline PTI materials typically contain $\mathrm{Li}^{+}, \mathrm{Cl}^{-}, \mathrm{Br}^{-}$ or other species included within their structures. ${ }^{25,26,69,71}$ The concentrations of these elements must be determined independently by other techniques, including inductively coupled plasma mass spectrometry (ICP-MS), electron microprobe or quantitative scanning electron microscopy (SEM) using energydispersive X-ray spectroscopy (EDX) analysis, ${ }^{72} \mathrm{X}$-ray photoelectron spectroscopy (XPS), ${ }^{73}$ EELS and RBS. ${ }^{24}$ The results of the different analyses must then be combined to give a best estimation of the chemical composition of the material that has been synthesized. Quantitative determination of Li contents is particularly challenging. EELS spectra give quantitative information on $\mathrm{C}, \mathrm{N}, \mathrm{O}$ contents as well as heavier elements such as $\mathrm{Cl}$ or $\mathrm{Br}$, but not for the lightest components including $\mathrm{H}$ and $\mathrm{Li}^{25}$ ICP-MS methods require the materials to be pre-digested, requiring complex and aggressive procedures that can affect the determined compositions. ${ }^{1,69}$ XPS analysis is particularly challenged by the presence of a strong signal from "adventitious" carbon, ${ }^{74}$ as well as uncertainty in some of the characteristic peak assignments: these are discussed in detail below. This introduces further potential errors into the compositional determination. In a few cases, the determined concentrations of some of the elements have been compared using different techniques, to give an idea of the actual composition along with the associated analytical errors. ${ }^{25,26}$ Additional information on the site occupancies of some of the elements can also be obtained from Rietveld analysis of the X-ray diffraction patterns, and more recently neutron scattering data, and from quantitative NMR measurements. ${ }^{27}$

\subsection{X-ray photoelectron spectroscopy (XPS)}

XPS has become a standard tool for chemical and surface structural analysis of materials. It is typically applied to carbon nitride samples to determine their $\mathrm{N}$ : $\mathrm{C}$ ratios, local bonding environments, and the presence and concentration of heteroatoms such as $0 .{ }^{73}$ It is a surface analysis technique, probing the top 1-10 nm of samples, and therefore the extent to which the surface structure truly represents the bulk composition must be taken into account. Powdered samples are typically mounted on carbon tape and the kinetic energies of electrons emitted following irradiation by X-rays of known wavelength are measured, creating a spectrum of the characteristic binding energies (BE) for elements contained within the sample (Fig. 7). Small chemical shifts in the BE examined at higher energy resolution then provide information on the local coordination, bonding environments and oxidation state. The signals are typically fitted with Gaussian or mixed Gaussian-Lorentzian (GL) components to determine the relative concentrations of various species contributing to the overall lineshape. The extent of any surface contamination can be evaluated by eroding the sample surface with a beam of Ar atoms applied during the analysis. Importantly for studies of the semiconducting carbon nitrides, the $\mathrm{BE}$ values can be modified by charging effects during spectral acquisition. An electron flood gun is typically used to counteract this effect, ${ }^{75}$ and the position of a standard $\mathrm{C}-\mathrm{C}$ environment $(\mathrm{BE} \sim 284.8 \mathrm{eV}$ ) is typically used to calibrate the resulting spectra.

A primary obstacle to obtaining quantitative XPS analyses of carbonaceous materials is the presence of an "adventitious" C1s signal $\left(\mathrm{C}_{\mathrm{adv}}\right)$ that partially derives from the carbon tape that is used to mount the samples. Powdered materials can also be pressed into malleable metal foils to avoid this problem, but this has rarely been applied in gCN studies. Other $\mathrm{C}_{\mathrm{adv}}$ contributions can also arise from contamination of the sample surface during handling in the atmosphere, or from degassing processes within the instrument itself. In order to help identify such problems and aid in future interpretation of C1s spectra, we discuss the standard spectrum obtained for carbon tape, before presenting the analysis of data for several typical carbon nitride materials (Fig. 7 and 8).

In addition to the $\mathrm{C} 1 \mathrm{~s}$ peak near $280 \mathrm{eV}$, the carbon tape survey spectrum shows a strong signal due to $\mathrm{O}$, as well as features assigned to Si (Fig. 7). The minor Si component could be derived from mineral particles $\left(\right.$ e.g., $\left.\mathrm{SiO}_{2}\right)$ deposited from the laboratory atmosphere, that could also contribute to the $\mathrm{O}$ signal. However, most of the much larger $\mathrm{O}$ signal likely indicates surface oxidation of the C-tape. Examination of the C1s region shows a main C-C peak at $284.8 \mathrm{eV}$, with a shoulder at higher BE $(286.1 \mathrm{eV})$. A further weak peak emerges at $288.7 \mathrm{eV}$ after careful fitting of the baseline in the region. The three contributions are fit using GL lineshapes (Fig. 8a). The weak peaks at higher $\mathrm{BE}$ values are typically interpreted as due to $\mathrm{C}-\mathrm{O}(286.1 \mathrm{eV})$ and $\mathrm{O}-\mathrm{C}=\mathrm{O}(288.7 \mathrm{eV})$ species, indicating surface oxidation of the carbon film. There is no evidence for $\mathrm{N}$ present.

The molecular crystal melamine contains the isolated $s$-triazine unit with three $-\mathrm{NH}_{2}$ substituents (Fig. 9a). ${ }^{22}$ The XPS survey spectrum of this material clearly shows the presence of a strong N1s peak near $400 \mathrm{eV}$ (Fig. 7). An O1s signal is also present in the same position as that observed for the underlying C tape, but with considerably lowered intensity, and it is likely that it could be derived from the supporting material. The C1s spectrum is dominated by a single peak at $287.5 \mathrm{eV}$ that is 


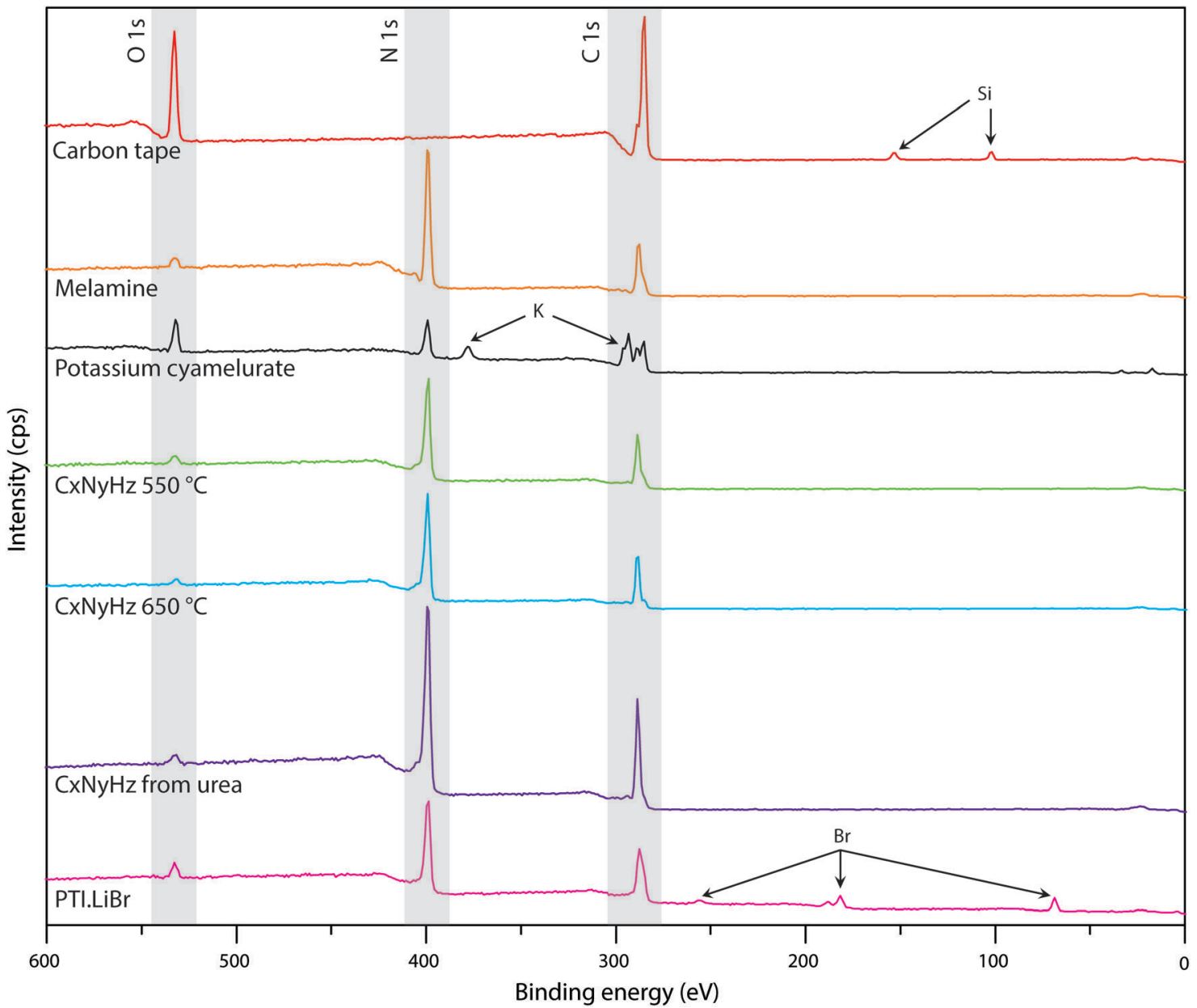

Fig. 7 XPS survey spectra of $C$ tape typically used to mount samples along with various carbon nitride materials.

clearly distinguished from the $\mathrm{C}_{\mathrm{adv}}$ signal, and that is readily assigned to the $\mathrm{sp}^{2}$-bonded carbon atoms bonded to $\mathrm{N}$ within the $s$-triazine ring (Fig. 8b). ${ }^{76}$ The corresponding N1s spectrum shows a broad band that appears to be symmetric but can be deconvoluted to reveal two main GL components in a $1: 1$ ratio consistent with the molecular structure (Fig. 8b). The contribution at $398.2 \mathrm{eV}$ is assigned to the $\mathrm{C}-\mathrm{N}=\mathrm{C}$ nitrogen atoms within the triazine rings, and that at $399.0 \mathrm{eV}$ to the $\mathrm{C}-\mathrm{NH}_{2}$ groups, based on electronegativity considerations. The fitting procedure also reveals a further small component with $\mathrm{BE}=400.1 \mathrm{eV}$, that has been assigned to a resonance form of the melamine structure involving the $-\mathrm{NH}_{2}$ group, similar to that found for aniline. ${ }^{76}$

To provide a similar model for heptazine-based structures we prepared potassium cyamelurate (KCM: $\mathrm{C}_{6} \mathrm{~N}_{7} \mathrm{O}_{3} \mathrm{~K}_{3}$, Fig. $9 \mathrm{~b}$ ) as white, acicular crystals with composition C: $19.18 \%$ (calculated: $21.5 \%$ ), N: $28.93 \%$ (calculated: $29.2 \%$ ), with some additional $\mathrm{H}$ content $(0.28 \%){ }^{138}$ The C1s spectrum (Fig. 8c) showed a single peak at $288.2 \mathrm{eV}$ in addition to the $\mathrm{C}_{\mathrm{adv}}$ contribution, that can be assigned to the unique $\mathrm{C}$ environment inside the heptazine rings. We note that the $\mathrm{BE}$ of this peak occurs at nearly the same position as that for melamine (287.5 eV), thus demonstrating that C1s XPS peak positions cannot be used to distinguish between the triazine and heptazine units that are potentially present within different gCN structures. Features observed near 284 and $380 \mathrm{eV}$ arise from the K2p spectrum (Fig. 7). The only $\mathrm{N}$ atoms present in KCM are contained within the heptazine ring, ${ }^{66}$ providing an opportunity to study the relative electronegativity of the different $\mathrm{N}$ sites (Fig. 9). The N1s spectrum shows a dominant peak near $400 \mathrm{eV}$ with a shoulder at higher BE values (Fig. 8c). The spectrum can be deconvoluted into three GL components. The main peak at $398.4 \mathrm{eV}$ is readily assigned to the outer $-\mathrm{C}-\mathrm{N}=\mathrm{C}-$ environments by analogy with that found at $398.2 \mathrm{eV}$ for melamine, whereas the smaller $399.7 \mathrm{eV}$ peak is attributed to the central $\mathrm{N}-\mathrm{C}_{3}$ unit. This $\mathrm{BE}$ value is very close to that for the $\mathrm{N}$ environment in triphenylamine. The observed ratio of the peak areas $(1: 0.22)$ is close to that expected $(1: 0.17)$ from the molecular structure. An additional contribution from $-\mathrm{C}-\mathrm{N}-\mathrm{H}$ species within the structure is suggested to be present at $400.8 \mathrm{eV}$ (Fig. 8c).

To illustrate the XPS spectra for gCN compounds prepared by thermolysis reactions from molecular precursors we compare data obtained from products of a 1:1 melamine/DCDA mixture treated at 550 and $650{ }^{\circ} \mathrm{C}$ in $\mathrm{NH}_{3}$ atmospheres (see Fig. 6), ${ }^{77}$ with that of a sample prepared from urea $\left(\mathrm{CH}_{4} \mathrm{~N}_{2} \mathrm{O}\right)$ heated to $550{ }^{\circ} \mathrm{C}$ in air $^{78}$ (Fig. 7 and $8 \mathrm{~d}-\mathrm{f}$ ). All of the materials 


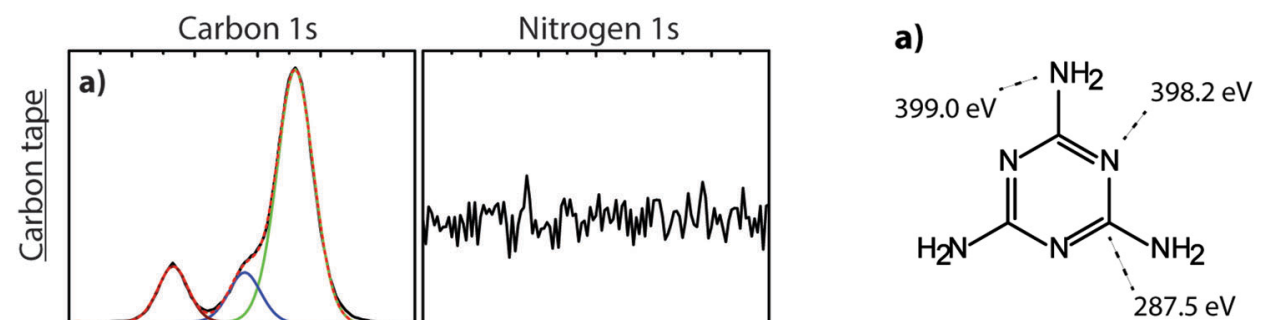

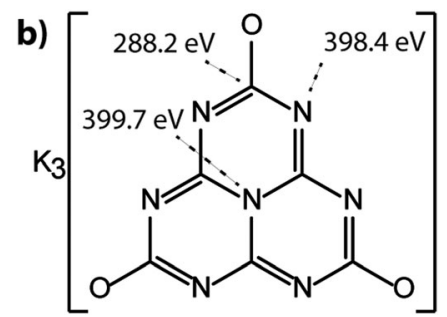

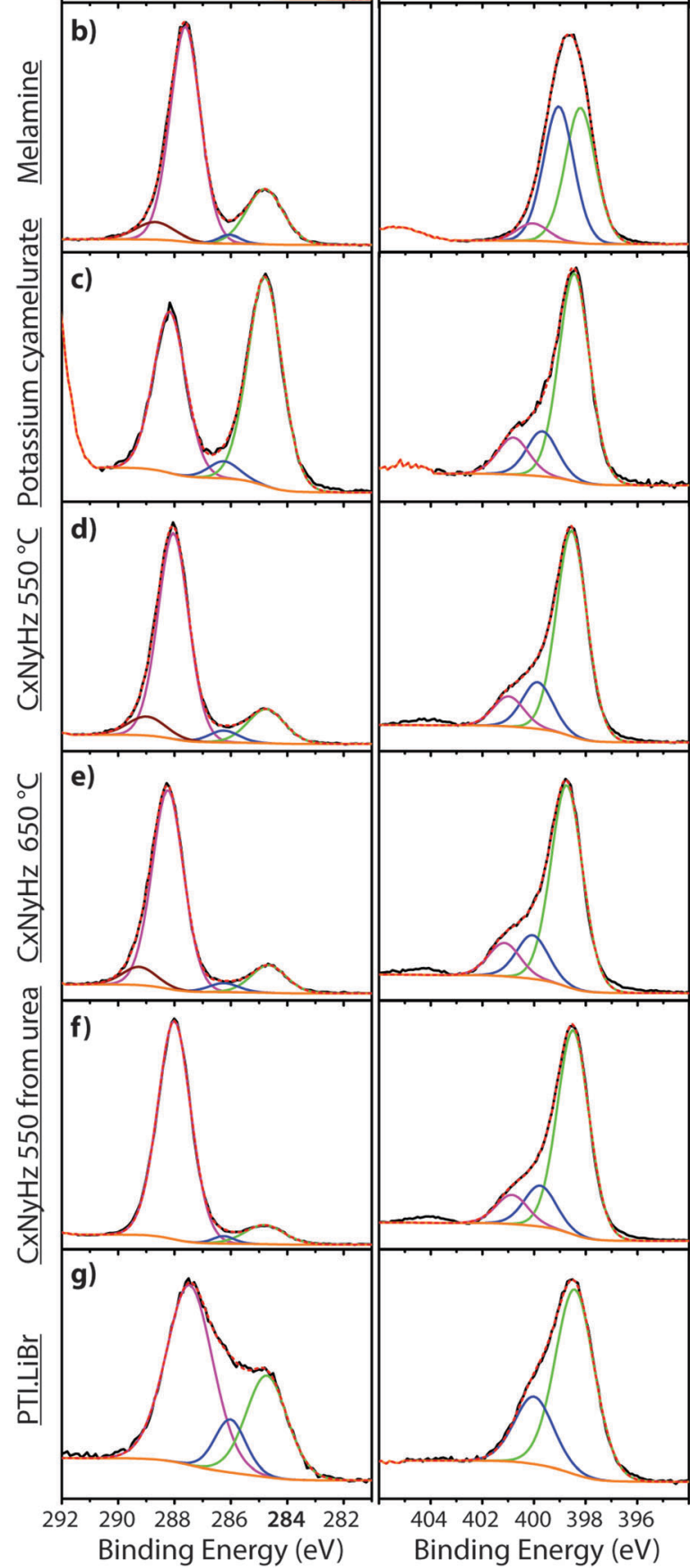

Fig. 8 XPS spectra of carbon tape and $\mathrm{C}_{x} \mathrm{~N}_{y} \mathrm{H}_{z}$ based materials in the regions of $\mathrm{C} 1 \mathrm{~s}$ (left) and N1s (right): (a) carbon tape, (b) melamine, (c) potassium cyamelurate, (d) $\mathrm{C}_{x} \mathrm{~N}_{y} \mathrm{H}_{z}-550{ }^{\circ} \mathrm{C}$, (e) $\mathrm{C}_{x} \mathrm{~N}_{y} \mathrm{H}_{z}-650{ }^{\circ} \mathrm{C}$, (f) $\mathrm{C}_{x} \mathrm{~N}_{y} \mathrm{H}_{z}$ from urea, (g) PTI. $\mathrm{LiBr}$. The $Y$ axis in all cases is the intensity of the emitted photoelectron signal (c.p.s) as a function of the binding energy.
Fig. 9 Structural representations of molecular carbon nitrides with characteristic binding energies indicated for specific sites and groups within the compounds: (a) melamine. (b) Potassium cyamelurate (KCM).

exhibited a weak O1s signal. However, the O content indicated for the gCN sample derived from urea is lower $(\sim 2 \%)$ than those recorded for the other materials $(\sim 4 \%)$. This observation could be related to a "self-supporting atmosphere" effect suggested by previous authors to have developed during the synthesis reaction. ${ }^{78}$ The $\mathrm{C} 1 \mathrm{~s}$ spectra of all three samples are similar, with a main peak near $288 \mathrm{eV}$ assigned to $\mathrm{sp}^{2}$ bonded $\mathrm{C}$ atoms associated with triazine or heptazine units (Fig. 8d-f). The N1s spectra are also nearly identical, showing a dominant feature near $398.6 \mathrm{eV}$ that is assigned to $\mathrm{C}-\mathrm{N}=\mathrm{C}$ units within either triazine or heptazine rings, along with a contribution at $401.1 \mathrm{eV}$ giving rise to a shoulder at higher $\mathrm{BE}$ indicative of $\mathrm{C}-\mathrm{N}-\mathrm{H}$ uncondensed amino $\left(-\mathrm{NH}_{2}\right)$ groups, and a further weak component at $399.9 \mathrm{eV}$ that is assigned to the central $\mathrm{N}$ atoms bridging between three heptazine rings

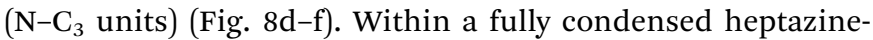
based $\mathrm{g}-\mathrm{C}_{3} \mathrm{~N}_{4}$ structure we would expect the ratio of $\mathrm{C}-\mathrm{N}=\mathrm{C}$ to $\mathrm{N}-\mathrm{C}_{3}$ units to be close to $1: 0.33$. However, the area ratios determined for gCN samples prepared by thermolysis reactions are always significantly lower than this, indicating that the compounds do not correspond to fully condensed graphitic structures.

To study the bonding properties of a gCN material containing fully condensed sheets formed from independent $s$-triazine rings connected by imido - NH- units, we obtained the XPS spectrum of crystalline PTI. $\mathrm{LiBr}$ (Fig. 7 and $8 \mathrm{~g}$ ) ${ }^{26,27}$ The presence of $\mathrm{Li}$ is indicated by the weak $1 \mathrm{~s}$ feature at $\mathrm{BE}=54.9 \mathrm{eV}$ (Fig. 10a). Although this can be fitted by a single GL component, it is broader than the equivalent peak for rocksalt-structured $\mathrm{LiBr}$, suggesting that a range of Li environments is present within the PTI structure. That suggestion is consistent with results of detailed structural analysis of PTI materials. ${ }^{26,27}$ This effect is also noted for the $\mathrm{Br} 3 \mathrm{~d}$ region, that contains two peaks due to spin-orbit $(I=3 / 2,5 / 2)$ coupling. The C1s spectrum of PTI-LiBr is different from those for polymeric to graphitic $\mathrm{C}_{x} \mathrm{~N}_{y} \mathrm{H}_{z}$ materials. Apart from the adventitious $\mathrm{C}_{\text {adv }}$ signal at $284.8 \mathrm{eV}$, there is a strong peak at $287.5 \mathrm{eV}$ and a weaker one at $286.1 \mathrm{eV}$, that were assigned by Schwinghammer et al. for the related crystalline material PTI. LiCl to " $\mathrm{sp}^{2}$ carbon atoms bonded to $\mathrm{N}$ inside the triazine ring",. ${ }^{1}$ However, structural models for the PTI materials only allow for a single $\mathrm{C}$ environment within the imide-linked triazine rings (Fig. 4), and so the origin of these two features remains undetermined at present. A similar second weak peak observed in the C1s spectrum for the bulk crystalline $\mathrm{g}^{-} \mathrm{C}_{3} \mathrm{~N}_{4}$ compound TGCN has been 

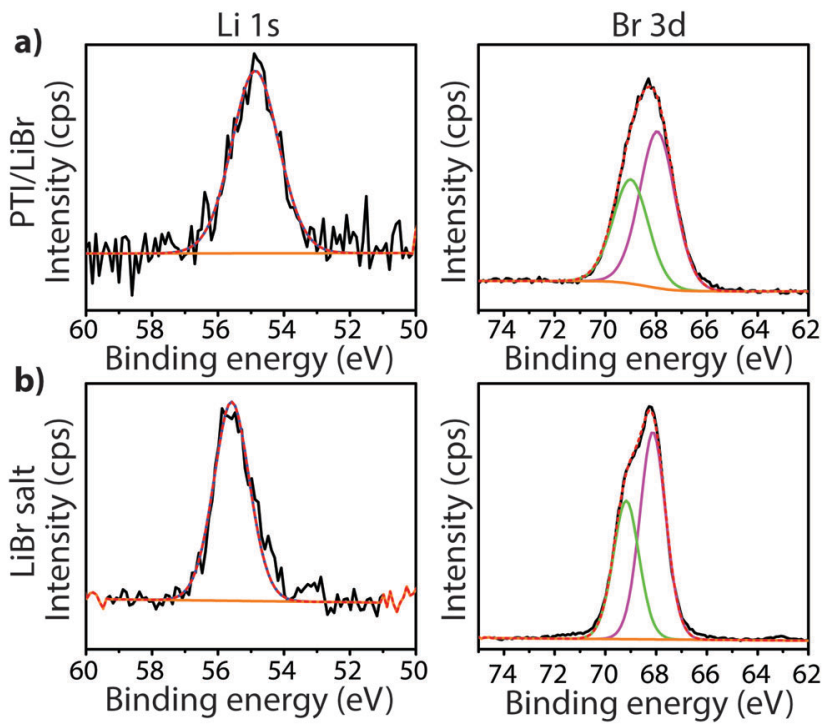

Fig. 10 Li1s and Br3d XPS spectra of crystalline (a) PTI.LiBr and (b) LiBr.

assigned to the presence of terminal $-\mathrm{C} \equiv \mathrm{N}$ units, although no features corresponding to these groups appeared to be present in the reported IR spectra. ${ }^{23}$

The XPS spectra for a TGCN sample prepared by Algara-Siller et al. ${ }^{23}$ are reproduced in Fig. 11. The N1s region contains peaks at $398.5 \mathrm{eV}$ and $399.9 \mathrm{eV}$ assigned to $\mathrm{N}-\mathrm{C}_{3}$ (bridge) and $\mathrm{C}=\mathrm{N}-\mathrm{C}$ (ring) environments respectively. However, the C1s spectrum shows a prominent $\mathrm{C}-\mathrm{C}$ feature at $284.7 \mathrm{eV}$, that was assigned by Algara-Siller $e t$ al. ${ }^{23}$ to adventitious carbon, and two further peaks at $286.7 \mathrm{eV}$ and $288.1 \mathrm{eV}$ with an area ratio of $1: 0.56$, assigned to terminal sp-bonded carbon atoms in $\mathrm{C} \equiv \mathrm{N}$ groups and $\mathrm{sp}^{2}$ carbon (ring) atoms, respectively. ${ }^{23}$ The peak at $286.7 \mathrm{eV}$ is notably larger than that of the $\mathrm{sp}^{2}$ triazine ring peak (288.1) and is significantly more prominent than in any of the other gCN materials studied. This peak lies close to $\mathrm{BE}$ values that are typically associated with surface $\mathrm{C}-\mathrm{O}$ species, and Algara-Siller et al. did note the presence of O component in their sample ${ }^{23}$ (Fig. 11).

Our conclusion is that XPS represents a primary analysis tool for studying both the chemical composition and the local structural environments in gCN materials. It must be applied with care and attention to details such as proper analysis of signals derived from the underlying C-tape support as well as other contributions to the $\mathrm{C}_{\mathrm{adv}}$ lineshape, including evaluation of likely origin of O components in the XPS spectra. There are main issues remaining related to the assignment of C1s and N1s peaks and minor components contributing to the overall line profile, in all types of amorphous, crystalline and polymeric materials examined to date. These must continue to be examined and interpreted, as they not only contribute to determination of the $\mathrm{C}: \mathrm{N}: \mathrm{H}:(\mathrm{O})$ ratios present within the bulk gCN material and at its surface, but also to the study of the intrinsic structure as well as defects present within it. Both areas of future investigation are critically implicated in determining the functional properties of $\mathrm{gCN}$ compounds, and they
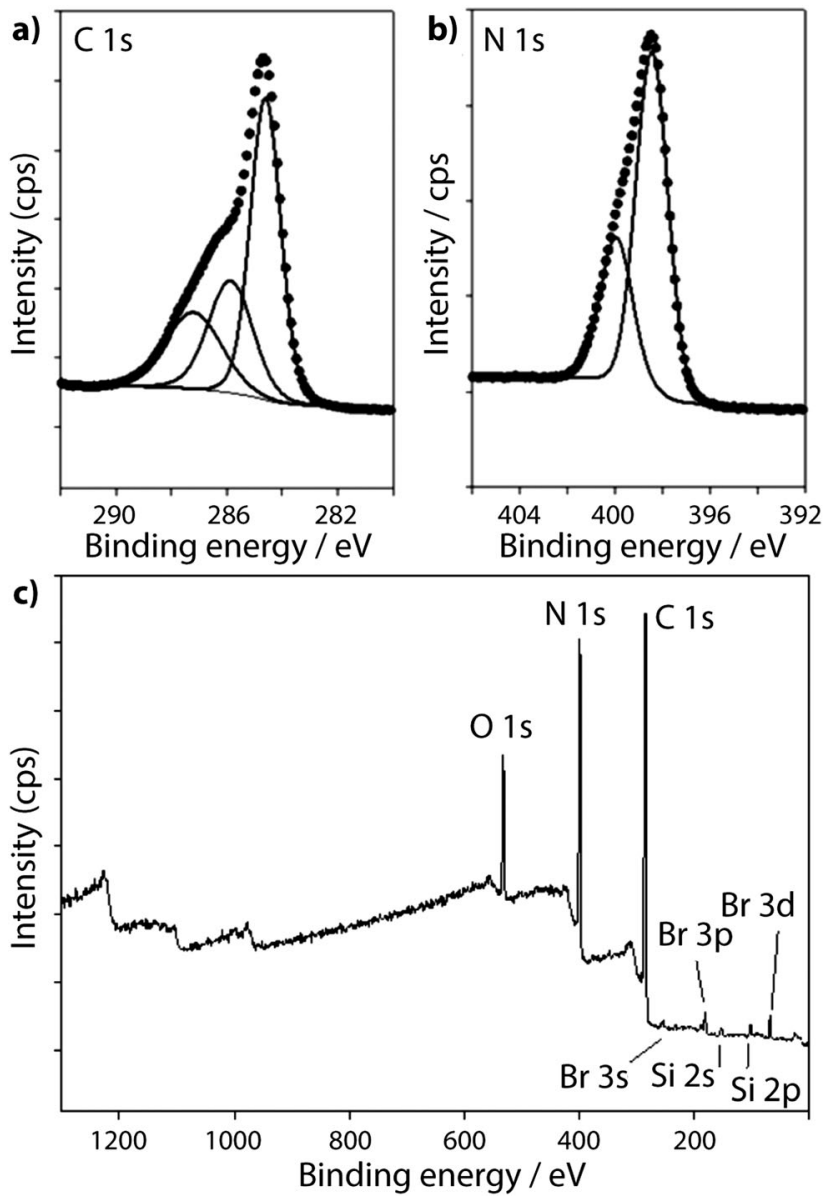

Fig. 11 XPS spectra of TGCN from Algara-Siller et al.:23 (a) C1s spectrum (b) N1s spectrum and (c) Survey spectrum. Reprinted with permission from ref. 23. Copyright John Wiley and Sons.

will help define synthesis and tuning parameters for future materials design.

\subsection{X-ray diffraction (XRD)}

$\mathrm{X}$-ray diffraction is a primary technique used in determining the structures of crystalline and polymeric solids. ${ }^{79}$ Most gCN materials exhibit XRD patterns that contain only a few broad features, consistent with their amorphous to nanocrystalline nature. They are typically dominated by a main peak at approximately $26-28^{\circ} 2 \Theta(\mathrm{Cu} \mathrm{K} \alpha$ radiation), that is usually interpreted as an indication of the presence of a "graphitic" structure, with an interplanar spacing of 3.2-3.4 A..,9,78 However, it is important to note that this is not a definitive criterion for such a definition: any compound containing discotic components stacked in an approximately planar arrangement, or polymeric units arranged with an approximately regular spacing, would also give rise to a similar pattern. The observation of the characteristic XRD pattern for gCN materials does not thus immediately imply the presence of graphitic sheets within the structure. Substantial advances in elucidating the structure of polymeric $\mathrm{C}_{x} \mathrm{~N}_{y} \mathrm{H}_{z}$ materials related on Liebig's melon have been achieved recently by modelling both the 
X-ray and neutron scattering patterns, including PDF analysis of data obtained over an extended $Q$ range. ${ }^{20,52}$ It is useful to begin a discussion with the expected diffraction properties of crystalline to highly disorded C-graphite.

Perfectly crystalline graphite contains planar sheets that are stacked according to an $\mathrm{AB}$ pattern with $P 6_{3} / m m c$ space group symmetry, with the centres of hexagons in each sheet lying above and below the $\mathrm{sp}^{2}$ bonded atoms of adjacent layers. The diffraction pattern is dominated by an intense $d_{002}$ reflection corresponding to an interlayer spacing of $3.36 \AA^{80} .^{80}$ Different "graphitic" forms of carbon that exhibit various degrees of disorder in the relative orientation, stacking arrangements, planarity and lateral extent of the layers, all maintain a similar XRD pattern that becomes broadened and with its main peak shifted to larger $d$ values, as the level of disorder increases. ${ }^{65}$

The XRD pattern of crystalline TGCN (Fig. 12a and b) has been observed to contain a main peak near $26.5^{\circ} 2 \Theta$, accompanied by a second feature at approximately $24^{\circ} 2 \Theta$, with further weak reflections near 50 and $56^{\circ} 2 \Theta .^{23}$ The diffraction pattern was analyzed within space group $\mathrm{P} \overline{6} m 2$ assuming $\mathrm{AB}$ stacking of planar $\mathrm{C}_{3} \mathrm{~N}_{4}$ layers, although analysis of TEM images presented in the same study suggested $\mathrm{ABC}\left(\mathrm{P6}_{3} \mathrm{~cm}\right)$ layer stacking. It was also noted that stacking disorder might be present within the sample, however. Our simulated XRD patterns for both stacking arrangements assuming a planar geometry for the g- $\mathrm{C}_{3} \mathrm{~N}_{4}$ sheets appear similar (Fig. 12c). However, DFT calculations indicate that the layers should in fact exhibit more or less substantial buckling. ${ }^{23}$ Stacking buckled g- $\mathrm{C}_{3} \mathrm{~N}_{4}$ sheets into either $\mathrm{AB}$ or $\mathrm{ABC}$ patterns in fact causes the subsidiary peak to occur on the opposite (high angle) side of the main reflection (Fig. 12). That result indicates that the true structure of TGCN may not yet be fully resolved, although the TEM results and compositional analyses do clearly indicate the triazine-based nature of the $\mathrm{g}-\mathrm{C}_{3} \mathrm{~N}_{4}$ layers.

The family of PTI compounds containing $\mathrm{Cl}^{-}, \mathrm{Br}^{-}$or other anionic species intercalated within or between the layers also exhibit a crystalline series of relatively sharp diffraction peaks in their powder XRD patterns (Fig. 13). ${ }^{25-27}$ However, in these compounds it is important to note that most of the XRD peak intensity is derived from scattering by the "heavy" elements $\mathrm{Cl}$ and $\mathrm{Br}$, that are maintained in their crystalline positions by the carbon nitride layered structure and thus act as a proxy for that arrangement. It is also important to note that the heavy anion sites may not be completely filled, but as long as their scattered $\mathrm{X}$-rays interfere coherently over an appropriate length scale they give rise to "crystalline" diffraction lines. Unfortunately for a general interpretation of these PTI structures, structure drawing programmes and schematic figures that appear in publications usually only depict structures with completely filled sites, and these structures may not be energetically favourable due to repulsive interactions between the large anions in close proximity to each other. It is also difficult to model such structures with partial occupancy of the anion and other sites theoretically, especially when the local distribution

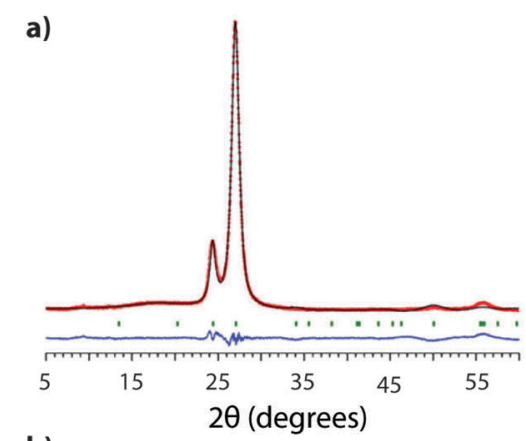

b)

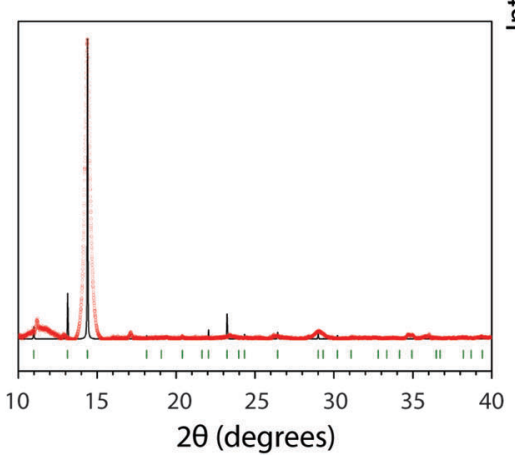

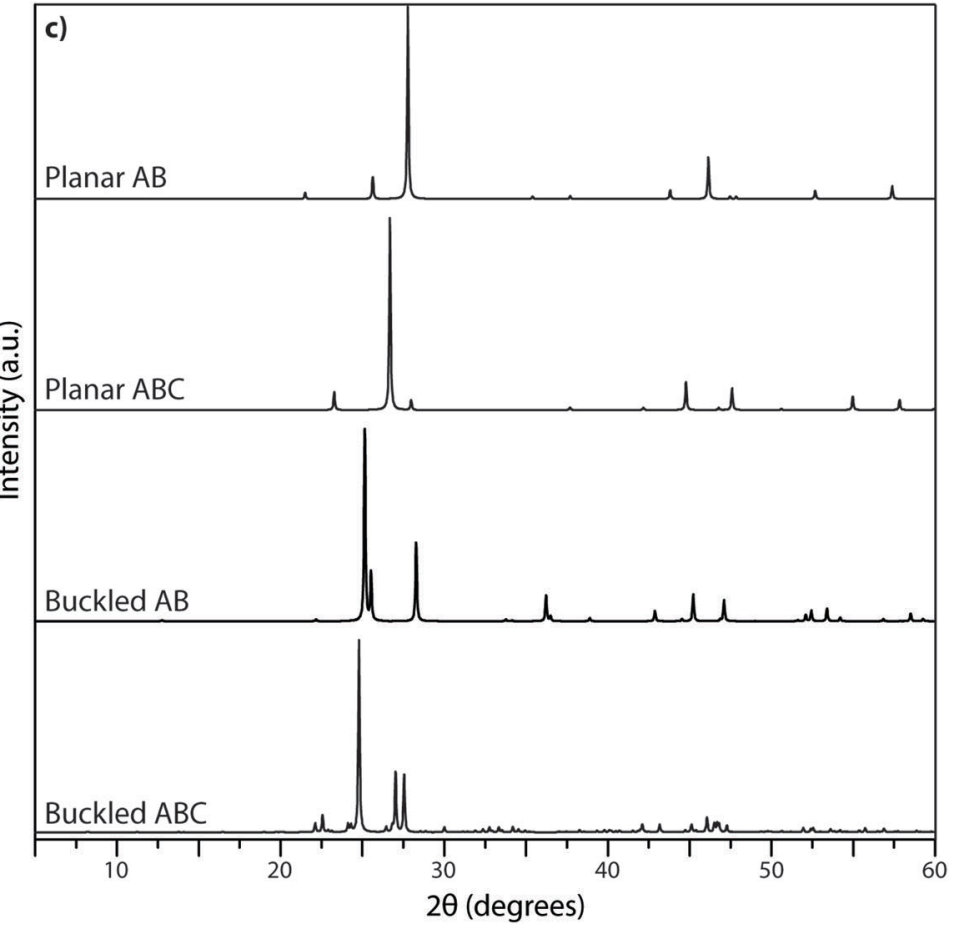

Fig. 12 XRD analysis of TGCN: (a) XRD pattern ( $\mathrm{Cu} \mathrm{K}_{\alpha}$ radiation) collected in reflection geometry observed pattern in red, refined profile in black, difference plot in blue, Bragg peak positions in green. Reprinted with permission from ref. 23. Copyright John Wiley and Sons. (b) Synchrotron PXRD data $(\lambda=0.827127 \AA)$ on ground TGCN flakes. Reprinted with permission from ref. 23. Copyright John Wiley and Sons. (c) Simulated powder XRD patterns ( $\mathrm{Cu} \mathrm{K} \mathrm{K}_{\alpha}$ radiation) for different stacking models of planar vs. buckled g- $\mathrm{C}_{3} \mathrm{~N}_{4}$ layers. (a) Planar $\mathrm{AB}$ stacked (b) planar $\mathrm{ABC}$ stacked (c) buckled $\mathrm{AB}$ stacked (d) buckled ABC stacked. 


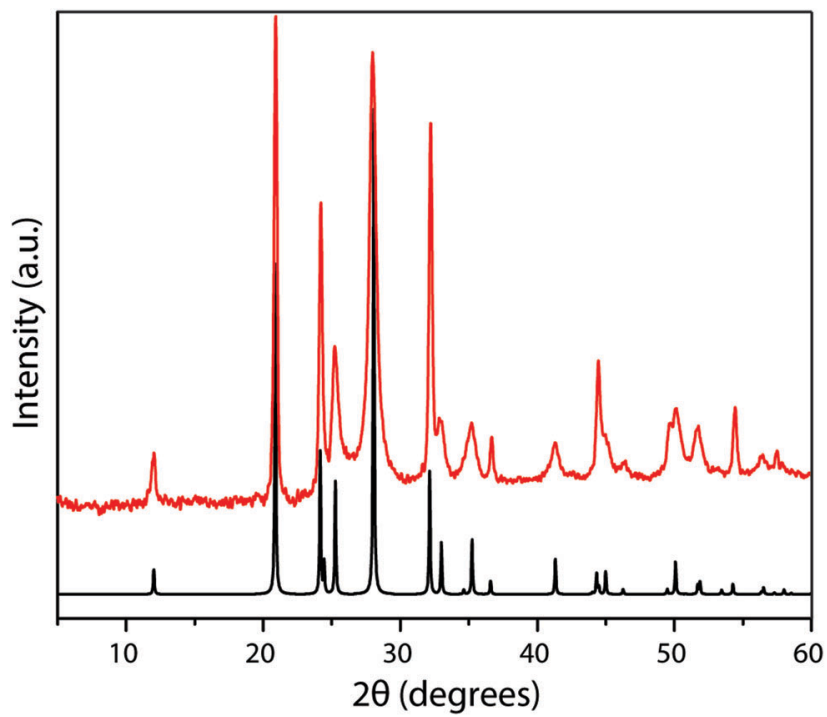

Fig. 13 Powder XRD pattern (Cu $\mathrm{K}_{\alpha}$ radiation) of PTI.LiBr prepared from $\mathrm{DCDA}$ precursor in $\mathrm{LiBr}-\mathrm{KBr}$ eutectic molten salt route (red). The predicted XRD pattern for a fully occupied structure is shown in black.

of atoms (such as the $\mathrm{Li}^{+}$or $\mathrm{N}-\mathrm{H}$ sites around the $\mathrm{C}_{12} \mathrm{~N}_{12}$ rings, or intercalated between the layers) might be disordered. Models used to predict and analyze their X-ray diffraction patterns typically rely on assuming a partial occupancy of sites. Accepting the boundaries imposed by these limitations, we present a series of calculated XRD patterns for PTI. $\mathrm{LiBr}$ and PTI.HCl compounds showing the effects of gradually changing the halide ion concentration on the calculated XRD patterns, that could be useful in future structural analyses (Fig. 14).

Jürgens et al. determined the crystal structure of melem (2,5,8-triamino-tri-s-triazine, Fig. 3 and 15a) using powder XRD data interpreted using Rietveld refinement techniques, combined with solid-state NMR, vibrational spectroscopy and DFT calculations. ${ }^{58}$ The $\mathrm{C}_{6} \mathrm{~N}_{7}$ heptazine core was found to be nearly planar. Layers of $\mathrm{C}_{6} \mathrm{~N}_{7}\left(\mathrm{NH}_{2}\right)_{3}$ were stacked approximately parallel to the $a$ axis with alternating stacking motifs appearing along the $c$ direction. The $\mathrm{C}_{6} \mathrm{~N}_{7}\left(\mathrm{NH}_{2}\right)_{3}$ molecules were linked sideways in the crystal structure by $\mathrm{H}$-bonding to $\mathrm{N}$ atoms of adjacent heptazine cores (Fig. 15a). Lotsch et al. addressed the related outstanding problem of determining the structure of Liebig's melon and demonstrated the existence of a high degree of two-dimensional order within the nanoscale domains of the crystalline material they prepared, using a similar range of complementary diffraction, spectroscopic and theoretical methods. ${ }^{21}$ The melon structure projected on to the $a-b$ plane consists of zig-zag ribbons of heptazine units linked laterally to form extended sheets via $\mathrm{H}$-bonding involving the terminal $-\mathrm{NH}_{2}$ units to bridging $-\mathrm{NH}-$ groups and $-\mathrm{N}=$ units in adjacent polyheptazine ribbons (Fig. 15b).

The XRD patterns of amorphous polymeric to graphitic $\mathrm{C}_{x} \mathrm{~N}_{y} \mathrm{H}_{z}$ materials prepared by thermal condensation from molecular precursors typically show a much smaller number of highly broadened features, that are dominated by a peak in the $25-30^{\circ} 2 \Theta$ range (Fig. 16). This is usually assigned as the
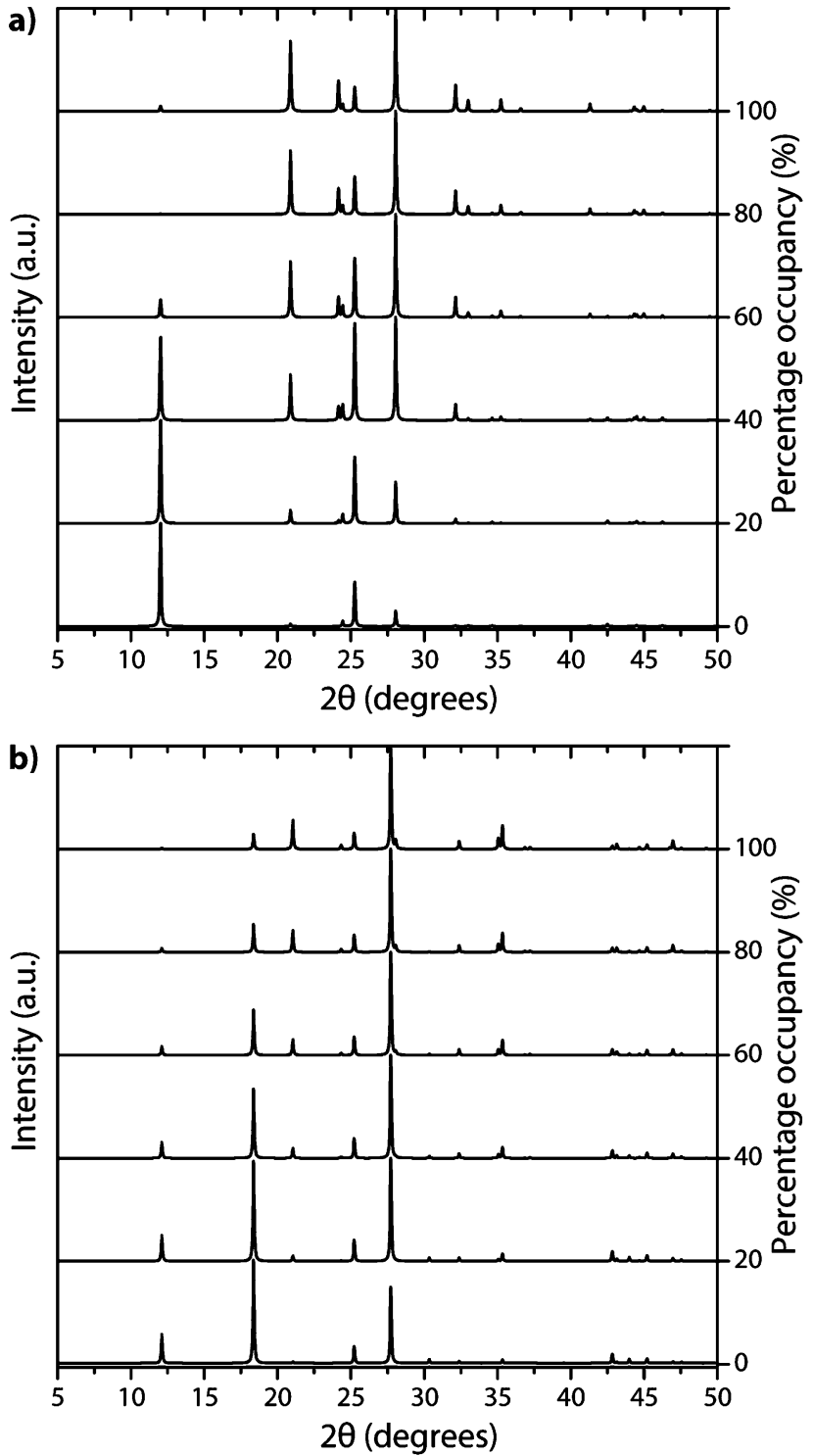

Fig. 14 Calculated XRD patterns of PTI with different halide ion concentrations contained within (a) PTI. $\mathrm{LiBr}$ and (b) PTI. $\mathrm{HCl}$ structures.

" 002 " feature of a graphitic structure, indicating the interlayer spacing dimension. A second broad feature with lower intensity is also observed near $6.7 \AA$, that has been associated with structural correlations occurring between heptazine ring units within the presumed "graphitic" layers. Tyborski et al. have described the analysis of a "unit cell" based on partially condensed polyheptazine sheets, developed from the ribbonlike structures present within the melon structure..$^{20}$ Fina et al. recently presented a careful analysis of powder X-ray and neutron scattering data including PDF profiles obtained over a wide $Q$ range. ${ }^{52}$ Both studies demonstrated that structural models based on triazine layers such as those that occur within TGCN could not account for the diffraction features of the gCN (i.e., polymeric $\mathrm{C}_{x} \mathrm{~N}_{y} \mathrm{H}_{z}$ ) materials, and that these were most likely dominated by polyheptazine units similar to those found in Liebig's melon. They might also contain more 


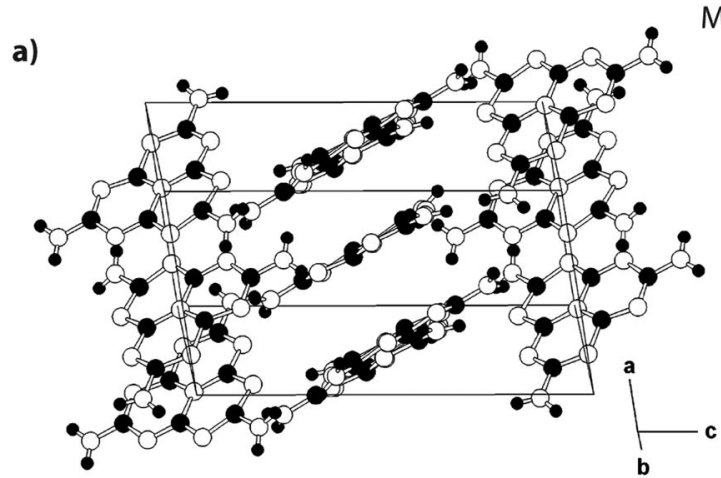

Melem
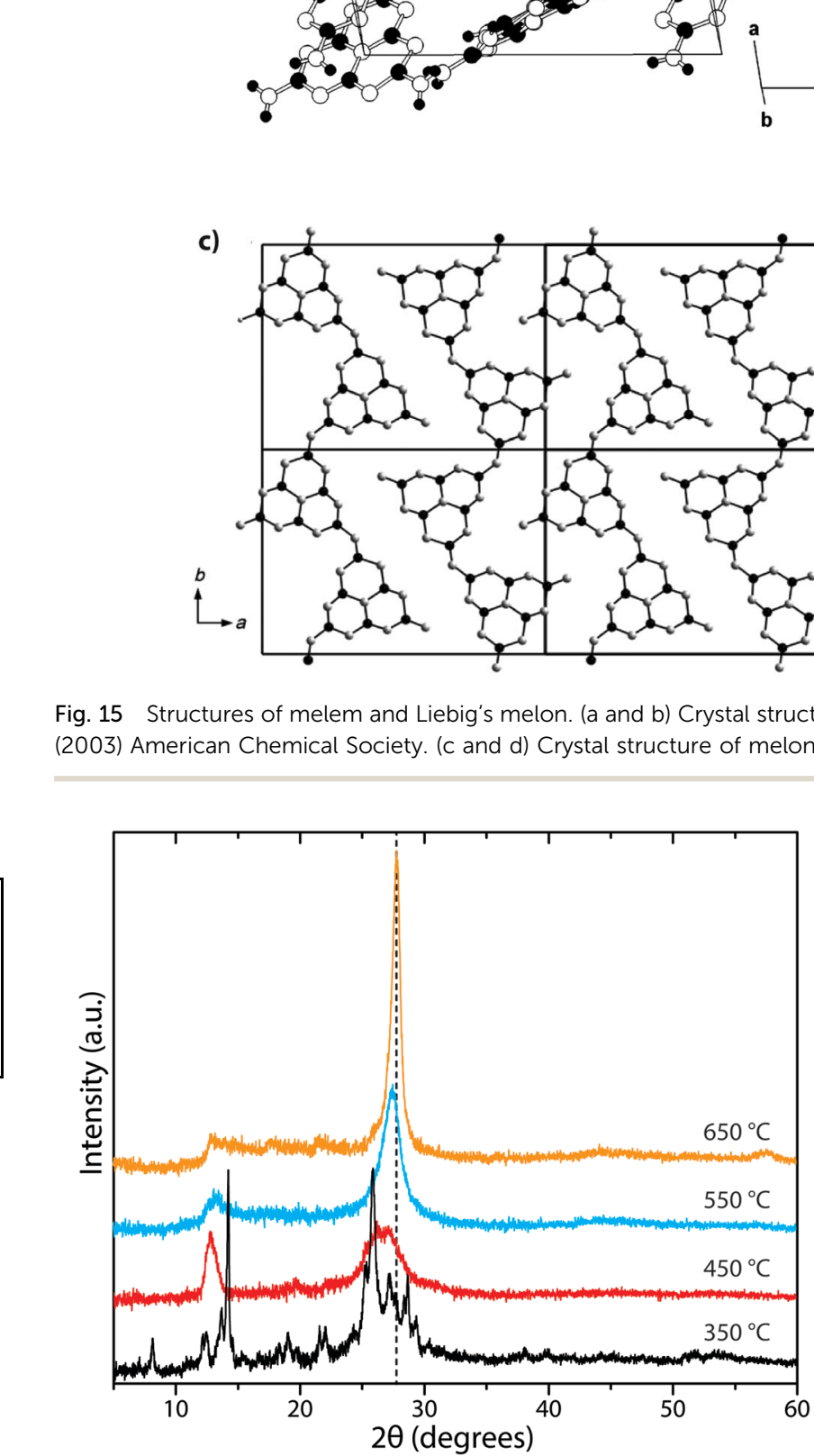

Fig. $16 \mathrm{XRD}$ patterns for gCN materials prepared from 1:1 melamine/ DCDA mixtures under $\mathrm{N}_{2}$ flow over a range of synthetic temperatures. The crystalline peaks at $350{ }^{\circ} \mathrm{C}$ correspond to those of the starting materials melamine and DCDA.

laterally condensed features that could correspond to "graphitic" domains within the amorphous to nanocrystalline structures. c)

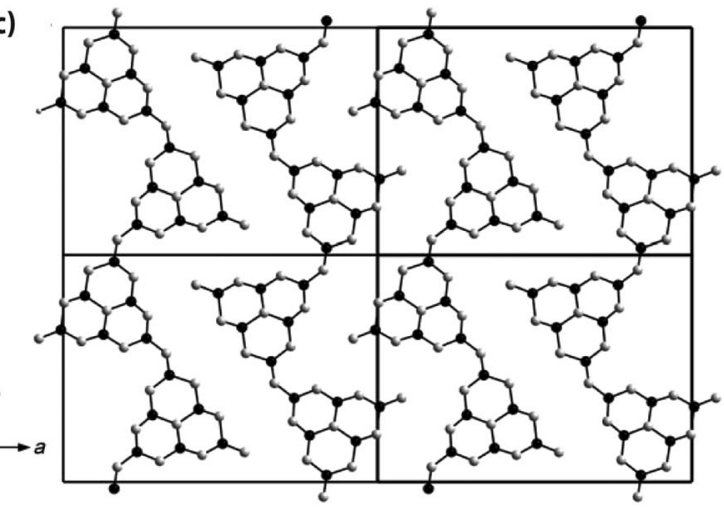

b)

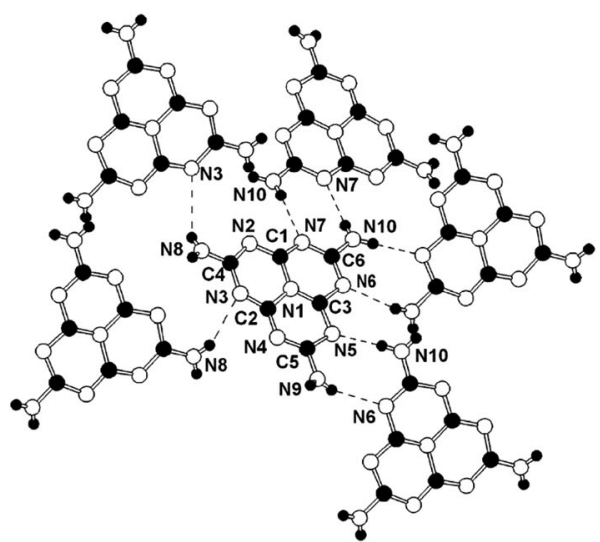

Melon

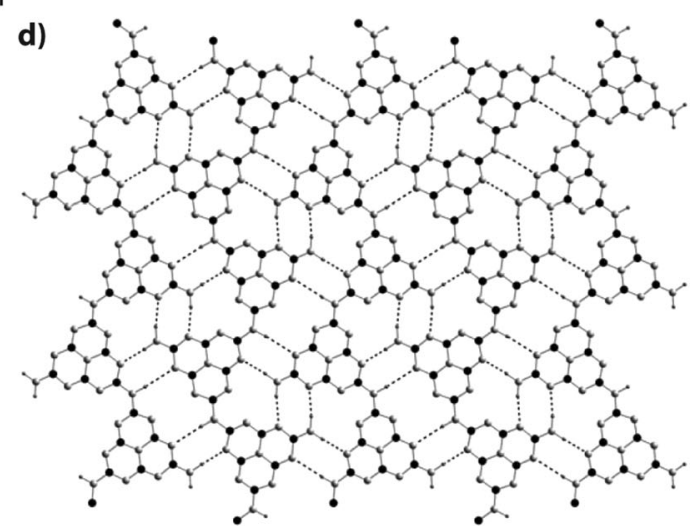

15 Structures of melem and Liebig's melon. (a and b) Crystal structure of melem. Reprinted (and adapted) with permission from ref. 58. Copyright 003) American Chemical Society. (c and d) Crystal structure of melon. Reprinted with permission from ref. 21 . Copyright John Wiley and Sons.

\subsection{Vibrational spectroscopy}

Vibrational spectroscopy methods, especially infrared (IR) absorption spectra obtained using powder transmission or more recently by attenuated total reflection (ATR), constitute a powerful family of techniques that are widely used for structure elucidation as well

Our conclusion is that challenges still remain for full interpretation of the XRD patterns of all types of gCN materials, ranging from the polymeric $\mathrm{C}_{x} \mathrm{~N}_{y} \mathrm{H}_{z}$ solids produced by thermolysis reactions to highly crystalline " $\mathrm{g}-\mathrm{C}_{3} \mathrm{~N}_{4}$ " and PTI materials formed by CVD, molten salt synthesis, or high- $P, T$ treatment. The data to date do indicate that most $\mathrm{g} \mathrm{CN}(\mathrm{H})$ compounds produced by thermolysis from molecular precursors have a polyheptazine structure, that is most likely related to Liebig's melon but that could contain more laterally extended "graphite-like" units, but with a limiting composition near $\mathrm{C}_{2} \mathrm{~N}_{3} \mathrm{H}$. In contrast, the crystalline PTI phases are defined by extended planar structures, also with a base composition near $\mathrm{C}_{2} \mathrm{~N}_{3} \mathrm{H}$, but based on imide-linked $\left(-\mathrm{NH}^{-}\right)$ polytriazine units to form graphitic layers containing large $\left(\mathrm{C}_{12} \mathrm{~N}_{12}\right)$ voids. Finally, the reported TGCN materials do appear to constitute fully-condensed g- $\mathrm{C}_{3} \mathrm{~N}_{4}$ structures containing $\mathrm{C}_{3} \mathrm{~N}_{3}$ rings linked through $\mathrm{sp}^{2}$ bonded $\mathrm{N}$ atoms to form graphitic sheets with smaller $\left(\mathrm{C}_{6} \mathrm{~N}_{6}\right)$ ring voids within the layers (Fig. 3). An analogous structure based on condensation of polyheptazine units is predicted theoretically to be more thermodynamically stable, but it has not been observed in experiments to date. 
as chemical analysis of all classes of molecular, polymeric and solid state compounds. Early results applying IR spectroscopy to the $\mathrm{C}_{x} \mathrm{~N}_{y} \mathrm{H}_{z}$ compounds melam, melem and melon first appeared in publications by Spiridinova and Finkel'shtein, who used the data to help develop structural models for these intriguing materials. ${ }^{48,81-85}$ An important observation for evaluation of current gCN materials as well as results reported in the literature is that the IR spectra of nearly all the compounds that have been examined to date contain prominent $\mathrm{N}-\mathrm{H}$ stretching bands between approximately 2800-3200 $\mathrm{cm}^{-1}$, demonstrating that they are best described as $\mathrm{C}_{x} \mathrm{~N}_{y} \mathrm{H}_{z}$ structures, rather than the " $\mathrm{g}-\mathrm{C}_{3} \mathrm{~N}_{4}$ " designation that is commonly and erroneously applied to them. ${ }^{3,15,19,86-94}$

We must examine the nature of characteristic features of the IR spectra of various gCN materials to evaluate their contribution to the structure determination of these elusive compounds. We begin with features in the $\mathrm{N}-\mathrm{H}$ stretching region (typically between $3000-3200 \mathrm{~cm}^{-1}$, but perhaps extending to lower wavenumbers due to H-bonding as well as other specific interaction effects). Generally, the observation of sharp peaks at high wavenumber values indicates a highly ordered structure with few possibilities for $\mathrm{N}-\mathrm{H}$ sites and local environments, and limited $\mathrm{H}$-bonding between neighboring units.
The $-\mathrm{NH}_{2}$ stretching vibrations of crystalline melamine $\left(\mathrm{C}_{3} \mathrm{~N}_{3}\left(\mathrm{NH}_{2}\right)_{3}\right)$ give rise to two sharp $\mathrm{N}-\mathrm{H}$ stretching peaks at 3469 and $3419 \mathrm{~cm}^{-1}$ in the IR spectrum due to symmetric and antisymmetric modes that are hardly affected by H-bonding within the molecular solid, along with broader bands at 3334 and $3132 \mathrm{~cm}^{-1}$. The IR spectrum for melem $\left(\mathrm{C}_{6} \mathrm{~N}_{7}\left(\mathrm{NH}_{2}\right)_{3}\right)$, containing the $\mathrm{C}_{6} \mathrm{~N}_{7}$ central heptazine unit, is similar. ${ }^{58}$ Melon represents a condensed $\mathrm{C}_{x} \mathrm{~N}_{y} \mathrm{H}_{z}$ polymer based on linked polyheptazine units. It shows a broad asymmetric feature with maxima near 3250 and $3070 \mathrm{~cm}^{-1}$, due to the bridging - $\mathrm{NH}-$ and terminal $-\mathrm{NH}_{2}$ groups that are engaged in H-bonding (Fig. 17). ${ }^{21}$

A powder IR transmission spectrum (obtained using a pressed $\mathrm{KBr}$ disc) for PTI-structured $\mathrm{C}_{6} \mathrm{~N}_{9} \mathrm{H}_{3} \cdot \mathrm{HCl}$ is shown in Fig. 18. ${ }^{25,64}$ The broad band at $3024 \mathrm{~cm}^{-1}$ is consistent with $\mathrm{N}-\mathrm{H}$ stretching of the imido units bridging between the triazine rings, whereas that at $2778 \mathrm{~cm}^{-1}$ was suggested to arise from the protonated triazine rings that are introduced to compensate for the $\mathrm{Cl}^{-}$ions located within the intralayer $\left(\mathrm{C}_{12} \mathrm{~N}_{12}\right)$ void sites. The unusually low $\mathrm{N}-\mathrm{H}$ stretching frequency was thought to arise from $\mathrm{H}$-bonding to the $\mathrm{N}$ site on an adjacent heterocycle, or perhaps by interaction with the $\mathrm{Cl}^{-}$ions located within the $\mathrm{C}_{12} \mathrm{~N}_{12}$ layer voids. ${ }^{25}$

The IR spectra of PTI. LiCl and PTI.LiBr samples are nearly identical in the $\mathrm{N}-\mathrm{H}$ stretching region, and they both lack the
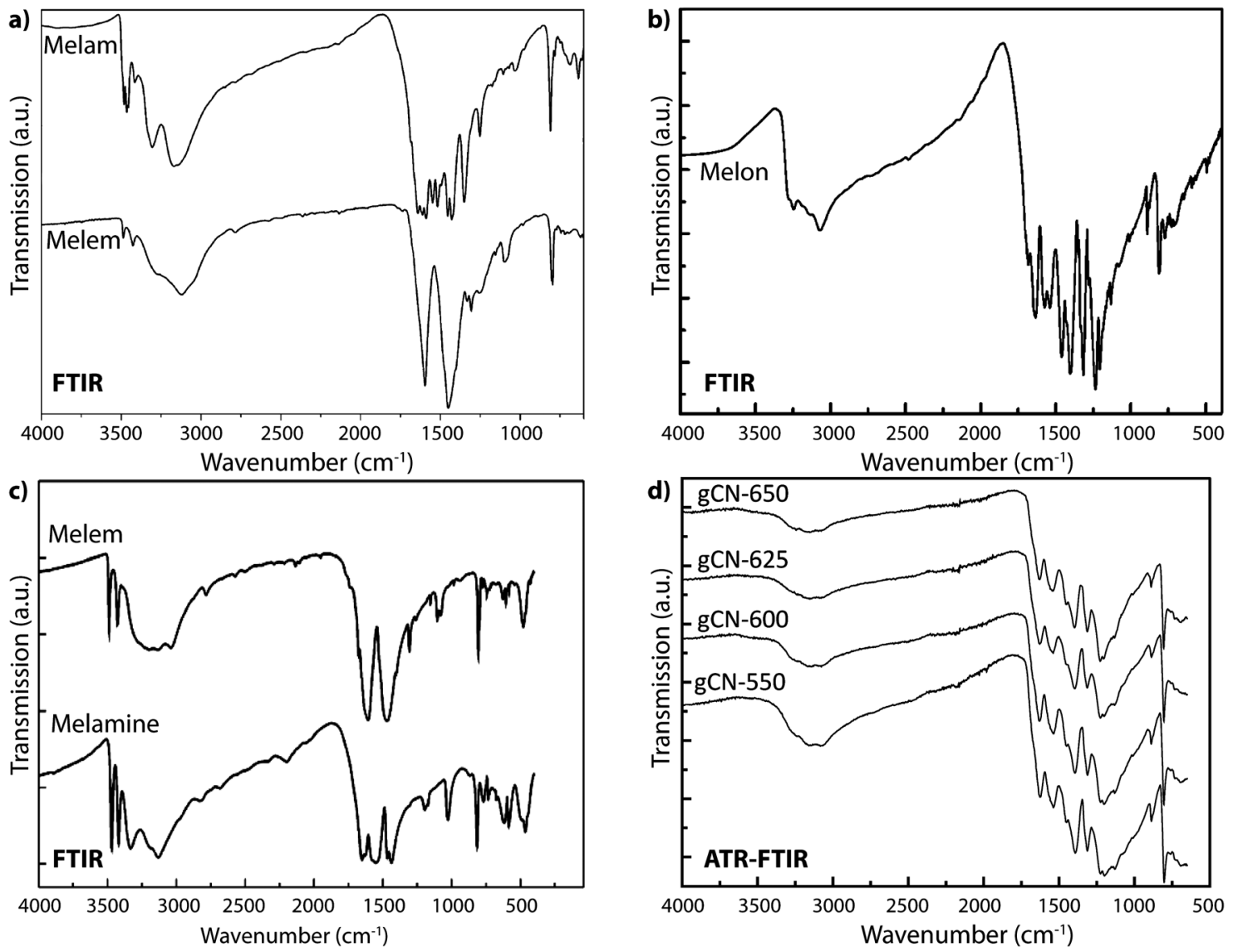

Fig. 17 IR spectra for $\mathrm{C}_{x} \mathrm{~N}_{y} \mathrm{H}_{z}$ molecular and polymeric compounds: (a) melam and melem. Reprinted with permission from ref. 95. Copyright John Wiley and Sons. (b) Melon. Reprinted with permission from ref. 21. Copyright John Wiley and Sons. (c) Melem and melamine. Reprinted (adapted) with permission from ref. 58. Copyright (2003) American Chemical Society. (d) Polymeric compounds formed by thermal condensation from melamine/ DCDA mixtures at a range of synthesis temperatures. 

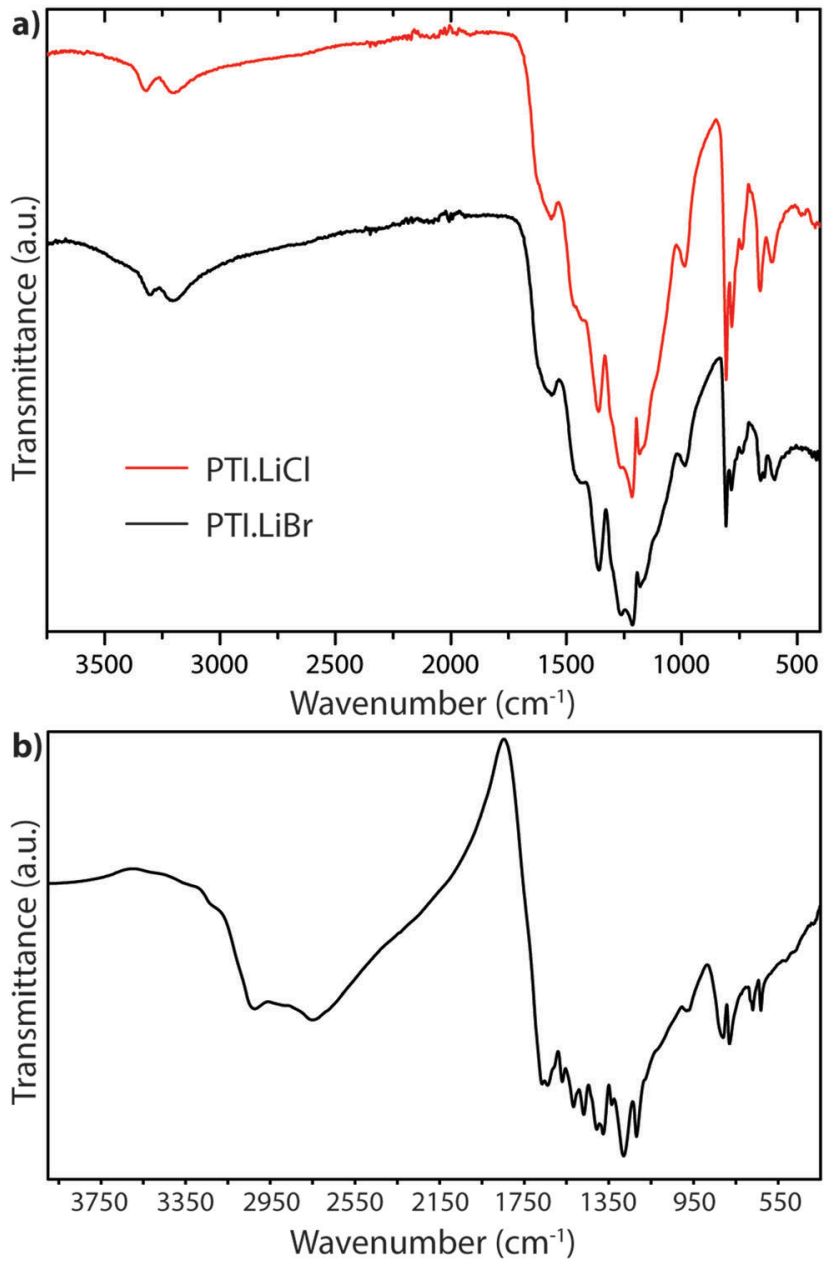

Fig. 18 FTIR powder transmission spectra for (a) PTI.LiCl and PTI.LiBr (b) $\mathrm{PTI} \cdot \mathrm{HCl}^{64}$

very low frequency band observed for PTI.HCl (Fig. 18a). That must be due to the replacement of all or part of the additional $\mathrm{H}^{+}$species around the $\mathrm{C}_{12} \mathrm{~N}_{12}$ rings attached to bridging -NH- groups by $\mathrm{Li}^{+}$cations. ${ }^{26,27}$ Two well defined peaks occur at 3321 and $3195 \mathrm{~cm}^{-1}$ for PTI.LiCl, and at slightly lower wavenumber values for the PTI-LiBr compound, due to the remaining $-\mathrm{NH}$ - linkages between triazine units within the planar PTI (poly- $\mathrm{C}_{2} \mathrm{~N}_{3} \mathrm{H}$ ) layers.

The only gCN materials have been shown to contain no $\mathrm{N}-\mathrm{H}$ stretching features in their IR spectra to date are the triazinebased nanocrystalline g- $\mathrm{C}_{3} \mathrm{~N}_{4}$ structures produced by CVD techniques. ${ }^{24}$ The data present a broad absorption band extending between approximately $1150-1650 \mathrm{~cm}^{-1}$ that can be assigned to in-plane $\mathrm{C}-\mathrm{N}$ stretching and bending vibrations of the graphitic layers. Our DFT calculations performed for a single layer of this structure predict three strong peaks spanning the range of the experimentally measured spectrum (Fig. 19a). ${ }^{24}$ The broad absorption band that is observed experimentally could arise from stacking disorder combined with different degrees of layer buckling within the thin films of the nanocrystalline material. The IR spectra of bulk crystalline TGCN reported by Algara-Siller et al. contain additional features

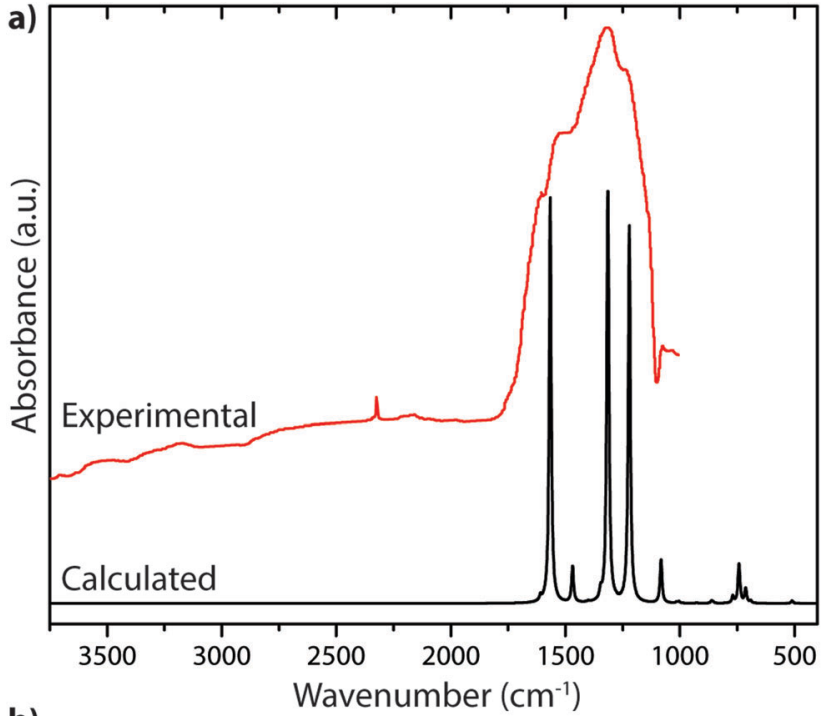

b)

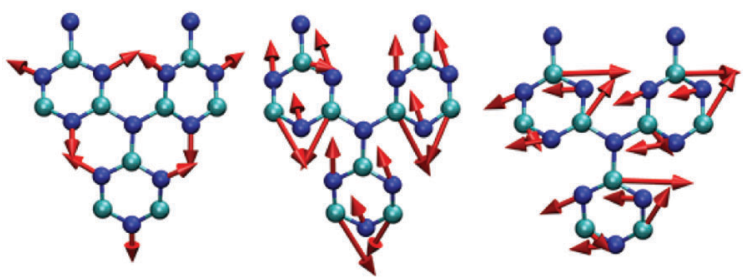

Fig. 19 IR spectra of $\mathrm{C}_{3} \mathrm{~N}_{4}$ : (a) IR spectrum for triazine based $\mathrm{C}_{3} \mathrm{~N}_{4}$ from Kouvetakis et al. (Reprinted (adapted) with permission from ref. 24. Copyright (1994) American Chemical Society). This includes a DFT calculated spectrum based on their proposed structure. (b) Selected normal mode displacement patterns from DFT calculations for one layer of triazine-based $\mathrm{g}-\mathrm{C}_{3} \mathrm{~N}_{4}$ showing the symmetric ring breathing mode that is expected to give rise to strong Raman activity near $1000 \mathrm{~cm}^{-1}$ (left), along with two in-plane bending vibrations expected to occur near $1550-1600 \mathrm{~cm}^{-1}$ (right).

that are most likely due to contributions from PTI-LiCl that formed a main product of the synthesis reaction in molten salt media. ${ }^{23}$

The IR spectra of polymeric $\mathrm{C}_{x} \mathrm{~N}_{y} \mathrm{H}_{z}$ materials formed by thermolysis reactions from precursors typically exhibit a large number of relatively sharp peaks extending throughout the $700-1700 \mathrm{~cm}^{-1}$ region. These can be assigned by analogy with organic molecular compounds as due to $\mathrm{C}-\mathrm{N}$ stretching and NCN/CNC bending vibrations, along with $\delta\left(\mathrm{NH}_{2}\right)$ deformation modes that are likely to be mainly concentrated in the higher frequency range, between $1550-1700 \mathrm{~cm}^{-195,96}$ (Fig. 17). The nature of these vibrations has been studied using both ab initio and empirical force field calculations, as well as by reference to compounds such as $s$-triazine $\left(\mathrm{C}_{3} \mathrm{~N}_{3} \mathrm{H}_{3}\right)$, melamine $\left(\mathrm{C}_{3} \mathrm{~N}_{3}\left(\mathrm{NH}_{2}\right)_{3}\right)$ and melem $\left(\mathrm{C}_{6} \mathrm{~N}_{7}\left(\mathrm{NH}_{2}\right)_{3}\right) .{ }^{58,95,97,98}$

The simplest molecular compound containing the $\mathrm{C}_{3} \mathrm{~N}_{3}$ ring is $s$-triazine $\left(\mathrm{C}_{3} \mathrm{~N}_{3} \mathrm{H}_{3}\right)$, that was first studied in detail by Larkin et al. ${ }^{97}$ Because $\mathrm{H}$ is linked to $\mathrm{C}$ rather than $\mathrm{N}$ atoms, it is only of limited use in understanding the vibrations of solid state and polymeric gCN structures. However, the terminology applied to its vibrational analysis is typically used to describe the vibrational mode assignments for the condensed carbon nitride phases. ${ }^{21,95,99}$ Larkin et al. based their assignments on those 
a)

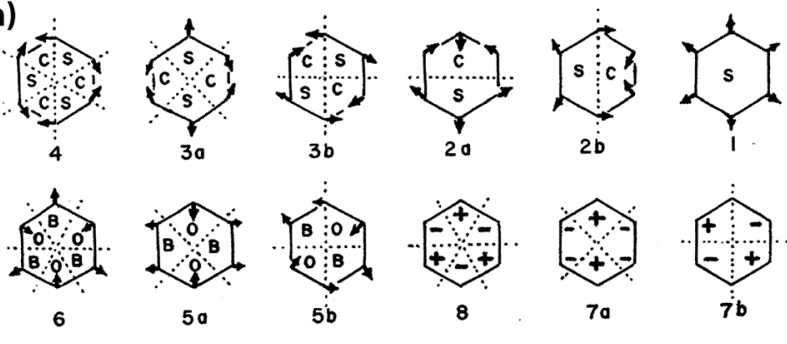

$-$
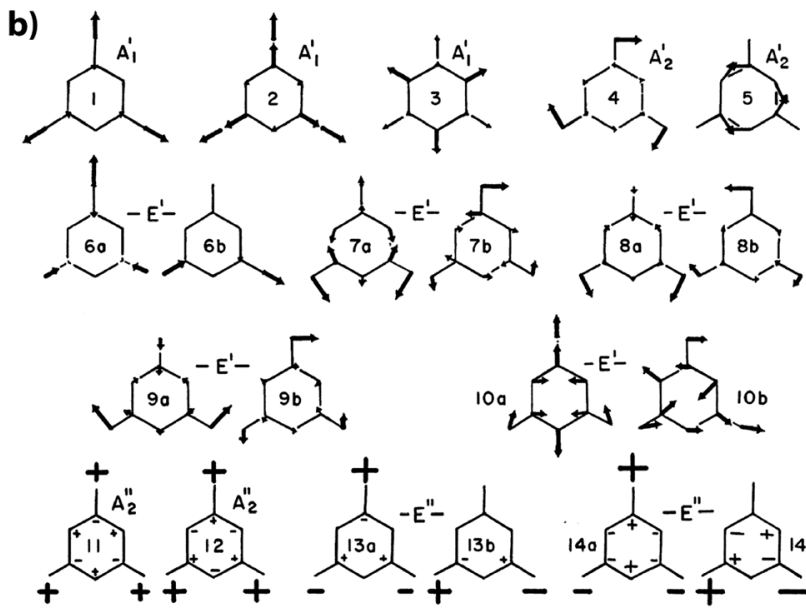

100
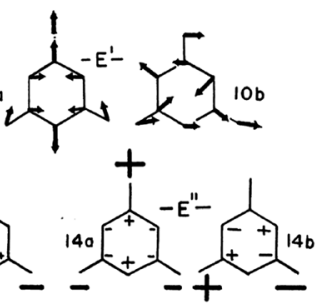

Fig. 20 (a) Normal mode description for a 6-membered ring structure from Larkin et al. indicating the characteristic atomic displacement patterns and numbering scheme (b) normal mode patterns for $\mathrm{s}$-triazine from Larkin et al. Reprinted from ref. 97 Copyright (1999), with permission from Elsevier.

for benzene, in terms of the normal modes for a planar six-membered ring. ${ }^{97}$ The ring was split into "quadrants", "sextants", hemicircles and whole-ring vibrations (Fig. 20a). ${ }^{97,100}$ That general description was then extended to describe the 21 normal vibrational modes of $s$-triazine (Fig. 20b). Larkin et al. noted that "sextant" ring CN stretching along with NCN bending contributions should occur between $950-1000 \mathrm{~cm}^{-1}$, with out-of-plane bending vibrations appearing near $750 \mathrm{~cm}^{-1}$. Of particular interest are the IR peaks at 748 and $675 \mathrm{~cm}^{-1}$ that were assigned to deformation vibrations of the $\mathrm{C}_{3} \mathrm{~N}_{3}$ ring. Characteristic sharp IR and Raman peaks that appear throughout these regions for both triazine- and heptazine-based molecules and gCN structures might be assigned to similar motions. Wang et al. used a related scheme to assign analogous peaks in the IR and Raman spectra of melamine $\left(\mathrm{C}_{3} \mathrm{~N}_{3}\left(\mathrm{NH}_{2}\right)_{3}\right)$, although significant contributions from $-\mathrm{NH}_{2}$ torsional components were also suggested to be associated with the vibrational modes throughout this region. ${ }^{101}$ The results of detailed IR and Raman studies of melamine are summarized by Mircescu et al. ${ }^{102}$

In their study of crystalline melem $\left(\mathrm{C}_{6} \mathrm{~N}_{7}\left(\mathrm{NH}_{2}\right)_{3}\right)$ containing the cyameluric (heptazine) core, Jürgens et al. correlated distinct peaks at 1606, 1496, 1304 and $802 \mathrm{~cm}^{-1}$ (Fig. 17) with similar features in the spectrum of chlorinated $\mathrm{C}_{6} \mathrm{~N}_{7} \mathrm{Cl}_{3}$ (at 1610, 1505, 1310 and $825 \mathrm{~cm}^{-1}$ ), indicating that they correspond to characteristic modes of the heptazine ring structure, and not to $\mathrm{N}-\mathrm{H}$ bending vibrations. ${ }^{58}$ Kroke et al. likewise suggested that the presence of IR peaks at 1608, 1529, 1359 and $818 \mathrm{~cm}^{-1}$ were characteristic of heptazine-based structures, based on studies of related molecular compounds. ${ }^{103}$

Lotsch et al. used IR spectroscopy to study the formation of melem from melamine by thermal condensation reactions. ${ }^{104}$ Following treatment at $500 \mathrm{~K}$ they observed a strong absorption band at $1610 \mathrm{~cm}^{-1}$ associated with the appearance of melem. This process also resulted in splitting of the $1475 \mathrm{~cm}^{-1}$ band of melamine into a doublet, along with appearance of a weaker IR peak at $1107 \mathrm{~cm}^{-1}$. In another study, Lotsch et al. noted that nanocrystalline melon that is built from ribbons of linked heptazine units contains prominent IR features at 1206, 1235 and $1316 \mathrm{~cm}^{-1} .^{21}$ These peaks were correlated with characteristic modes associated with $\mathrm{C}-\mathrm{NH}-\mathrm{C}$ units, as found in melam $\left[\mathrm{C}_{3} \mathrm{~N}_{3}\left(\mathrm{NH}_{2}\right)_{2}\right]_{2} \mathrm{NH}$ (Fig. 17). ${ }^{26}$ During formation of polymeric $\mathrm{C}_{x} \mathrm{~N}_{y} \mathrm{H}_{z}$ samples from melamine/DCDA mixtures at temperatures between 550-650 ${ }^{\circ} \mathrm{C},{ }^{77}$ we observed characteristic features occurring at $1626,1550,1396 \mathrm{~cm}^{-1}$, along with a sharp peak at $808 \mathrm{~cm}^{-1}$, that likewise indicate the presence of heptazinebased structures (Fig. 17).

A sharp IR peak occurring near $800 \mathrm{~cm}^{-1}$ was initially assigned to a "sextant" out-of-plane bend according to the description of the $\mathrm{C}_{3} \mathrm{~N}_{3}$ ring vibrations for molecular $s$-triazine by Larkin et al. ${ }^{97}$ However, a similar peak is observed for molecular compounds and polymeric gCN materials that are now known to be based on heptazine motifs. ${ }^{21,50,58,83,97,105-107}$ Wang et al. assigned sharp IR peaks at 748 and $675 \mathrm{~cm}^{-1}$ to outof-plane and in-plane bending vibrations of the $\mathrm{C}_{3} \mathrm{~N}_{3}$ ring in the IR and Raman spectra of melamine $\left(\mathrm{C}_{3} \mathrm{~N}_{3}\left(\mathrm{NH}_{2}\right)_{3}\right)$, while peaks at $810 \mathrm{~cm}^{-1}$ and $798 \mathrm{~cm}^{-1}$ occur for melam and melem that both contain the $\mathrm{C}_{6} \mathrm{~N}_{7}$ heptazine species (Fig. 17). ${ }^{95}$ During thermal condensation of melamine to form melem, Lotsch et al. noted that the sharp peak near $800 \mathrm{~cm}^{-1}$ remained present throughout the polymerization process. ${ }^{104}$ Sharp IR peaks also appear in the same region for PTI. LiCl and PTI-LiBr compounds, that are known to be built only from triazine ring units (Fig. 18). Additionally, Antonietti et al. proposed that an IR peak at $1350 \mathrm{~cm}^{-1}$ in spectra of PTI compounds synthesized in $\mathrm{ZnCl}_{2}, \mathrm{LiCl} / \mathrm{ZnCl}_{2}$ and $\mathrm{KCl} / \mathrm{ZnCl}_{2}$ molten salt media indicated that they were built from triazine rather than heptazine groups. ${ }^{108}$ Bian et al. ${ }^{109}$ deposited yellow-brown gCN films derived by condensation from melamine heated to $500{ }^{\circ} \mathrm{C}$ in air on fluorinated tin oxide glass. The resulting films showed a weak, broad X-ray feature at $27.8^{\circ}$ $2 \Theta\left(\mathrm{Cu} \mathrm{K}_{\alpha}\right)$ but the data could not reveal any information on the $12-14^{\circ} 2 \Theta$ region that might indicate formation of heptazine- $v s$. triazine based structures. ${ }^{20,52}$ They then carried out ab initio (DFT) calculations based on polyheptazine units to help interpret the IR spectra of the films, noting that a peak observed at $823 \mathrm{~cm}^{-1}$ could correspond to the collective "wagging" mode of the model oligomeric structure calculated at $818 \mathrm{~cm}^{-1}$, and that a second feature observed at $605 \mathrm{~cm}^{-1}$ might be due to $\mathrm{N}-\mathrm{H}$ deformation vibrations. ${ }^{109}$

In Fig. 21 we compare the IR spectra of a typical polymeric $\mathrm{C}_{x} \mathrm{~N}_{y} \mathrm{H}_{z}$ material prepared by thermolysis of a melamine/DCDA mixture that has a structure related to Liebig's melon, based on partly condensed polyheptazine units, and crystalline layered PTI.LiCl formed by linked triazine groups. We have highlighted 


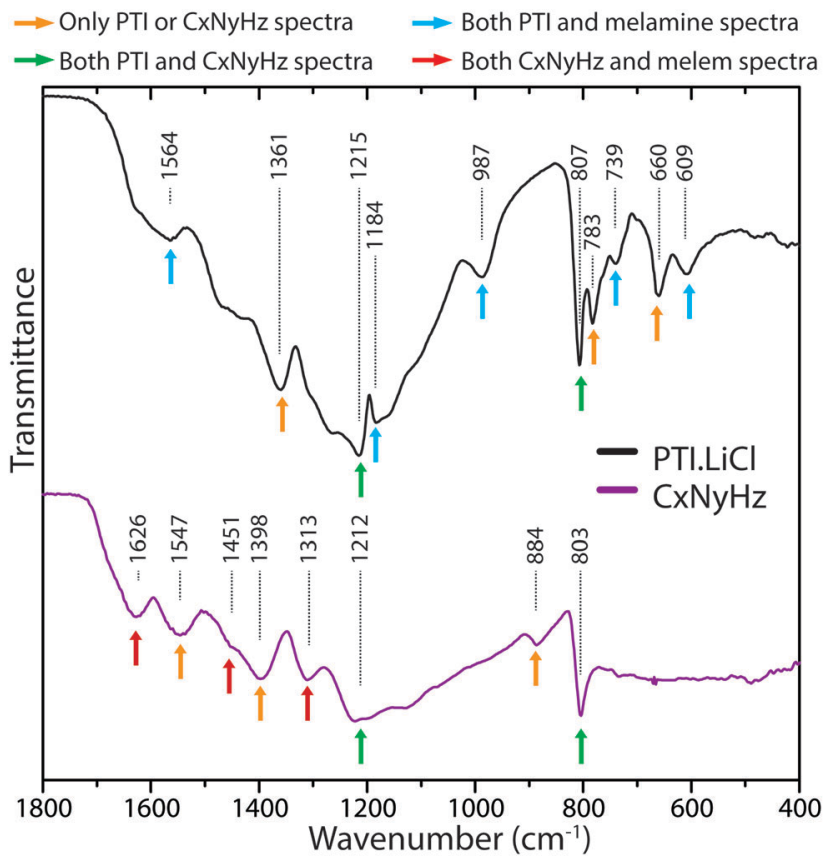

Fig. 21 Comparison of IR spectra for polymeric/graphitic $\mathrm{C}_{x} \mathrm{~N}_{y} \mathrm{H}_{z}$ vs. $\mathrm{PTI} \cdot \mathrm{LiCl}$, indicating characteristic peaks found in each type of structure.

specific features that are found in each or both solid state materials, or in the molecular compounds melamine and melem that provide models for the $s$-triazine $v s$. heptazine core units. Obtaining definitive evidence for the presence or absence of particular ring motifs is not obvious at our present state of understanding, however there appear to be sufficient systematic differences between the two types of structure that further systematic calculations using ab initio theoretical methods for hierarchies of structural models could enable use of FTIR spectroscopy as a powerful tool for distinguishing different states of gCN polymerization.

Raman spectroscopy constitutes a complementary technique for studying the vibrational properties of molecules and solids. However, fewer Raman data have been reported for polymeric or graphitic carbon nitride materials, mainly because of interference from strong fluorescence background signals when the spectra are excited using visible light lasers that are typically available. However, the Raman spectra provide additional data especially in the low wavenumber range that is not readily accessible to conventional laboratory IR techniques, and the complementary vibrational modes observed due to symmetry considerations can help complete the structural elucidation process. However, for more condensed gCN materials, the Raman data become dominated by solid state excitation and resonance effects, including electron-phonon coupling. ${ }^{64}$

Jürgens et $a l .{ }^{58}$ reported Raman data for the molecular crystal melem using near-IR (1064 $\mathrm{nm})$ laser irradiation and Fourier transform (FT) acquisition techniques. Quirico et al. also recorded Raman spectra for polymeric $\mathrm{C}_{x} \mathrm{~N}_{y} \mathrm{H}_{z}$ compounds prepared by gas phase reactions as models for the atmospheric "tholins" of Titan, as well as melamine, $s$-triazine and PTI. $\mathrm{HCl}$,

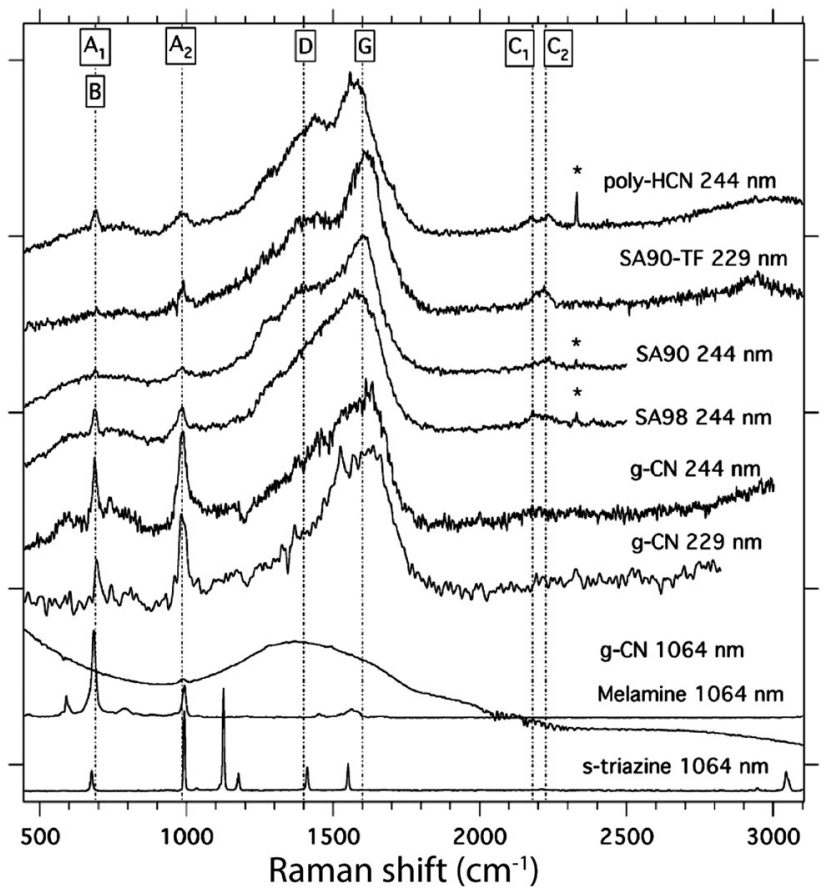

Fig. 22 Raman spectra of various polymeric to molecular $\mathrm{C}_{x} \mathrm{~N}_{y} \mathrm{H}_{z}$ structures. Reprinted from ref. 110 Copyright (2008), with permission from Elsevier.

using UV (244, $229 \mathrm{~nm})$ as well as near-IR (1064 nm) excitation (Fig. 22). ${ }^{110}$ The Raman data for the molecular compounds exhibited series of sharp peaks, but the spectra for the highly condensed materials more closely resembled the broad features found in the $1350-1700 \mathrm{~cm}^{-1}$ region and assigned to the " $\mathrm{G}$ " and " $\mathrm{D}$ " bands of disordered graphite, that are best interpreted using a solid state approach to the phonon dynamics and excitation profiles.

Ferrari and colleagues have summarized the use of Raman spectroscopy to study the phonon physics and optoelectronic coupling in a wide range of carbon-based materials included N-doped graphite and graphene. ${ }^{111-113}$ Single crystalline graphite exhibits a strong sharp Raman peak at $1578 \mathrm{~cm}^{-1}$ due to in-plane $\mathrm{C}-\mathrm{C}$ stretching vibrations of the $\mathrm{sp}^{2}$-bonded structure at the Brillouin zone centre ( $\Gamma$ point), generally termed the "G band", along with broader second-order (2D) features maximized near $2700 \mathrm{~cm}^{-1} \cdot{ }^{112-114}$ Disordered graphites exhibit various states of layer stacking disorder and buckling depending on the mode of preparation, that cause broadening and a shift to higher wavenumber in the $\mathrm{G}$ band, along with appearance of a second " $D$ band" feature near $1350 \mathrm{~cm}^{-1}$. ${ }^{112-115}$ At the same time, the $2 \mathrm{D}$ feature typically moves upwards to wavenumber values near $3000 \mathrm{~cm}^{-1}$. The analysis has been extended to lower-dimensional materials including graphene and carbon nanotubes. ${ }^{112,116,117}$ Due to electron-phonon coupling, the features change in appearance and relative position as a function of incident laser wavelength and resonance Raman effects. ${ }^{112}$ Similar signatures have been recorded for $\mathrm{N}$-doped $\mathrm{CN}_{x}$ materials, where it has been noted that that the apparent correspondence between peaks observed at similar 
wavenumber values in Raman and IR data can be misleading. ${ }^{118}$ Some interpretations of the detailed molecular structure have also been proposed. The UV-Raman spectra for PTI·HCl as well as other gCN materials exhibited sharp Raman peaks at 980 and $690 \mathrm{~cm}^{-1}$ that were assigned to symmetric breathing motions associated with the triazine rings, by comparison with the peaks present in the $1064 \mathrm{~nm}$ Raman spectra of $s$-triazine and melamine. ${ }^{110} \mathrm{How}$ ever, the Raman spectrum for PTI.HCl obtained using the same near-IR excitation showed only a broad band extending between 1000-2000 $\mathrm{cm}^{-1}$. That result was interpreted in terms of loss of phonon coherence and spectral broadening for longer excitation wavelengths that probed more extended vibrational states, compared with more localized vibrational modes observed using UV excitation. ${ }^{64}$ Although Raman scattering is commonly used to complement IR spectroscopy in structural analysis studies of molecular compounds and solid state materials, the fact that electronic transitions associated with both localized and extended states occur throughout the visible range for $\mathrm{gCN}$ compounds and enter into resonance with exciting laser wavelengths means that interpretation of the data is more subtle rather than simply giving information on the molecular structure. As we begin to better understand the optoelectronic properties of gCN materials, the Raman data will help us develop better control and optimization of functional properties related to light harvesting, luminescence and photocatalysis, as well as optically assisted routes to synthesis and functionalization.

\subsection{Solid state NMR studies}

High-field solid-state NMR, involving magic angle spinning (MAS) and multiple pulse excitation-acquisition techniques, represents a powerful family of methods used to obtain detailed structure information on molecular and solid state compounds. Because the primary elements contained within the various carbon nitride materials all represent NMR active nuclei $\left({ }^{13} \mathrm{C},{ }^{14} \mathrm{~N},{ }^{15} \mathrm{~N},{ }^{1} \mathrm{H},{ }^{7} \mathrm{Li}\right.$ etc. $),{ }^{21,27,58,119}$ it could be expected that this approach might be readily applied on a routine basis to provide unambiguous information on the structural units present. However, this is only partly the case because of the characteristics of the nuclei involved and the constraints imposed by the NMR experiment. Although the spin-1/2 ${ }^{13} \mathrm{C}$ nucleus is only present at $1.1 \%$ natural abundance, ${ }^{120}$ it is readily observed by modern instruments in non-enriched samples. $^{21,26,27}$ The sensitivity can be enhanced by crosspolarization (CP) techniques as ${ }^{1} \mathrm{H}$ resonances are excited and the spin polarization is transferred to ${ }^{13} \mathrm{C}$ nuclei located close to the ${ }^{1} \mathrm{H}$ sites. ${ }^{58,119}$ These spin transfer dynamics provide useful additional information on ${ }^{1} \mathrm{H} \cdots{ }^{13} \mathrm{C}$ separations within the structure. ${ }^{14} \mathrm{~N}$ is naturally present in high abundance (99.6\%), but it is a spin-1 quadrupolar nucleus resonating at low frequency (36 MHz at 11.7 Tesla), ${ }^{120}$ and it is difficult to observe in practice. Instead, the spin $1 / 2{ }^{15} \mathrm{~N}$ nucleus $(51 \mathrm{MHz}$ at $11.7 \mathrm{~T}$ ) is usually targeted, although it is only present at $0.37 \%$ natural abundance. ${ }^{120}$ Its detection is typically enhanced by ${ }^{1} \mathrm{H}-{ }^{15} \mathrm{~N} \mathrm{CP}$ studies for non-enriched samples, but that procedure preferentially highlights those nuclei that lie close to ${ }^{1} \mathrm{H}$ centres. Several key studies have used samples isotopically enriched in
${ }^{15} \mathrm{~N}$ to carry out detailed structural studies of $\mathrm{C}_{x} \mathrm{~N}_{y} \mathrm{H}_{z}$ compounds. $^{21,26,27}$ These results have been of critical importance for establishing the local structural arrangements in key gCN materials, but this approach is unlikely to be applied generally for routine characterization of samples.

${ }^{13} \mathrm{C}$ NMR. CP-MAS ${ }^{13} \mathrm{C}$ spectra of PTI.HCl materials were reported by Zhang et al., ${ }^{25}$ with data reportedly referenced to hexamethylbenzene (HMB), although the ${ }^{13} \mathrm{C}$ chemical shifts appear to correspond better to tetramethylsilane (TMS) $\left({ }^{13} \mathrm{C}\right.$ for HMB appears at $132 \mathrm{ppm}$ relative to TMS). Two main peaks were observed to be present, in a 2:1 ratio, at 166 and 159 ppm respectively. These peaks were assigned to " $\alpha$-type" $\mathrm{C}$ atoms surrounding the $\mathrm{C}_{12} \mathrm{~N}_{12}$ ring void, bonded to the in-ring nitrogen atom and unprotonated, and " $\beta$ " $\mathrm{C}$ atoms bonded to the protonated in-ring nitrogen atoms. The $159 \mathrm{ppm}$ peak was observed to be broader and it had an unresolved shoulder at $156 \mathrm{ppm}$, indicating small differences in the local ${ }^{13} \mathrm{C}$ environments. The ${ }^{13} \mathrm{C}$ NMR spectrum of TGCN exhibits a single broad line, peaking at approximately $160 \mathrm{ppm}$, but extending throughout the $175-145$ ppm range. ${ }^{23}$

${ }^{13} \mathrm{C}$ NMR studies of melamine and melem have indicated that resonances at 164-169 ppm should be assigned to $\mathrm{C}$ atoms bonded to the external $-\mathrm{NH}_{2}$ groups, whereas peaks at $155-156 \mathrm{ppm}$ are due to the $\mathrm{sp}^{2}$ species linked trigonally to three $\mathrm{N}$ atoms within the triazine or heptazine rings and not directly connected to any $\mathrm{N}-\mathrm{H}$ functional groups. ${ }^{58}$ These assignments appear to contradict the conclusions of Zhang et al. noted above, and this question has not yet been resolved in the literature. ${ }^{25} \mathrm{We}$ also note that other, presumably triazinebased, carbon nitride materials that reportedly contain $\mathrm{N}-\mathrm{H}$ species, exhibit both a main ${ }^{13} \mathrm{C}$ peak at $169 \mathrm{ppm}$ with shoulders at 165 and $156 \mathrm{ppm}$. Sehnert et al. carried out ab initio calculations to predict and analyze the ${ }^{13} \mathrm{C}$ and ${ }^{15} \mathrm{~N}$ chemical shift positions for different $\mathrm{C}$ and $\mathrm{N}$ sites in various $\mathrm{C}, \mathrm{N}$-containing molecules and molecular fragments. ${ }^{121}$ Melamine spectra calculated for "planar" vs. "non-planar" geometries showed ${ }^{13} \mathrm{C} \delta_{\text {iso }}$ resonances occurring between 170-175 ppm. For melem a second resonance emerged at a lower $\delta_{\text {iso }}$ chemical shift, between 160-170 ppm (calculated). These were identified with "outer" $\left(\mathrm{C}_{\mathrm{o}}\right)$ and "inner" $\left(\mathrm{C}_{\mathrm{i}}\right)$ carbon atoms contained within the heptazine unit, respectively.

Theoretically computed NMR shifts typically exhibit systematic differences from experimental values that can be accounted for by establishing a scaling protocol by comparison with data for known molecules. In our studies at UCL, we investigated this using CASTEP (version 5.5), ${ }^{122}$ in which fully converged geometry optimizations were first carried out using PBE exchange-correlation functionals and ultrasoft pseudopotentials. Values for the NMR shielding tensor elements were obtained using the GIPAW method. ${ }^{123,124}$ Calculations of the ${ }^{13} \mathrm{C}$ and ${ }^{15} \mathrm{~N}$ standards TMS and nitromethane $\left(\mathrm{CH}_{3} \mathrm{NO}_{2}\right)$ gave isotropic shielding parameters $\sigma_{\text {iso }}\left({ }^{13} \mathrm{C}\right)=178.2 \mathrm{ppm}$ and $\sigma_{\text {iso }}\left({ }^{15} \mathrm{~N}\right)=-165.5 \mathrm{ppm}$, which were used to establish ${ }^{13} \mathrm{C}$ and ${ }^{15} \mathrm{~N}$ chemical shift parameters $\left(\delta_{\text {iso }}\right)$ for various $\mathrm{C}, \mathrm{N}$-containing molecules and fragments for comparison with experiment. Comparing experimental $v s$. calculated ${ }^{13} \mathrm{C} \sigma_{\text {iso }}$ values for molecules ranging from 
hydrocarbons to melamine and triazine provided linear relationships leading to the scaling factor:

$$
\delta_{\text {iso }}\left({ }^{13} \mathrm{C} \text {, scaled }\right)=0.9295 \delta_{\text {iso }}(\text { calc. })-0.8771
$$

A similar approach applied to ${ }^{15} \mathrm{~N}$ chemical shifts provided the scaling equation: ${ }^{123}$

$$
\delta_{\text {iso }}\left({ }^{15} \mathrm{~N}, \text { scaled }\right)=0.9114 \delta_{\text {iso }}(\text { calc. })-0.16613
$$

If this scaling is applied to the DFT calculation results of Sehnert et al. ${ }^{121}$ this leads to an estimation of ${ }^{13} \mathrm{C} \delta_{\text {iso }}$ values of $\sim 150 \mathrm{ppm}$ for the $\mathrm{C}_{\mathrm{i}}$ atoms and $\sim 162 \mathrm{ppm}$ for the $\mathrm{C}_{\mathrm{o}}$ atoms of heptazine-derived $\mathrm{g}-\mathrm{C}_{3} \mathrm{~N}_{4}$. The experimental ${ }^{13} \mathrm{C}$ NMR peak for the triazine-based PTI.HCl compound reported by Zhang et $a .^{25}$ had $\delta_{\text {iso }}=166 \mathrm{ppm}$ and was assigned to " $\alpha$-type" $\mathrm{C}$ atoms that were not associated with $\mathrm{N}-\mathrm{H}$ protonation, whereas a second peak at 159-156 ppm was suggested to represent $\mathrm{C}$ atoms close to the bridging $-\mathrm{NH}-$ or $-\mathrm{NH}_{2}{ }^{+}$- groups. It therefore appears that assignment of the ${ }^{13} \mathrm{C}$ NMR signals of the different gCN materials requires further systematic investigation, combining experimental determinations with theoretical predictions.

${ }^{15} \mathbf{N}$ NMR. Obtaining and interpreting NMR data on the $\mathrm{N}$ environments of carbon nitride materials is more challenging than for ${ }^{13} \mathrm{C}$. As noted above, nitrogen has two NMR active isotopes: ${ }^{14} \mathrm{~N}$ has high abundance but moderate sensitivity and it exhibits large broadening due to quadrupolar effects, that can result in non-observance of signals for $\mathrm{N}$ sites in low symmetry environments. ${ }^{15} \mathrm{~N}$ typically shows sharp lines but this nucleus is present in low abundance and has low NMR sensitivity. ${ }^{15} \mathrm{~N}$ NMR experiments are typically carried out using spin transfer from neighbouring protons to enhance the signal in $\mathrm{CP}$ experiments with variable pulse sequences and ${ }^{1} \mathrm{H}-{ }^{15} \mathrm{~N}$ spin transfer times. ${ }^{21,26,27}$ These data give important information on the relative arrangement of ${ }^{1} \mathrm{H}$ and ${ }^{15} \mathrm{~N}$ species within the sample, however, signals from $\mathrm{N}$ atoms that are remote from ${ }^{1} \mathrm{H}$ nuclei can be diminished or even overlooked, especially in analyses of materials at natural ${ }^{15} \mathrm{~N}$ isotopic abundance.

During their extensive structural investigations of melon, melem and other gCN materials, Lotsch, ${ }^{21}$ Senker $^{27,58}$ and co-workers prepared ${ }^{15} \mathrm{~N}$-enriched (by $\sim 25 \%$ ) compounds to carry out detailed series of multiple pulse, ${ }^{1} \mathrm{H}-{ }^{15} \mathrm{~N} \mathrm{CP}$ and magnetization transfer experiments to characterize the local structural environments around $\mathrm{N}$ atoms. The results led to significant new understanding of the polymeric $\mathrm{C}_{x} \mathrm{~N}_{y} \mathrm{H}_{z}$ structures, that were shown to be based on heptazine motifs, leading to ribbon-like and potentially layered structural units. ${ }^{21,58}$ One main result was identification of an isolated peak at $-225 \mathrm{ppm}$ (relative to nitromethane) with the central $\left(\mathrm{N}_{\mathrm{c}}\right)$ nitrogen atom of the heptazine core unit. A group of signals extending between -175 to $-180 \mathrm{ppm}$ were identified as due to " $\mathrm{N}_{\text {tert }}$ " species bonded to $-\mathrm{C}(\mathrm{NH})$ and $-\mathrm{C}\left(\mathrm{NH}_{2}\right)$ units, whereas others at larger

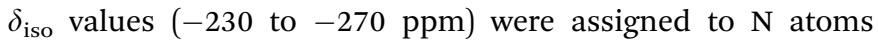
directly bonded to hydrogen ( $\mathrm{NH}, \mathrm{NH}_{2}$ species). Those assignments generally agreed well with the theoretical predictions made by Sehnert et al. ${ }^{121}$ The $\mathrm{N}-\mathrm{H}$ species typically give rise to the largest (most negative) chemical shifts, and so these could be used as diagnostic of the presence of significant $\mathrm{N}-\mathrm{H}$ content within the samples. In their study of TGCN, Algara-Siller et al. noted two asymmetric peaks occurring at -210 and $-160 \mathrm{ppm}$, referenced relative to glycine (that itself appears at $33 \mathrm{ppm}$ relative to $\mathrm{NH}_{3}$ liquid, and at $381 \mathrm{ppm}$ relative to nitromethane). ${ }^{23,125}$ The peaks were assigned respectively to $\mathrm{N}$ atoms contained within the $\mathrm{C}_{3} \mathrm{~N}_{3}$ rings (199 ppm) and the bridging $\mathrm{N}$ atoms between triazine units (128 ppm). These authors did not comment on the fact that their ${ }^{1} \mathrm{H}^{15}{ }^{15} \mathrm{CP}$ MAS NMR spectra were obtained for a nominally $\mathrm{H}$-free $\mathrm{g}-\mathrm{C}_{3} \mathrm{~N}_{4}$ material.

NMR of other elements. Several PTI-based materials contain $\mathrm{Li}$ as an essential component of their structure. ${ }^{26,27,69}{ }^{7} \mathrm{Li}$ $(I=3 / 2 ; 92.6 \% \text { natural abundance; } 194 \mathrm{MHz} \text { at } 11.7 \mathrm{~T})^{120}$ is an excellent probe of local structure arrangements, as is the ${ }^{6} \mathrm{Li}$ nucleus $(I=1 ; 7.4 \% \text { abundance; } 73.6 \mathrm{MHz} \text { at } 11.7 \mathrm{~T})^{120}$ that exhibits almost no quadrupolar broadening. Recently, Senker et al. combined multiple-pulse, multi-dimensional NMR with total powder diffraction analysis to work out the local environments surrounding ${ }^{7} \mathrm{Li}$ in PTI. $(\mathrm{Li}, \mathrm{H}) \mathrm{Cl}$ crystalline compounds, leading to an improved structural model for the layered carbon nitride. $^{27}$

\section{Carbon nitrides for energy provision and sustainability applications}

Carbon nitride materials are currently being proposed, examined and developed for technological applications, especially in areas of catalysis, energy provision and sustainability. ${ }^{5}$ However, optimizing the materials and their in-device performance relies critically on understanding and controlling the properties through structural studies on an atomistic scale. Here we briefly present the projected use of carbon nitrides for several key applications, highlighting the structure-performance characteristics that have been determined and that must be refined in future investigations.

\subsection{Carbon nitrides as semiconducting materials and photocatalysts}

One of the targeted outcomes for a successful photocatalyst is its ability to efficiently capture light from the Sun within the visible range at the Earth's surface, and thus enable splitting of Earth-abundant water into its elemental constituents (i.e., perform the reaction $2 \mathrm{H}_{2} \mathrm{O} \rightarrow 2 \mathrm{H}_{2}+\mathrm{O}_{2}$ ) to provide hydrogen fuel for energy production via its exothermic recombination with oxygen to reform water. ${ }^{2,10,126}$ Intense activity began in this area with the discovery that nanocrystalline anatase-structured $\mathrm{TiO}_{2}$ could perform this function under UV illumination, ${ }^{127}$ followed by many suggestions for doped $\mathrm{TiO}_{2}$ and other alternative materials to improve the efficiency, that could be extended into the visible range.

Recent interest in carbon nitride materials has largely arisen from identification of their photocatalytic properties, that are either intrinsic or following doping with co-catalysts such as nanocrystalline $\mathrm{Pt}$ or $\mathrm{RuO}_{2}$, to enable water splitting and/or methanol reduction reactions under UV-visible light irradiation. These useful properties are enabled by their wide semiconducting 
a)

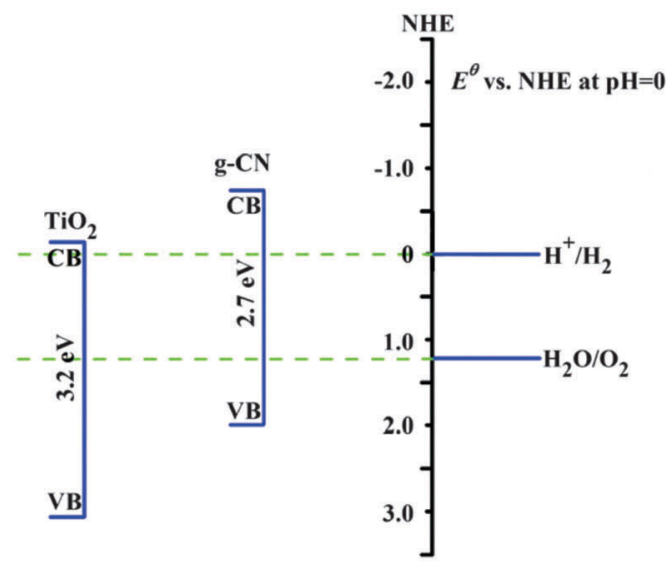

b)

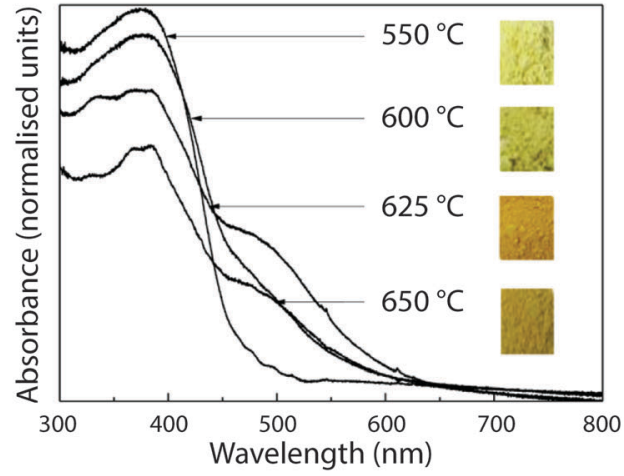

c)

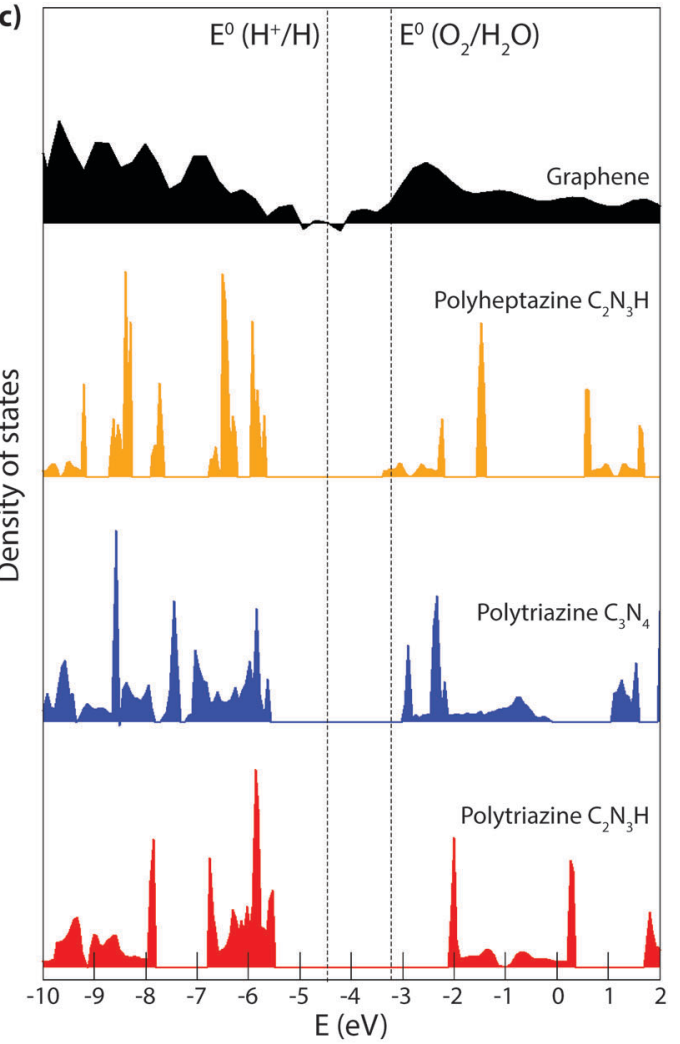

Fig. 23 Semiconducting properties of carbon nitrides. (a) Band-edge positions of ' $\mathrm{g}-\mathrm{CN}$ ' and titanium dioxide relative to the energy levels of $\mathrm{H}^{+} / \mathrm{H}_{2}$ and $\mathrm{H}_{2} / \mathrm{H}_{2} \mathrm{O}$ in water at $\mathrm{pH}=0$. Reproduced from ref. 128 with permission from the PCCP Owner Societies. (b) UV-vis diffuse reflectance spectra of gCNs prepared at different temperatures. Reprinted (adapted) with permission from ref. 77. Copyright (2013) American Chemical Society. (c) Calculated electronic density of states for conductive $C$ (graphene) and a selection of three representative layered carbon nitride structures. Adapted from ref. 6 under the terms of the Creative Commons Attribution License (CC BY).

bandgaps, that are ideal for solar energy harvesting, and the position of their HOMO and LUMO levels, that straddle the oxidation and reduction potentials of water (Fig. 23a). ${ }^{2,5,10,128}$ The first report of gCN being used for photocatalytic water splitting, that has played a significant role in reinvigorating modern interest in carbon nitrides, was published by Wang et $a .^{2}$ (Fig. 1). These researchers produced heptazine-structured polymeric $\mathrm{C}_{x} \mathrm{~N}_{y} \mathrm{H}_{z}$ compounds formed by heating cyanamide (DCDA) to temperatures between $400-600{ }^{\circ} \mathrm{C}$, although the products of the reactions were incorrectly described as "g- $\mathrm{C}_{3} \mathrm{~N}_{4}$ ". They showed that over a period of 25 hours up to $100 \mu \mathrm{mol} \mathrm{H}_{2}$ could be evolved from "unmodified $\mathrm{g}-\mathrm{C}_{3} \mathrm{~N}_{4}$ " and $260 \mu \mathrm{mol} \mathrm{H}_{2}$ for "g- $\mathrm{C}_{3} \mathrm{~N}_{4}$ decorated with $3 \mathrm{wt} \%$ Pt co-catalyst" using triethanolamine as electron donor under visible light (of wavelength $>420 \mathrm{~nm}$ ) under a $300 \mathrm{~W}$ lamp. ${ }^{2}$ The quantum efficiency of both of these catalysts was low $(<0.1 \%$ with irradiation of 420-460 $\mathrm{nm}$ ). Other researchers have found similar results. ${ }^{5,10,126}$ Despite much work in this area, most gCN compounds investigated to date do not show high intrinsic photocatalytic activity in the visible wavelength range, unless co-catalysts such as $\mathrm{Pt}$ or $\mathrm{RuO}_{2}$ are introduced, and sacrificial electron donors or acceptors (e.g. methanol) are usually present. ${ }^{126}$ Care must also be taken when interpreting the results of these photocatalytic experiments as most utilize high-power $(300 \mathrm{~W})$ illumination sources, with or without inclusion of UV wavelengths, that do not always reflect the actual solar irradiation conditions at the Earth's surface. ${ }^{129}$ Comparative reviews of photocatalytic efficiencies of various materials as well as projected future targets have appeared recently. ${ }^{126,128}$ Overall, the photocatalytic performance of polymeric to graphitic $\mathrm{C}_{x} \mathrm{~N}_{y} \mathrm{H}_{z}$ materials remains substantially lower than that achieved by other materials, although there is obvious potential for future development to be derived from systematic understanding of the structure-composition-properties relationships of the light element compounds. ${ }^{130}$

The semiconducting bandgaps of gCNs are determined by $\pi-\pi^{*}$ transitions of the heterocyclic aromatic constituents between around 2.5-2.8 eV, leading to optical absorption beginning in the violet-blue range of the visible spectrum. ${ }^{2,77}$ This causes the yellow/brown coloration typically exhibited by gCN materials, ${ }^{77}$ while also resulting in their poor electronic conductivity. ${ }^{14}$ The optical absorption color evolves from pale yellow to deep brown as the degree of polymer condensation increases with cross-linking and loss of terminal $-\mathrm{NH}_{2}$ components. As condensation occurs, the polytriazine and polyheptazine structural units become increasingly buckled and non-bonded electrons based on the $\mathrm{N}$ atoms can increasingly undergo normally nonallowed $n-\pi^{*}$ transitions, giving rise to absorption features near 
$500 \mathrm{~nm}$ and an apparent redshift in the absorption edge that lead to a brown color (Fig. 23b). ${ }^{77}$ The ability to tune the bandgap of gCN materials is of particular interest for photocatalytic applications. ${ }^{77,131}$

One significant recent development in the use of gCN materials for photocatalysis is the discovery by Lau et al. ${ }^{130}$ that defects with particular functionalities play a crucial role in the photocatalytic activity of carbon nitrides. By studying the structure-hydrogen evolution activity relationships of a range of molecular or polymeric carbon nitride analogues (methanol electron donor, Pt co-catalyst, $300 \mathrm{~W}$ xenon lamp, $2000 \mathrm{~nm}>$ $\lambda>200 \mathrm{~nm}$ ), including some of those described here (melem, cyameluric acid, potassium cyamelurate and melon), they were able to determine the cyanamide moiety to be photocatalytically important. By applying this knowledge to the design of a melon-based photocatalyst, with increased cyanamide functionalities, they were able to demonstrate greatly improved hydrogen evolution rate and apparent quantum efficiency (at $400 \mathrm{~nm}$ ) over pure, untreated melon. ${ }^{130}$ This approach is an example of how improved understanding of the carbon nitride compositional-structural relationships can directly impact on development of their functional applications.

\subsection{Carbon nitrides as energy storage materials}

Lithium ion battery (LIB) anodes are typically formed from graphitic carbon that can theoretically result in the stoichiometric intercalation compound $\mathrm{LiC}_{6}$, giving a maximum capacity of $372 \mathrm{~mA} \mathrm{~h} \mathrm{~g}{ }^{-1} \cdot{ }^{132}$ DFT calculations have predicted that idealized models of layered carbon nitride structures can have a much higher theoretical Li capacity, extending up to $524 \mathrm{~mA} \mathrm{~h} \mathrm{~g}{ }^{-1}\left(\mathrm{Li}_{2} \mathrm{C}_{3} \mathrm{~N}_{4}\right),{ }^{133}$ due to additional storage sites derived from $\mathrm{Li}^{+}$ions residing in intra-layer voids as well as intercalated between the layers. Veith et al. used solid-state lithiation techniques to achieve carbon nitride materials containing 10.6 at\% Li (reported from XPS analysis) for a "disordered $\mathrm{C}_{3} \mathrm{~N}_{4}$ ", and $\mathbf{1 2 . 1}$ at\% for a "crystalline $\mathrm{C}_{3} \mathrm{~N}_{4}$ ", material. Although not precisely defined in the report, the latter was most likely a triazine-based compound with a structure related to PTI-LiCl. ${ }^{15}$ Upon incorporation, the Li selectively reacted with the quaternary $\mathrm{N}-\mathrm{C}_{3}$ environments, which reduced the crystallinity of the carbon nitride. It has also been reported that $\sim 3$ wt $\%$ Li can be taken up by amorphous gCN, using liquid ammonia based lithiation. ${ }^{134}$ Such results indicate that $\mathrm{C}_{x} \mathrm{~N}_{y} \mathrm{H}_{z}$ materials could potentially be developed as useful materials for high-capacity anodes for LIB or sodium ion batteries (NIBs). ${ }^{13-15,93}$ A report by Yang et al. examined a carbon nitride that was suggested to be a layered triazine-based material, but was more likely an amorphous, heptazine-based structure. ${ }^{93}$ Their first cycle capacity was adequate $\left(>130 \mathrm{~mA} \mathrm{~h} \mathrm{~g}^{-1}\right)$, but there were significant irreversible capacity losses on subsequent cycling (the second cycle capacity was only $\sim 8 \%$ of that of the first, and after $\sim 20$ cycles it was approximately zero). This result was later confirmed by Veith et al. who observed that the electrochemical capacity in their anode primarily resulted from the carbon black component they added to boost the electronic conductivity. ${ }^{15}$ Miller et al. carried out a systematic investigation of this problem using composite gCN/conductive graphite anodes and found a clear correlation between the $\mathrm{Li}^{+}$capacity of the composite and the electrode resistivity. ${ }^{14}$ It is now clear that the electrical resistance of the $\mathrm{gCN}$ material is a major factor limiting $\mathrm{Li}^{+}$uptake, and the incorporation of electronically conducting additives has so far been insufficient to overcome this barrier.

Most recently, Hankel et al. used a combination of DFT calculations and experiment to further investigate $\mathrm{Li}^{+}$and $\mathrm{Na}^{+}$ uptake into gCN materials. ${ }^{13}$ Results of this work supported the previous theoretical predictions that the carbon nitrides should have a large uptake capacity for $\mathrm{Li}^{+}$, but they showed that this process is irreversible, due to $\mathrm{Li}^{+}$favouring the pyridinic nitrogen sites, that then also weaken the $\mathrm{C}_{3} \mathrm{~N}$ bonds. In their work, Hankel et al. also examined the possibility of using gCN as an NIB anode. ${ }^{13}$ The $\mathrm{Na}^{+}$storage performance was found to be just as poor as that recorded for LIB anodes, with a reversible capacity lower than $25 \mathrm{~mA} \mathrm{~h} \mathrm{~g}{ }^{-1}$, much of which could be attributed to the conductive carbon additive. The overall conclusion is that, although the introduction of large amounts of nitrogen into graphitic anode materials to create additional potential storage sites within and between the layers has been predicted to boost the theoretical capacity, ${ }^{135}$ the large semiconducting band gap and bonding structure gCN materials means they are likely unsuitable for use in their current form. It has been proposed that by reducing the content of $\mathrm{N}-\mathrm{C}_{3}$ sites, while maintaining the pyridinic ones, carbon nitrides might yet be designed that would lead to viable LIB/NIB anode materials, ${ }^{13}$ and this could be a useful avenue to explore in future work.

\subsection{Carbon nitrides as catalysts and catalyst support materials}

The significant mechanical, chemical and thermal resilience of carbon nitrides, combined with their surface and intralayer chemical reactivity, has led to possibilities for developing carbon nitride materials for catalysis applications, either intrinsically or when decorated with metal/metal oxide NPs. gCN materials have been shown to act as metal-free heterogeneous catalysts, relying on the intrinsic abundance of Brønsted acid and Lewis base functionalities that provide catalytically active sites, while the nature of gCN materials and their surfaces that makes them amenable to chemical modifications including doping, protonation and molecular functionalization, can be exploited to improve performance and selectivity. ${ }^{9,10,12}$ They are also being developed as active NP support materials that survive under harsh operating conditions.

One main application of NP catalysts supported on gCN Is in the area of fuel cell devices, especially polymer electrolyte or proton exchange membrane fuel cells (PEMFC), as well as water electrolyzers. ${ }^{6}$ The success of gCN materials in these applications is generally due to their wide electronic band gaps that bracket the $\mathrm{H}^{+} / \mathrm{H}_{2}$ and $\mathrm{O}_{2} / \mathrm{H}_{2} \mathrm{O}$ potentials and make corrosion of the $\mathrm{C}-\mathrm{N}$ backbone thermodynamically unfavourable under electrochemical operation. ${ }^{6}$ Metal or metal oxide NPs deposited onto the gCN are also less prone to the effects of poisoning and agglomeration caused by etching of traditional carbonaceous 
support materials. In one study, Kim et al. ${ }^{136}$ examined Pt/Ru NPs supported on gCN to show that in a direct methanol fuel cell (DMFC) device the electrocatalyst exhibited 78-83\% higher power density than the same catalyst deposited on carbon black. ${ }^{136}$ In another investigation, Mansor et al. ${ }^{7}$ prepared Pt NPs supported on gCN and PTI materials and demonstrated enhanced electrochemical stability over that of traditional carbon black during accelerated corrosion testing. In particular, Pt NPs deposited on the highly crystalline PTI-LiCl showed excellent durability and this catalyst-support combination was found to have superior intrinsic methanol oxidation activity. ${ }^{7}$ However, as for the LIB applications described above, a main limiting factor to the use of gCNs for these catalyst support applications derives from their low electronic conductivity, that particularly affects kinetically slow processes like the oxygen reduction reaction (ORR). If the gCN materials are embedded within a conductive matrix, e.g. graphene or reduced graphene oxide (rGO), these hybrid systems are shown to perform significantly better. ${ }^{6,137}$ They might therefore lead to useful catalyst support systems that provide extended lifetime at comparable performance levels to existing material combinations. These applications are currently under development, but will require expanded understanding of the physical and chemical properties of the gCN surfaces and their interaction with catalyst NPs, as the reactions proceed under real operating conditions. ${ }^{6}$

\section{Conclusions and perspectives}

The discovery of carbon nitride materials began as modern chemical science was just beginning to emerge. Since that time a diverse family of materials has been developed with potentially useful physical and chemical properties leading to important functionality for applications ranging from catalysis, photocatalysis and photoluminescence, to energy storage and conversion. An unfortunate practice has developed within recent literature to term all such materials " $\mathrm{g}-\mathrm{C}_{3} \mathrm{~N}_{4}$ ", or graphitic carbon nitride with a precise and ideal stoichiometry, when in fact most of the materials produced are likely to have polymeric structures related to that of Liebig's melon with a limiting composition near $\mathrm{C}_{2} \mathrm{~N}_{3} \mathrm{H}$. We propose instead use of a hierarchical scheme for naming these materials and compounds. All of the materials produced with large $\mathrm{N}$ : C ratios that are likely to contain layered elements within their structures should be termed "gCN" or "GCN". To designate more specifically the more or less condensed polymeric structures formed by thermolysis or other reactions from precursors, we should implement "gCN(H)" or " $\mathrm{pCN}(\mathrm{H})$ " as a general term, to denote the large and essential $\mathrm{H}$ component within the structures, that has implications for the physical properties and functionality. Crystalline layered compounds based on polytriazine imide-linked layers with intercalated $\mathrm{M}^{n+}$ and $\mathrm{X}^{n-}$ species are PTI-MX materials, with specific properties related to their intercalation chemistry and redox behavior. Finally, the term " $\mathrm{g}-\mathrm{C}_{3} \mathrm{~N}_{4}$ " should be reserved for those layered compounds with a stoichiometry close to the ideal value. That class includes both nanocrystalline materials produced by CVD techniques and bulk triazine-based graphitic carbon nitrides (TGCN), as well as the hypothetical heptazine-based equivalent (HGCN). Adopting such a hierarchical naming scheme would help avoid confusion in the literature, when attempting to match the chemical and structural characterization of the compounds with their physical properties and anticipated functionality. It will also help in more rational design of the synthesis approaches, as new gCN materials are optimized and created for existing and emerging applications.

Most of the gCN materials that have been investigated are polymeric $\mathrm{C}_{x} \mathrm{~N}_{y} \mathrm{H}_{z}$ structures related to Liebig's melon, containing ribbon-like heptazine units linked by $-\mathrm{NH}$ - and $\mathrm{sp}^{2}$-bonded $\mathrm{N}$ atoms and terminated laterally by $-\mathrm{NH}_{2}$ groups. A smaller family of gCN materials is constituted by the layered PTI materials, that contain $\mathrm{Li}^{+}, \mathrm{Cl}^{-}, \mathrm{Br}^{-}$and other ions intercalated within or between the graphitic sheets with approximately $\mathrm{C}_{2} \mathrm{~N}_{3} \mathrm{H}$ composition, giving rise to new ion exchange and intercalation chemistries as well as modifying the optoelectronic and semiconducting properties. True $\mathrm{g}-\mathrm{C}_{3} \mathrm{~N}_{4}$ materials have only been reported in two instances, as nanocrystalline thin films produced by CVD techniques, or as bulk TGCN crystals as a by-product from PTI-LiCl or PTI·LiBr syntheses in molten salt media. ${ }^{23,24}$ These structures are shown to be derived from condensed triazine units, rather than the linked heptazine (HGCN) motifs predicted by DFT calculations to constitute the most stable polymorph of $\mathrm{g}-\mathrm{C}_{3} \mathrm{~N}_{4}$. Achieving and demonstrating the existence of such heptazine-based graphitic structures represents a major challenge for the field. Understanding the structures and physical properties of different types of gCN materials is progressing rapidly due to the application of advanced techniques for chemical and physical characterization combined with $a b$ initio theoretical methods. However, much work remains to be done in order for us to fully understand and provide the necessary tunability and control over their physical properties. All of these compounds exhibit many possibilities leading to useful functional behavior. They contain exchangeable N-H and Lewis-basic N: sites for catalysis and attachment of catalytically active NPs on their surface, while maintaining a high resistance to adverse chemical and physical conditions. They have a wide bandgap extending into the visible range resulting in photocatalytic activity. In addition, they provide enhanced storage sites for $\mathrm{Li}^{+}$or $\mathrm{Na}^{+}$for battery applications, although the poor electronic conductivity for gCN materials counteracts that possibility. All of these useful and intriguing results indicate that carbon nitride materials indeed form a class of emerging materials for advanced technological applications. However, their structures and compositional properties must be properly evaluated and reported in order to define and target the research that is needed to predict and optimize their behavior. The results reviewed here show the great potential of this unique family of materials for a wide range of modern applications. Through their continued development, including the scalable production of new technological inks and 3D porous networks, the preparation of new families of integrated catalysts containing protective $\mathrm{N}$-rich regions and selective functionalization of materials to promote specific activity (e.g. visible light absorption), it is likely 
that carbon nitrides will become increasingly important in future technologies. However, it will be critically important to the industrial uptake of these materials to also develop efficient, low-cost and truly scalable processes for their synthesis, exfoliation and deposition, especially via drop-in technologies that will enable new developments to rapidly enter the commercial marketplace.

\section{Acknowledgements}

Our work on carbon nitride materials has been supported by the EPSRC (EP/L017091/1) and the EU Graphene Flagship grant agreement No. 696656 - GrapheneCore1. Additional support to advance the science and technology of these materials was also received from the UCL Enterprise Fund and the Materials Innovation Impact Acceleration funding enabled by the UK EPSRC.

\section{References}

1 K. Schwinghammer, M. B. Mesch, V. Duppel, C. Ziegler, J. Senker and B. V. Lotsch, J. Am. Chem. Soc., 2014, 136, 1730-1733.

2 X. Wang, K. Maeda, A. Thomas, K. Takanabe, G. Xin, J. M. Carlsson, K. Domen and M. Antonietti, Nat. Mater., 2009, 8, 76-80.

3 F. Su, S. C. Mathew, G. Lipner, X. Fu, M. Antonietti, S. Blechert and X. Wang, J. Am. Chem. Soc., 2010, 132, 16299-16301.

4 E. J. McDermott, E. Wirnhier, W. Schnick, K. S. Virdi, C. Scheu, Y. Kauffmann, W. D. Kaplan, E. Z. Kurmaev and A. Moewes, J. Phys. Chem. C, 2013, 117, 8806-8812.

5 F. Kessler, Y. Zheng, D. Schwarz, C. Merschjann, W. Schnick, X. Wang and M. J. Bojdys, Nat. Rev. Mater., 2017, 2, 17030.

6 N. Mansor, T. S. Miller, I. Dedigama, A. B. Jorge, J. Jia, V. Brázdová, C. Mattevi, C. Gibbs, D. Hodgson, P. R. Shearing, C. A. Howard, F. Corà, M. Shaffer, D. J. L. Brett and P. F. McMillan, Electrochim. Acta, 2016, 222, 44-57.

7 N. Mansor, A. B. Jorge, F. Corà, C. Gibbs, R. Jervis, P. F. McMillan, X. Wang and D. J. L. Brett, J. Phys. Chem. C, 2014, 118, 6831-6838.

8 V. Di Noto, E. Negro, K. Vezzù, F. Bertasi and G. Nawn, Electrochem. Soc. Interface, 2015, 24, 59-64.

9 A. Thomas, A. Fischer, F. Goettmann, M. Antonietti, J. O. Muller, R. Schlogl and J. M. Carlsson, J. Mater. Chem., 2008, 18, 4893-4908.

10 Y. Wang, X. Wang and M. Antonietti, Angew. Chem., Int. Ed., 2012, 51, 68-89.

11 A. Schwarzer, T. Saplinova and E. Kroke, Coord. Chem. Rev., 2013, 257, 2032-2062.

12 F. Goettmann, A. Fischer, M. Antonietti and A. Thomas, Angew. Chem., Int. Ed., 2006, 45, 4467-4471.

13 M. Hankel, D. Ye, L. Wang and D. J. Searles, J. Phys. Chem. C, 2015, 119, 21921-21927.

14 T. S. Miller, A. B. Jorge, A. Sella, F. Corà, P. R. Shearing, D. J. L. Brett and P. F. McMillan, Electroanalysis, 2015, 27, 2614-2619.
15 G. M. Veith, L. Baggetto, L. A. Adamczyk, B. Guo, S. S. Brown, X. G. Sun, A. A. Albert, J. R. Humble, C. E. Barnes, M. J. Bojdys, S. Dai and N. J. Dudney, Chem. Mater., 2013, 25, 503-508.

16 F. Withers, O. Del Pozo-Zamudio, A. Mishchenko, A. P. Rooney, A. Gholinia, K. Watanabe, T. Taniguchi, S. J. Haigh, A. K. Geim, A. I. Tartakovskii and K. S. Novoselov, Nat. Mater., 2015, 14, 301-306.

17 X. Zhang, X. Xie, H. Wang, J. Zhang, B. Pan and Y. Xie, J. Am. Chem. Soc., 2013, 135, 18-21.

18 J. Oh, R. J. Yoo, S. Y. Kim, Y. J. Lee, D. W. Kim and S. Park, Chem. - Eur. J., 2015, 21, 6241-6246.

19 Wikipedia article: graphitic carbon nitride, https://en.wiki pedia.org/wiki/Graphitic_carbon_nitride, accessed March 2017.

20 T. Tyborski, C. Merschjann, S. Orthmann, F. Yang, M. C. L. Steiner and T. Schedel Niedrig, J. Phys.: Condens. Matter, 2013, 25, 395402.

21 B. V. Lotsch, M. Döblinger, J. Sehnert, L. Seyfarth, J. Senker, O. Oeckler and W. Schnick, Chem. - Eur. J., 2007, 13, 4969-4980.

22 E. Kroke and M. Schwarz, Coord. Chem. Rev., 2004, 248, 493-532.

23 G. Algara-Siller, N. Severin, S. Y. Chong, T. Björkman, R. G. Palgrave, A. Laybourn, M. Antonietti, Y. Z. Khimyak, A. V. Krasheninnikov, J. P. Rabe, U. Kaiser, A. I. Cooper, A. Thomas and M. J. Bojdys, Angew. Chem., Int. Ed., 2014, 53, 7450-7455.

24 J. Kouvetakis, M. Todd, B. Wilkens, A. Bandari and N. Cave, Chem. Mater., 1994, 6, 811-814.

25 Z. Zhang, K. Leinenweber, M. Bauer, L. A. J. Garvie, P. F. McMillan and G. H. Wolf, J. Am. Chem. Soc., 2001, 123, 7788-7796.

26 E. Wirnhier, M. Döblinger, D. Gunzelmann, J. Senker, B. V. Lotsch and W. Schnick, Chem. - Eur. J., 2011, 17, 3213-3221.

27 M. B. Mesch, K. Bärwinkel, Y. Krysiak, C. Martineau, F. Taulelle, R. B. Neder, U. Kolb and J. Senker, Chem. Eur. J., 2016, 22, 16878-16890.

28 A. Y. Liu and M. L. Cohen, Science, 1989, 245, 841.

29 H. Wang, T. Maiyalagan and X. Wang, ACS Catal., 2012, 2, 781-794.

30 Y. Deng, Y. Xie, K. Zou and X. Ji, J. Mater. Chem. A, 2016, 4, 1144-1173.

31 Y.-X. Yu, Phys. Chem. Chem. Phys., 2013, 15, 16819-16827.

32 N. Roy, K. T. Leung and D. Pradhan, J. Phys. Chem. C, 2015, 119, 19117-19125.

33 S. Pylypenko, A. Borisevich, K. L. More, A. R. Corpuz, T. Holme, A. A. Dameron, T. S. Olson, H. N. Dinh, T. Gennett and R. O'Hayre, Energy Environ. Sci., 2013, 6, 2957-2964.

34 Y. Zhou, K. Neyerlin, T. S. Olson, S. Pylypenko, J. Bult, H. N. Dinh, T. Gennett, Z. Shao and R. O'Hayre, Energy Environ. Sci., 2010, 3, 1437-1446.

35 M. M. Barsan, K. P. Prathish, X. Sun and C. M. A. Brett, Sens. Actuators, B, 2014, 203, 579-587. 
36 C. Scheele, R. Swed. Acad. Sci., Proc., 1782, 3, 264-275.

37 R. Porrett, Philos. Trans. R. Soc. London, 1814, 104, 527-556.

38 H. Irving, Sci. Prog., 1935, 30, 62-66.

39 T. L. Davis, J. Chem. Educ., 1940, 17, 268.

40 The Holy Bible: King James edition, Exodus vii, 8-12.

41 NileRed, How to make the Pharaoh's Serpent (Mercury(II) Thiocyanate), https://www.youtube.com/watch?v=PC3o2KgQ stA, accessed March, 2017.

42 E. C. Franklin, J. Am. Chem. Soc., 1922, 44, 486-509.

43 J. Liebig, Ann. Pharm., 1834, 10, 1-47.

44 J. Liebig, Justus Liebigs Ann. Chem., 1844, 50, 337-363.

45 J. Liebig, Justus Liebigs Ann. Chem., 1855, 95, 257-282.

46 A. Laurent and C. Gerhardt, Ann. Chim., 1847, 19, 85.

47 H. May, J. Appl. Chem., 1959, 9, 340-344.

48 A. I. Finkel'shtein and N. V. Spiridonova, Russ. Chem. Rev., 1964, 33, 400.

49 E. Kroke, M. Schwarz, E. Horvath-Bordon, P. Kroll, B. Noll and A. D. Norman, New J. Chem., 2002, 26, 508-512.

50 B. V. Lotsch and W. Schnick, Chem. Mater., 2006, 18, 1891-1900.

51 M. J. Bojdys, PhD thesis, Max Planck Institute of Colloids and Interfaces, 2009, On new allotropes and nanostructures of carbon nitrides.

52 F. Fina, S. K. Callear, G. M. Carins and J. T. S. Irvine, Chem. Mater., 2015, 27, 2612-2618.

53 J. Gracia and P. Kroll, J. Mater. Chem., 2009, 19, 3013-3019.

54 L. Pauling and J. H. Sturdivant, Proc. Natl. Acad. Sci. U. S. A., 1937, 23, 615-620.

55 R. S. Hosmane, M. A. Rossman and N. J. Leonard, J. Am. Chem. Soc., 1982, 104, 5497-5499.

56 T. Komatsu, J. Mater. Chem., 2001, 11, 799-801.

57 T. Komatsu, J. Mater. Chem., 2001, 11, 802-803.

58 B. Jürgens, E. Irran, J. Senker, P. Kroll, H. Müller and W. Schnick, J. Am. Chem. Soc., 2003, 125, 10288-10300.

59 M. Todd, J. Kouvetakis, T. L. Groy, D. Chandrasekhar, D. J. Smith and P. W. Deal, Chem. Mater., 1995, 7, 1422-1426.

60 C. J. Pickard, A. Salamat, M. J. Bojdys, R. J. Needs and P. F. McMillan, Phys. Rev. B: Condens. Matter Mater. Phys., 2016, 94, 094104.

61 H. Dong, A. R. Oganov, Q. Zhu and G. R. Qian, Sci. Rep., $2015,5,9870$.

62 A. I. Cooper and M. J. Bojdys, Mater. Today, 2014, 17, 468-469.

63 G. Demazeau, H. Montigaud, B. Tanguy, M. Birot and J. Dunogues, Rev. High Pressure Sci. Technol., 1998, 7, 1345-1347.

64 P. F. McMillan, V. Lees, E. Quirico, G. Montagnac, A. Sella, B. Reynard, P. Simon, E. Bailey, M. Deifallah and F. Corà, J. Solid State Chem., 2009, 182, 2670-2677.

65 J. B. Aladekomo and R. H. Bragg, Carbon, 1990, 28, 897-906.

66 E. Horvath-Bordon, R. Riedel, P. F. McMillan, P. Kroll, G. Miehe, P. van Aken, A. Zerr, P. Hoppe, O. Shebanova, I. McLaren, S. Lauterbach, E. Kroke and R. Boehler, Angew. Chem., Int. Ed., 2007, 46, 1476-1480.
67 A. Salamat, M. Deifallah, R. Q. Cabrera, F. Corà and P. F. McMillan, Sci. Rep., 2013, 3, 2122.

68 S. Y. Chong, J. T. A. Jones, Y. Z. Khimyak, A. I. Cooper, A. Thomas, M. Antonietti and M. J. Bojdys, J. Mater. Chem. A, 2013, 1, 1102-1107.

69 M. J. Bojdys, J. O. Müller, M. Antonietti and A. Thomas, Chem. - Eur. J., 2008, 14, 8177-8182.

70 V. P. Fadeeva, V. D. Tikhova and O. N. Nikulicheva, J. Anal. Chem., 2008, 63, 1094-1106.

71 G. Goglio, D. Foy and G. Demazeau, Mater. Sci. Eng., R, 2008, 58, 195-227.

72 J. Goldstein, D. E. Newbury, D. C. Joy, C. E. Lyman, P. Echlin, E. Lifshin, L. Sawyer and J. R. Michael, Scanning electron microscopy and X-ray microanalysis, Springer Science \& Business Media, New York, 2012.

73 J. F. Watts and J. Wolstenholme, An introduction to surface analysis by XPS and AES, Wiley, Chichester, UK, 2003.

74 T. L. Barr and S. Seal, J. Vac. Sci. Technol., A, 1995, 13, 1239-1246.

75 D. R. Baer, M. H. Engelhard, D. J. Gaspar, A. S. Lea and C. F. Windisch, Surf. Interface Anal., 2002, 33, 781-790.

76 A. P. Dementjev, A. de Graaf, M. C. M. van de Sanden, K. I. Maslakov, A. V. Naumkin and A. A. Serov, Diamond Relat. Mater., 2000, 9, 1904-1907.

77 A. B. Jorge, D. J. Martin, M. T. S. Dhanoa, A. S. Rahman, N. Makwana, J. Tang, A. Sella, F. Corà, S. Firth, J. A. Darr and P. F. McMillan, J. Phys. Chem. C, 2013, 117, 7178-7185.

78 J. Liu, T. Zhang, Z. Wang, G. Dawson and W. Chen, J. Mater. Chem., 2011, 21, 14398-14401.

79 Y. Waseda, E. Matsubara and K. Shinoda, X-ray diffraction crystallography: Introduction, examples and solved problems, Springer Berlin Heidelberg, 2011.

80 Y. X. Zhao and I. L. Spain, Phys. Rev. B: Condens. Matter Mater. Phys., 1989, 40, 993-997.

81 A. G. Koryakin, V. A. Gal'perin, A. N. Sarbaev and A. I. Finkel'shtein, Zh. Org. Khim., 1971, 7, 972.

82 A. I. Finkel'shtein, Zh. Obshch. Khim., 1961, 31, 1132.

83 A. I. Finkelshtein and E. N. Boitsov, Russ. Chem. Rev., 1962, 31, 712-720.

84 N. I. Zhagrova, N. V. Spiridonova and A. I. Finkel'shtein, Zh. Prikl. Spektrosk., 1973, 19, 153.

85 N. I. Zhagrova, N. V. Spiridonova and A. I. Finkel'shtein, Zh. Prikl. Khim., 1975, 48, 452.

86 Z. Li, J. Wang, K. Zhu, F. Ma and A. Meng, Mater. Lett., 2015, 145, 167-170.

87 G. Dong, Y. Zhang, Q. Pan and J. Qiu, J. Photochem. Photobiol., C, 2014, 20, 33-50.

88 C. Z. Li, Z. B. Wang, X. L. Sui, L. M. Zhang and D. M. Gu, RSC Adv., 2016, 6, 32290-32297.

89 Y. Yuan, L. Zhang, J. Xing, M. I. B. Utama, X. Lu, K. Du, Y. Li, X. Hu, S. Wang, A. Genc, R. Dunin-Borkowski, J. Arbiol and Q. Xiong, Nanoscale, 2015, 7, 12343-12350.

90 G. Zhang, Z. A. Lan, L. Lin, S. Lin and X. Wang, Chem. Sci., 2016, 7, 3062-3066.

91 J. J. Duan, S. Chen, M. Jaroniec and S. Z. Qiao, ACS Nano, 2015, 9, 931-940. 
92 X. Zhang, H. Wang, H. Wang, Q. Zhang, J. Xie, Y. Tian, J. Wang and Y. Xie, Adv. Mater., 2014, 26, 4438-4443.

93 X. Yang, H. Wang, X. Lu, D. Cui and S. Zhang, Acta Chim. Sin., 2009, 67, 1166-1170.

94 H. Montigaud, B. Tanguy, G. Demazeau, I. Alves, M. Birot and J. Dunogues, Diamond Relat. Mater., 1999, 8, 1707-1710.

95 E. Wirnhier, M. B. Mesch, J. Senker and W. Schnick, Chem. Eur. J., 2013, 19, 2041-2049.

96 B. V. Lotsch, M. Döblinger, J. Sehnert, L. Seyfarth, J. Senker, O. Oeckler and W. Schnick, Chem. - Eur. J., 2007, 13, 4969-4980.

97 P. J. Larkin, M. P. Makowski and N. B. Colthup, Spectrochim. Acta, Part A, 1999, 55, 1011-1020.

98 B. V. Lotsch and W. Schnick, Chem. - Eur. J., 2007, 13, 4956-4968.

99 Y. Zhang, L. Hu, C. Zhu, J. Liu, H. Huang, Y. Liu and Z. Kang, Catal. Sci. Technol., 2016, 6, 7252-7258.

100 P. Larkin, M. Makowski, N. Colthup and L. Flood, Vib. Spectrosc., 1998, 17, 53-72.

101 Y. L. Wang, A. M. Mebel, C. J. Wu, Y. T. Chen, C. E. Lin and J. C. Jiang, J. Chem. Soc., Faraday Trans., 1997, 93, 3445-3451.

102 N. E. Mircescu, M. Oltean, V. Chiş and N. Leopold, Vib. Spectrosc., 2012, 62, 165-171.

103 T. Saplinova, V. Bakumov, T. Gmeiner, J. Wagler, M. Schwarz and E. Kroke, Z. Anorg. Allg. Chem., 2009, 635, 2480-2487.

104 B. V. Lotsch and W. Schnick, Chem. Mater., 2006, 18, 1891-1900.

105 B. V. Lotsch and W. Schnick, Chem. Mater., 2005, 17, 3976-3982.

106 M. K. Marchewka, J. Chem. Res., 2003, 2003, 518-521.

107 W. J. Jones and W. J. Orvillethomas, Trans. Faraday Soc., 1959, 55, 193-202.

108 C. Fettkenhauer, J. Weber, M. Antonietti and D. Dontsova, RSC Adv., 2014, 4, 40803-40811.

109 J. Bian, J. Li, S. Kalytchuk, Y. Wang, Q. Li, T. C. Lau, T. A. Niehaus, A. L. Rogach and R. Q. Zhang, ChemPhysChem, 2015, 16, 954-959.

110 E. Quirico, G. Montagnac, V. Lees, P. F. McMillan, C. Szopa, G. Cernogora, J. N. Rouzaud, P. Simon, J. M. Bernard, P. Coll, N. Fray, R. D. Minard, F. Raulin, B. Reynard and B. Schmitt, Icarus, 2008, 198, 218-231.

111 A. C. Ferrari, S. E. Rodil and J. Robertson, Phys. Rev. B: Condens. Matter Mater. Phys., 2003, 67, 155306.

112 A. C. Ferrari, Solid State Commun., 2007, 143, 47-57.

113 A. C. Ferrari and D. M. Basko, Nat. Nanotechnol., 2013, 8, 235-246.

114 A. C. Ferrari, J. C. Meyer, V. Scardaci, C. Casiraghi, M. Lazzeri, F. Mauri, S. Piscanec, D. Jiang, K. S. Novoselov, S. Roth and A. K. Geim, Phys. Rev. Lett., 2006, 97, 187401.

115 A. C. Ferrari and J. Robertson, Phys. Rev. B: Condens. Matter Mater. Phys., 2000, 61, 14095-14107.

116 M. S. Dresselhaus, G. Dresselhaus, R. Saito and A. Jorio, Phys. Rep., 2005, 409, 47-99.

117 J. C. Charlier, P. C. Eklund, J. Zhu and A. C. Ferrari, in Carbon nanotubes: Advanced topics in the synthesis, structure, properties and applications, ed. A. Jorio, G. Dresselhaus and M. S. Dresselhaus, Springer Berlin Heidelberg, Berlin, 2008, pp. 673-709.

118 S. E. Rodil, A. C. Ferrari, J. Robertson and W. I. Milne, J. Appl. Phys., 2001, 89, 5425-5430.

119 H. Gunther, NMR spectroscopy: basic principles, concepts and applications in chemistry, Wiley-VCH, UK, 2013.

120 W. M. Haynes and D. R. Lide, CRC handbook of chemistry and physics: a ready-reference book of chemical and physical data, CRC Press, Boca Raton, 2011.

121 J. Sehnert, K. Baerwinkel and J. Senker, J. Phys. Chem. B, 2007, 111, 10671-10680.

122 J. Clark Stewart, D. Segall Matthew, J. Pickard Chris, J. Hasnip Phil, I. J. Probert Matt, K. Refson and C. Payne Mike, Z. Kristallogr., 2005, 220, 567.

123 A. S. Rahman, PhD thesis, University College London, 2014, Theoretical and experimental investigations of graphitic and crystalline carbon nitrides.

124 A. E. Aliev, S. E. Mann, A. S. Rahman, P. F. McMillan, F. Corà, D. Iuga, C. E. Hughes and K. D. M. Harris, J. Phys. Chem. A, 2011, 115, 12201-12211.

125 P. Bertani, J. Raya and B. Bechinger, Solid State Nucl. Magn. Reson., 2014, 61-62, 15-18.

126 W. J. Ong, L. L. Tan, Y. H. Ng, S. T. Yong and S. P. Chai, Chem. Rev., 2016, 116, 7159-7329.

127 J. Schneider, M. Matsuoka, M. Takeuchi, J. Zhang, Y. Horiuchi, M. Anpo and D. W. Bahnemann, Chem. Rev., 2014, 114, 9919-9986.

128 H. Zhang, X. Zuo, H. Tang, G. Li and Z. Zhou, Phys. Chem. Chem. Phys., 2015, 17, 6280-6288.

129 B. G. Liepert, Geophys. Res. Lett., 2002, 29, 61.

130 V. W. H. Lau, I. Moudrakovski, T. Botari, S. Weinberger, M. B. Mesch, V. Duppel, J. Senker, V. Blum and B. V. Lotsch, Nat. Commun., 2016, 7, 12165.

131 Z. Mo, X. She, Y. Li, L. Liu, L. Huang, Z. Chen, Q. Zhang, H. Xu and H. Li, RSC Adv., 2015, 5, 101552.

132 T. Ohzuku, Y. Iwakoshi and K. Sawai, J. Electrochem. Soc., 1993, 140, 2490-2498.

133 M. Wu, Q. Wang, Q. Sun and P. Jena, J. Phys. Chem. C, 2013, 117, 6055-6059.

134 Y. Yin, J. Han, X. Zhang, Y. Zhang, J. Zhou, D. Muir, R. Sutarto, Z. Zhang, S. Liu and B. Song, RSC Adv., 2014, 4, 32690-32697.

135 H. Wang, C. Zhang, Z. Liu, L. Wang, P. Han, H. Xu, K. Zhang, S. Dong, J. Yao and G. Cui, J. Mater. Chem., 2011, 21, 5430-5434.

136 M. Kim, S. Hwang and J.-S. Yu, J. Mater. Chem., 2007, 17, 1656-1659.

137 Y. Zheng, Y. Jiao, J. Chen, J. Liu, J. Liang, A. Du, W. Zhang, Z. Zhu, S. C. Smith, M. Jaroniec, G. Q. Lu and S. Z. Qiao, J. Am. Chem. Soc., 2011, 133, 20116-20119.

138 E. Horvath-Bordon, E. Kroke, I. Svoboda, H. Fueß, R. Riedel, S. Neeraj and A. K. Cheetham, Dalton Trans., 2004, 3900-3908. 